Autores

Yolanda González Castro

Omaira Manzano Durán Marleny Torres Zamudio

Categorías de análisis Responsabilidad

Social Universitaria
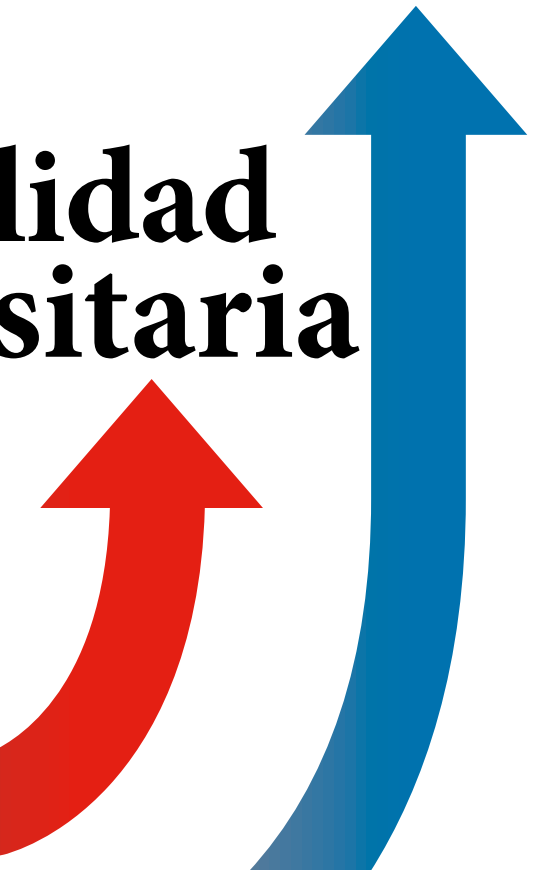

Categorías de análisis

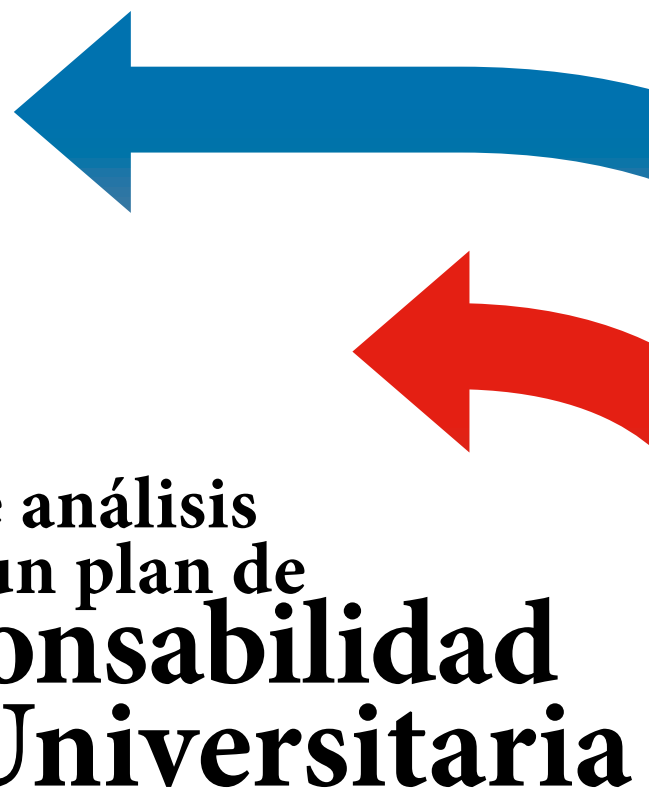

Yolanda González Castro

Omaira Manzano Durán

Marleny Torres Zamudio 



\section{Categorías de análisis para un plan de Responsabilidad Social Universitaria}

Yolanda González Castro

Omaira Manzano Durán

Marleny Torres Zamudio 
RECTOR

Jaime Alberto Leal Afanador

VICERRECTORA ACADÉMICA Y DE INVESTIGACIÓN

Constanza Abadía García

VICERRECTOR DE MEDIOS Y MEDIACIONES PEDAGÓGICAS

Leonardo Yunda Perlaza

VICERRECTOR DE DESARROLLO REGIONAL Y PROYECCIÓN COMUNITARIA

Leonardo Evemeleth Sánchez Torres

VICERRECTOR DE SERVICIOS A ASPIRANTES, ESTUDIANTES Y EGRESADOS

Edgar Guillermo Rodríguez Díaz

VICERRECTOR DE RELACIONES INTERNACIONALES

Luigi Humberto López Guzmán

DECANA ESCUELA DE CIENCIAS DE LA SALUD

Myriam Leonor Torres

DECANA ESCUELA DE CIENCIAS DE LA EDUCACIÓN

Clara Esperanza Pedraza Goyeneche

DECANA ESCUELA DE CIENCIAS JURÍDICAS Y POLÍTICAS

Alba Luz Serrano Rubiano

DECANA ESCUELA DE CIENCIAS SOCIALES, ARTES Y HUMANIDADES

Sandra Milena Morales Mantilla

DECANO ESCUELA DE CIENCIAS BÁSICAS, TECNOLOGÍA E INGENIERÍA

Claudio Camilo González Clavijo

DECANA ESCUELA DE CIENCIAS AGRÍCOLAS, PECUARIAS Y DEL MEDIO AMBIENTE

Julialba Ángel Osorio

DECANA ESCUELA DE CIENCIAS ADMINISTRATIVAS, ECONÓMICAS, CONTABLES Y DE NEGOCIOS

Sandra Rocio Mondragón 
Categorías de análisis para un Plan de Responsabilidad Social Universitaria / González Castro, Yolanda ... [et al.] -- [1.a. ed.]. Bogotá: Sello Editorial UNAD/2018. (Grupo de investigación GRINDES. Escuela de Ciencias Administrativas, Contables, Económicas y de Negocios - ECACEN)

ISBN: $\quad$ e-ISBN:978-958-651-655-6

1. EDUCACIÓN SUPERIOR 2. RESPONSABILIDAD SOCIAL UNIVERSITARIA I. Manzano Duran, Omaira II. Torres Zamudio, Marleny III. Título.

CATEGORÍAS DE ANÁLISIS PARA UN PLAN DE RESPONSABILIDAD SOCIAL UNIVERSITARIA

(C) Yolanda González Castro, Omaira Manzano Durán, Marleny Torres Zamudio

\section{GRUPO DE INVESTIGACIÓN: GRINDES}

ISBN: 978-958-651-655-6

Escuela de Ciencias Administrativas, Contables, Económicas y de Negocios ECACEN.

(C) UNAD

Sello Editorial UNAD

Universidad Nacional Abierta y a Distancia

Calle 14 sur No. $14-23$

Bogotá D.C

2018.

2018

Editora: Matilde Salazar Ospina

Diseño y diagramación: María Paula Berón Ramírez

Esta obra está bajo una licencia Creative Commons - Atribución - No comercial - Sin Derivar 4.0 internacional. https://co.creativecommons.org/?page_id=13. 



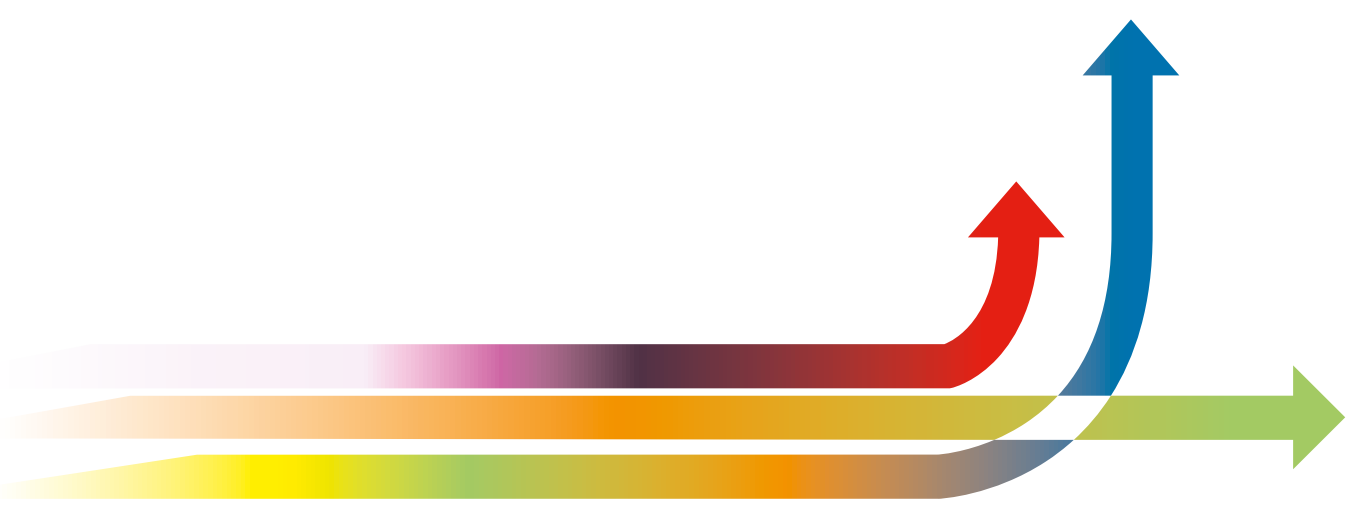

\section{Autores}

\section{Yolanda González Castro}

Administradora de Empresas. Especialista en Dirección Prospectiva y Estratégica de Organizaciones Universitarias. Magister en Recursos Humanos y Gestión del Conocimiento. Magister en Dirección Estratégica. Doctor en Administración de Negocios. Docente Asistente de la Escuela de Ciencias Administrativas, Contables, Económicas y de Negocios de la Universidad Nacional Abierta y a Distancia. Grupo de Investigación GRINDES. UNAD CCAV Pamplona, Calle 5 \# 3 - 05. Barrio el Carmen. Correo Electrónico yolanda,gonzalez@unad.edu.co

\section{Omaira Manzano Durán}

Licenciada en Matemáticas y Física. Especialista en Práctica Docente Universitaria. Especialista en Informática Educativa. Magister en Administración de Empresas. Candidata a Doctor en Administración de Negocios. Docente Asistente de la Escuela de Ciencias Administrativas, Contables, Económicas y de Negocios de la Universidad Nacional Abierta y a Distancia. Grupo de Investigación GRINDES. UNAD CEAD Ocaña, Calle 10 \# 9-61. Correo Electrónico omaira.manzano@unad.edu.co

\section{Marleny Torres Zamudio}

Economista. Especialista en Finanzas. Magister en Administración. Docente Asociada de la Escuela de Ciencias Administrativas, Contables, Económicas y de Negocios de la Universidad Nacional Abierta y a Distancia. Grupo de Investigación GRINDES. UNAD CEAD Tunja, Calle 18 con Carrera 1. Barrio Manzanares. Correo Electrónico marleny.torres@unad.edu.co 



\section{Contenido}

Prólogo

Carlos Perea Sandoval

Introducción

Materiales y métodos

\section{CAPÍTULO 1}

Evolución de la Responsabilidad Social Universitaria: línea del tiempo y análisis bibliométrico

1.1. Revisión epistemológica

1.2. Análisis bibliométrico de la responsabilidad social universitaria 


\section{CAPÍTULO 2}

Descripción de las categorías relacionadas con la Responsabilidad Social Universitaria

2.1. Aprendizaje organizacional

2.2. Necesidades regionales

2.3. Internacionalización, interdisciplinariedad e interculturalidad

2.4. Sustentabilidad y calidad de vida

2.5. Redes

2.6. Planeación y aplicación innovadora

2.7. Filosofía institucional

\section{CAPÍTULO 3}

Integración sistémica de las categorías dentro de un Plan de Responsabilidad Social Universitaria

3.2. Elementos que promueven la humanización en el plan de RSU

3.3. La transferencia de conocimiento desde el aprendizaje organizacional 
3.4. Cumplimiento de las normas sustentables y de calidad de vida

3.5. Acceso e intervención por medio de las redes

3.6. Relaciones entre cultura, disciplinas y naciones

3.7. La universidad de cara a las necesidades regionales.

Conclusiones

Agradecimientos 



\section{Lista de tablas}

Tabla 1. Integración Teorías e Impactos en la Responsabilidad Social Universitaria

Tabla 2. Conceptualización de las categorías de la RSU 71

Tabla 3. Subcategorías de la RSU 



\section{Lista de figuras}

Figura 1. Aplicación de la metodología de la teoría fundamentada.

Figura 2. Producción literaria en responsabilidad social universitaria por año.

Figura 3. Fuentes de mayor publicación en responsabilidad Social universitaria.

Figura 4. Autores sobresalientes en temas de responsabilidad social universitaria.

Figura 5. Clasificación de los autores según la productividad.

Figura 6. Afiliación de los autores con interés en el tema de responsabilidad social universitaria.

Figura 7. Países con mayores publicaciones en el tema.

Figura 8. Publicaciones en documentos sobre RSU.

Figura 9. Área temática de la RSU.

Figura 10. Palabras claves sobre la temática de la RSU.

Figura 11. Análisis de relaciones de la data de RSU.

Figura 12. Análisis de relaciones de la RSU.

Figura 13. El concepto de la responsabilidad social universitaria como asistencialismo

Figura 14. El concepto de la responsabilidad social y su evolución hacia la consideración del ser humano como el centro de la organización

Figura 15. Estructuras internas y relaciones externas de la RSU

Figura 16. Autorregulación para el cumplimiento de la RSU 
Figura 17. Gráfico Categórico de la Responsabilidad Social Universitaria con la aplicación del Software Atlas Ti.

Figura 18. Evolución de la RSE a RSU 54

Figura 19. Transferencia de conocimiento del entorno hacia la sociedad 55

Figura 20. Propósitos de la universidad para con las necesidades de la región

Figura 21. Compromisos con la internacionalización, interdisciplinariedad e interculturalidad.

Figura 22. Aportes de la universidad que pueden hacer posible la sustentabilidad y una mejor calidad de vida

Figura 23. El trabajo universitario en red

Figura 24. Elementos que permiten dar un carácter diferenciador a la planeación de la responsabilidad social universitaria

Figura 25. Integración de la filosofía institucional con las necesidades de la sociedad.

Figura 26. La humanización desde la dignificación y el desarrollo de las potencialidades.

Figura 27. Plan innovador de RSU

Figura 28. Elementos que promueven la humanización.

Figura 29. Transferencia de conocimiento desde al aprendizaje organizacional

Figura 30. Cumplimiento de normas sustentables y de calidad de vida

Figura 31. Acceso e intervención por medio de las redes 89

Figura 32. Transformación de las realidades en un mundo global. 91

Figura 33. La universidad de cara a las necesidades regionales

Figura 34. Integración de las categorías para la implementación de un Plan de Responsabilidad Social Universitaria. 


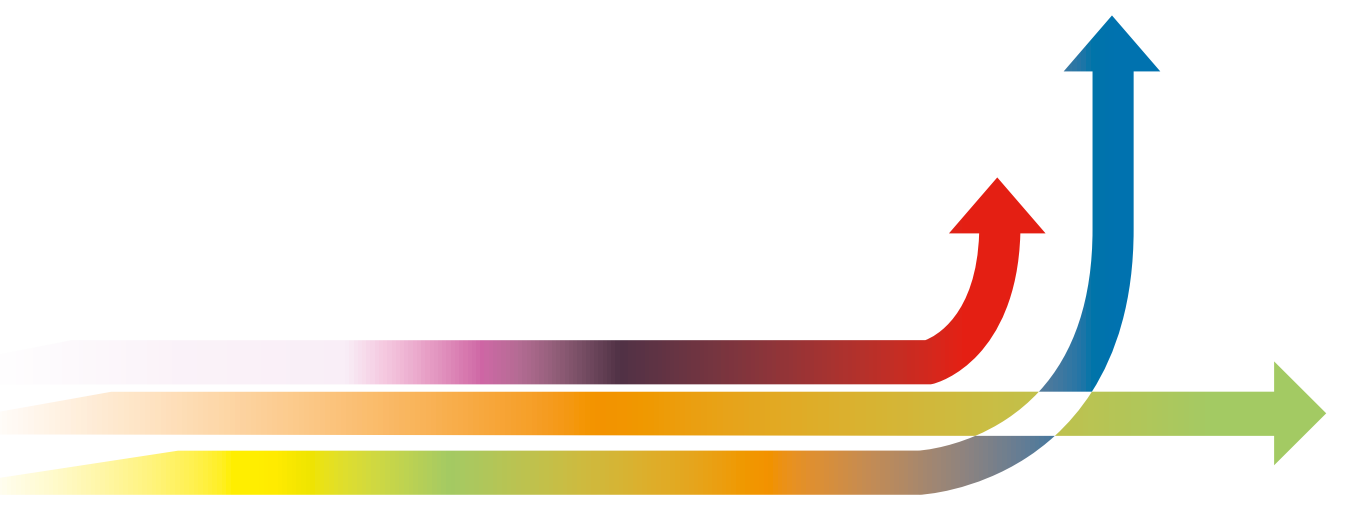

\section{Prólogo}

Carlos Perea Sandoval ${ }^{1}$

La Responsabilidad Social Universitaria es un campo de investigación en el que han confluido diversos enfoques teóricos y metodológicos encaminados a profundizar la comprensión de esta exigencia de carácter ético que reclama el accionar académico. En este contexto, la Universidad Nacional Abierta y a Distancia se ha constituido en una institución educativa posibilitadora de estudios académicos rigurosos en los que la investigación se consolida como una actividad de impacto social, medio en el cual el grupo de investigación GRINDES y sus integrantes Yolanda González Castro, Omaira Manzano Durán, Marleny Torres Zamudio lideraron la investigación en "Categorías de análisis para un Plan de Responsabilidad Social Universitaria" tema central del libro que se presenta ante la comunidad académica.

Las investigadoras realizan, desde una visión sistémica y sistemática, un seguimiento histórico a las concepciones y prácticas que sobre la Responsabilidad Social Universitaria (RSU) se han manifestado en las últimas décadas. La bibliometría realizada se constituye en una fuente de referencia consolidada para que las instituciones educativas de educación superior amplíen el horizonte sobre la RSU. De igual forma, es un aporte para el planteamiento de nuevas preguntas de investigación relacionadas con el tema.

1 PhD. Sociología Jurídica e Instituciones Políticas Universidad Externado de Colombia. Postdoctorado en Educación. Universidad pedagógica experimental El Libertador. Caracas. Especialista en Pedagogía para el Desarrollo del Pensamiento. Universidad del Tolima. Licenciado en Filosofía y Letras. Universidad Santo Tomás. Bogotá. 
La metodología desarrollada en la investigación, la recolección, tratamiento, análisis e interpretación de los resultados permiten evidenciar el alto nivel de las competencias investigativas que poseen las autoras del libro. En este sentido se resalta la selección de las categorías de análisis que fundamentan la investigación: el aprendizaje organizacional, las necesidades regionales, la Internacionalización, interdisciplinariedad e Interculturalidad, la Sustentabilidad y calidad de vida, las Redes, la Planeación y aplicación innovadora, la Filosofía Institucional y Humanización.

Estas categorías configuran una visión holística del fenómeno a investigar, propiciando nuevos escenarios de reflexión; enriqueciendo teórica y conceptualmente la acción de la RSU. Sobresale la importancia que toma la concepción de humanización como un fin de la RSU, en palabras de las autoras "La universidad es responsable de que sus estudiantes contribuyan a la justicia social la humanización y el cumplimiento de la ética a la vez que de contribuir a una formación académica de calidad".

Ligada a esta categoría de humanización es de interés el tratamiento dado a las demás categorías en especial a la categoría de necesidades regionales, en la que se fundamenta la responsabilidad ética que deben asumir la Instituciones de Educación Superior en cuanto a las problemáticas de carácter social, económico, cultural y político que se expresan en las regiones en las cuales hacen presencia e impactan. Es así como las investigadoras generan de manera propositiva un Plan de Responsabilidad Social Universitaria, en el que se dan los lineamientos, desde una visión de integralidad, para que los diferentes actores institucionales y sociales se apropien y participen en la construcción y el enriquecimiento de la RSU.

En mi calidad de investigador de la Responsabilidad Social Universitaria como perspectiva ética en la educación superior latinoamericana, tema que he venido trabajando con la Socióloga Tania Meneses Cabrera ( Docente Investigadora de la Universidad Nacional a Distancia), hago un reconocimiento a la calidad 
y pertinencia del trabajo realizado por las autoras de este libro e invito a la comunidad académica para que sea incorporado como fuente de estudio y reflexión en lo relacionado con el papel que juegan las universidades, su responsabilidad ética y compromiso con la sociedad. 



\section{Introducción}

El papel de la universidad en un mundo globalizado ha permitido enlazar los lazos entre la sociedad y la empresa. En este proceso el conocimiento se constituye en la herramienta para que el estudiante además de realizarse como persona ayude a otros a dar soluciones a problemas generales. De ahí el cuestionamiento que se hace a las universidades sobre la influencia que estas deben impulsar como contribución al desarrollo de las regiones en forma sostenible y sustentable, conocido este aspecto como responsabilidad social universitaria (RSU) (De la Cuesta \& Sánchez, 2012).

Hoy, los lineamientos de calidad exigen que las universidades impacten tanto en los grupos de interés como también en sectores externos como son la sociedad, las organizaciones, al igual que en aquellos actores que hacen parte de las dinámicas regionales de la economía y en general de la sociedad como tal. La labor académica de la Universidad como formadora integral de futuros profesionales, se enmarca en una relación social, en tal sentido, deben situarse en su entorno, conocer sus necesidades y urgencias y encontrar dentro del conocimiento acciones y formas de fortalecer y aportar en su beneficio.

Ese compromiso social de las universidades va de la mano con las exigencias de la excelencia en la gestión del conocimiento, de igual forma es innegable la importancia de la transferencia de conocimiento como compromiso para una sociedad más equitativa y más humana. De ahí la necesidad de un sistema universitario que parta de una planeación integral y que integre en sus actividades las problemáticas locales, regionales e incluso mundiales para darle solución desde la academia. En definitiva, las universidades, en su papel 
de formación y constructoras de un país mejor a partir del conocimiento, deben responder a las necesidades y expectativas que tanto las personas como agrupaciones y sociedad requieran y soliciten.

El presente libro es el resultado de una investigación documental realizada con el propósito de inventariar y sistematizar la producción en un área del saber y de esta forma trascender a una reflexión profunda sobre las tendencias y vacíos existentes en el campo de estudio (Molina, 2005). En tal sentido, este documento es el resultado de una investigación realizada con el objetivo de identificar las categorías de análisis útiles en el diseño de planes de responsabilidad social universitaria, a partir de una revisión bibliométrica de bases de datos y la construcción de una línea del tiempo comprendida desde los años 50 hasta la actualidad, para ello fue necesario conceptualizar las categorías seleccionados, mediante un análisis documental, deduciendo subcategorías que explican con mayor claridad los ordenadores epistemológicos que se deben integrar en un plan de responsabilidad social universitaria; al igual que Integrar categorías y subcategorías que sirvan de referente para el diseño de un plan de responsabilidad social universitaria, mediante un diagrama causal, resultado del análisis.

En el capítulo 1, titulado. "Evolución de la Responsabilidad Social Universitaria: línea del tiempo y análisis bibliométrico", se presenta la evolución conceptual de la responsabilidad social universitaria a partir de la revisión de artículos publicados desde 1984 hasta el 2018, que parte, en los primeros años, desde una concepción asistencialista, escalando hacia la dinamización de las funciones sustantivas, que impactan tanto a los actores al interior de las universidades como en su entorno. De esta forma se logra establecer cómo, más allá del concepto, las Universidades han comprendido que, inmerso dentro de su esencia misional de formación integral, está la responsabilidad de construir conocimiento para la solución de problemáticas sociales. De la misma forma, se establece como la responsabilidad social de las Universidades no solo se entiende como el impacto en su contexto externo, sino que requiere una mirada, reconocimiento y dignificación de su talento humano como núcleo de las instituciones. 
Dentro de esa evolución del pensamiento en el campo de la RSU, se destaca, además, la necesidad de consolidar estructuras dinámicas con actores sociales como organizaciones, sector productivo, gubernamental, las mismas comunidades, con quienes se aúnen esfuerzos y se consoliden acciones que propicien mejores condiciones de vida. En el ejercicio de revisión documental se recurrió además a la bibliometría, buscando medir desde la productividad literaria, la evolución del pensamiento en materia de RSU, reconociendo de esta forma, que, si bien un buen porcentaje de publicaciones se presentan por autores transeúntes, el interés de los investigadores sociales por dar a conocer la dinámica del tema ha venido creciendo. De esta forma, como resultado de la revisión documental y tomando en cuenta diferentes criterios de clasificación, se determinaron ocho (8) categorías de análisis que servirán como eje central de este libro. Dichas categorías se mencionan sin tomar en cuenta un orden o criterio de importancia así: el aprendizaje organizacional, las necesidades regionales, la internacionalización, interdisciplinariedad e interculturalidad, la sustentabilidad y calidad de vida, las redes, la planeación y aplicación innovadora, la filosofía institucional y, por último, pero no menos importante está la categoría humanización.

En el capítulo 2, "Descripción de las categorías relacionadas con la Responsabilidad Social Universitaria. (Categorías de Análisis de la RSU)" se presenta un recorrido por las ocho categorías de análisis de la RSU, buscando establecer su significado dentro de las Instituciones universitarias, lo que constituyó la discusión desde la mirada de otros autores para poder ratificar las categorías seleccionadas.

El aprendizaje organizacional, como primera categoría, explica como la RSU, hace parte de las prácticas organizacionales que han venido evolucionando, reinventándose de acuerdo con los cambios que le genera y reclama el entorno. La categoría de necesidades regionales destaca el rol que debe jugar la Universidad frente a las particularidades de las regiones, siendo parte activa de los acontecimientos y procesos sociales, así como de la misma institución. En cuanto a Internacionalización, interdisciplinariedad e interculturalidad, se retoma el criterio aportado por Delors (1996), para quien los procesos 
globalización contribuyen al cumplimiento de la misión de educación de las universidades. Es necesario superar las tensiones que hay entre lo mundial y lo local, "ser ciudadano del mundo sin perder sus raíces y participando activamente en la vida de la nación y las comunidades de base".

La sustentabilidad y calidad de vida, en esta categoría se hace un reconocimiento de la responsabilidad de las Universidades hacia dos áreas fundamentales, de una parte, el acceso a la educación como instrumento que posibilita el desarrollo socioeconómico del individuo como tal y a su vez el de la comunidad en la que está inmerso, sin perder de vista la necesidad de velar por la preservación de los recursos medioambientales. En el marco de las Redes, como categoría de análisis de la RSU, se analiza la necesidad de implementar prácticas pedagógicas con un enfoque holístico que fortalezcan las habilidades y competencias para el trabajo en red; sumado a la voluntad de las universidades por establecer alianzas estratégicas y relaciones interinstitucionales con organizaciones públicas y privadas.

La Planeación y aplicación innovadora, desde la RSU se analiza a partir de la necesidad de plantear estrategias de diferenciación, buscando la coherencia e integración entre el plan de RSU con el plan de desarrollo de cada universidad. La RSU vista desde la categoría de la Filosofía institucional, se concibe como elemento transversal del proyecto académico de la universidad ligada, a los principios y valores que fundan su filosofía. Siendo la Humanización la última categoría, la universidad debe contribuir en la construcción de una sociedad más justa, en donde el ser humano sea el centro de preocupación, logrando formar ciudadanos éticos y con excelencia académica.

El apartado 3, "Integración sistémica de las categorías dentro de un Plan de Responsabilidad Social Universitaria", se entiende como la aplicación de los resultados a una estrategia de mejoramiento, presenta cada una de las categorías establecidas y cómo se conciben dentro de un plan de RSU. Se realiza este recorrido de implementación del plan por cada categoría y su ejecución en tres momentos, la transferencia de conocimiento a su entorno, la entrega de 
egresados integrales y el compromiso con los stakeholders. Se exponen también los elementos que promueven la humanización en el plan de RSU, tales como las condiciones laborales, la motivación, la resolución de conflictos, la democracia participativa, cualificación social y la sinergia. Haciendo énfasis en el impacto que pueden tener las decisiones que se toman desde la universidad no solo para las comunidades en las que está inmersa, sino en quienes conforman la comunidad universitaria, docentes, estudiantes, administrativos y sus familias. De esta forma, el plan de RSU y su implementación debe concebirse desde una perspectiva integral, planeando acciones pertinentes que logren integrarse con la sociedad de la cual forman parte y contribuya al mejoramiento de las condiciones de vida de las mayorías. 



\section{Materiales y métodos}

La investigación correspondió a un enfoque cualitativo de tipo teoría fundamentada (Ver Figura 1), e integró las siguientes fases en forma sistemática:

Fase 1 Recolección de datos: se realizó una revisión documental en bases de datos científicas y se construyó una bibliometría que permitió llegar a una aproximación de las categorías.

Fase 2. Organización de datos: Los documentos seleccionados se empaquetaron en el software Atlas Ti.

Fase 3. Análisis de datos: Se realizó con el uso del software Atlas Ti, que permitió a través de un método comparativo constante, realizar una codificación abierta para identificar las categorías del fenómeno analizado (Quilaqueo \& San Martín, 2008). Una vez seleccionadas las categorías se realizó una codificación axial para conceptualizar cada una de ellas. Los criterios para categorizar fueron cinco: relevancia, exclusividad, complementariedad, especificidad y exhaustividad (Romero, 2005). El análisis se efectuó hasta acontecer la saturación teórica, es decir, hasta ocurrir la repetición o la ausencia de datos. La codificación selectiva facilitó la integración de categorías y subcategorías, para ello, los códigos se agruparon en niveles mayores de abstracción que posteriormente permitieron clasificar subcategorías dentro de las mismas categorías buscando conexiones entre las mismas (Carvalho, Luzia, Soares \& Andrade, 2009). 
Fase 4. Construcción dela teoría: Posteriormentese realizó una línea detiempoy la selección definitiva de las categorías, quedandolas siguientes: (a)Aprendizaje Organizacional (b) Necesidades regionales, (c) Internacionalización, interdisciplinariedad e interculturalidad, (d) Sustentabilidad y calidad de vida, (e) Redes (f) Planeación y aplicación innovadora (g) Filosofía institucional y (I) humanización. para finalmente construir la teoría sustantiva, representada en este estudio como la integración de elementos recomendados para la construcción de un plan de responsabilidad social universitario. Para el tratamiento y análisis de la información se emplearon mapas causales.

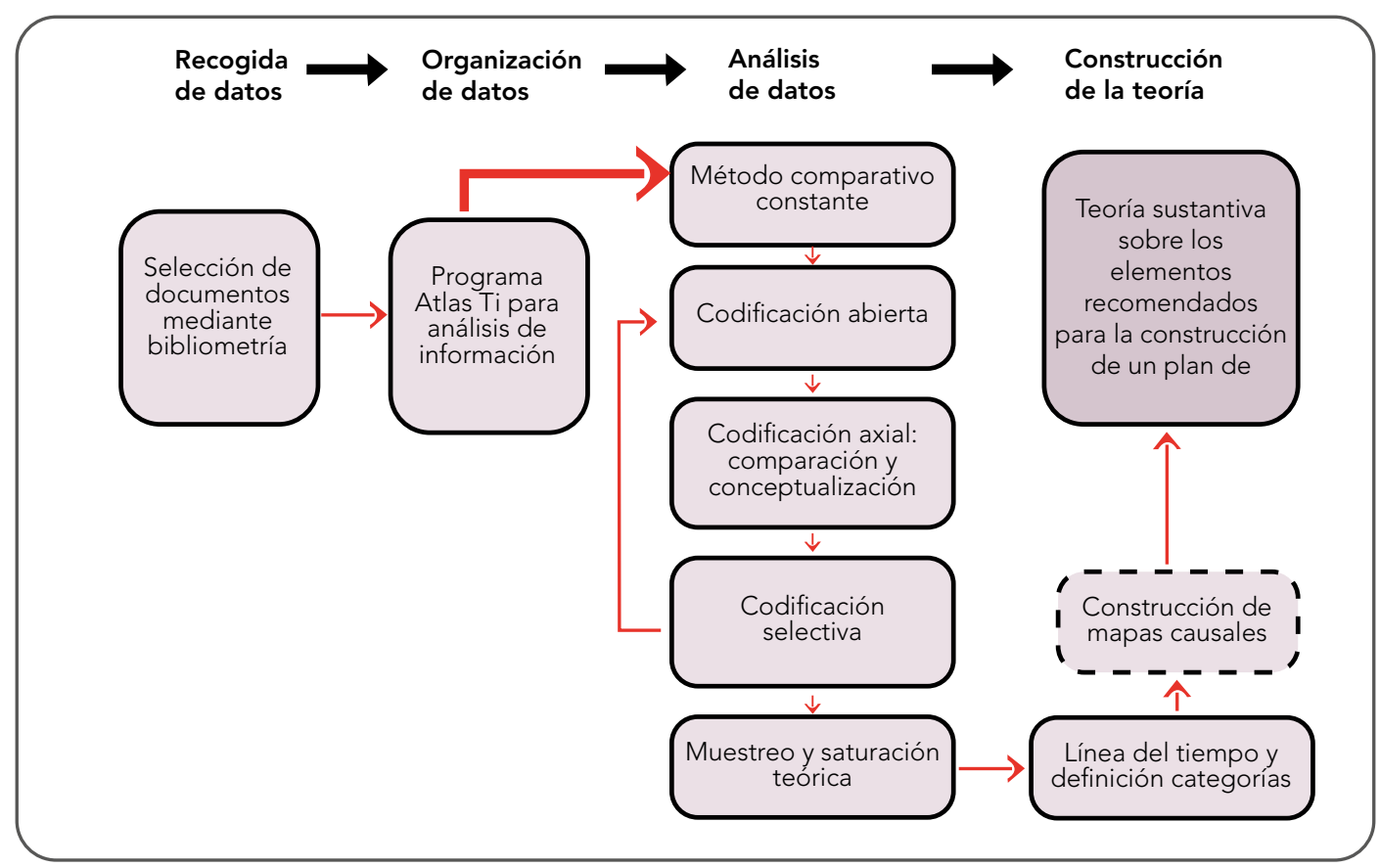

Figura 1. Aplicación de la metodología de la teoría fundamentada.

Fuente: Las autoras a partir de Vivar, Arantzamendi, López-Dicastillo \& Gordo (2010) 


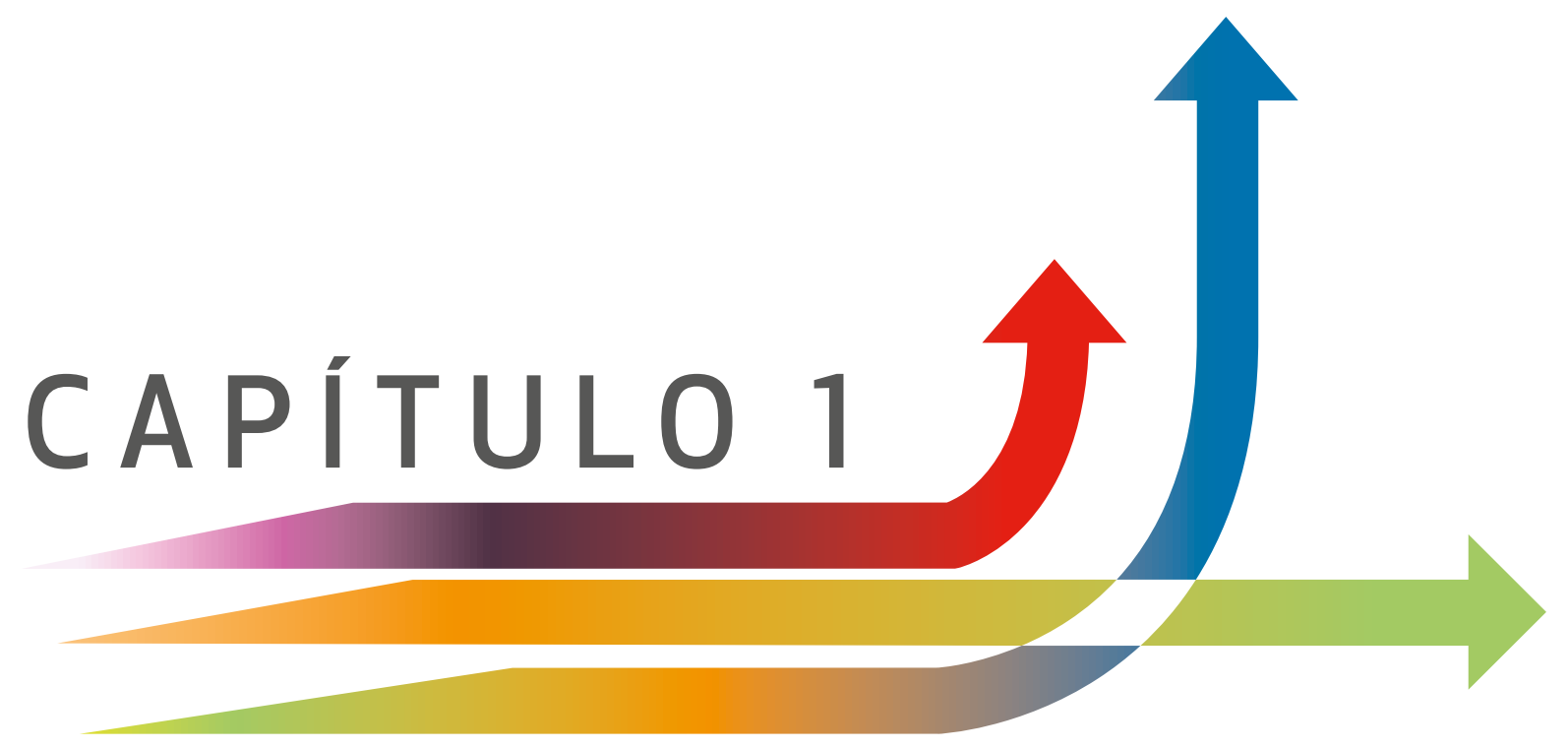





\section{Evolución de la Responsabilidad Social Universitaria: línea del tiempo y análisis bibliométrico}

\subsection{Revisión epistemológica}

De acuerdo a Vallaeys (2015), la responsabilidad social debe cuidar los impactos de nuestras acciones, que incluye la gente, el futuro, el medio ambiente, entre otros. Los impactos de una universidad, afirma el autor, se presentan en lo organizacional, social, académico y cognitivo. Por otra parte, Larrán y Andrades (2015) a partir de Gaete (2012), realizan una aproximación a las teorías de la responsabilidad social universitaria. En relación a los aportes de estos autores se presenta a continuación los referentes teóricos en los que se enfocó la presente investigación (Ver Tabla 1). 
Tabla 1. Integración Teorías e Impactos en la Responsabilidad Social Universitaria

\begin{tabular}{|c|c|c|c|}
\hline Impactos & Postulado & Indicador & $\begin{array}{c}\text { Teorías } \\
\text { Involucradas }\end{array}$ \\
\hline $\begin{array}{l}\text { Organizacional } \\
\text { (laborales y } \\
\text { ambientales) }\end{array}$ & $\begin{array}{l}\text { La RSU impacta en } \\
\text { las personas, en } \\
\text { la gestión y en la } \\
\text { sustentabilidad. }\end{array}$ & $\begin{array}{l}\text { Calidad de vida, respeto de los } \\
\text { derechos, rendición de cuentas, } \\
\text { gestión responsable con el } \\
\text { ambiente, clima laboral, códigos de } \\
\text { conducta }\end{array}$ & $\begin{array}{c}\text { Agencia } \\
\text { Stakeholders } \\
\text { Recursos y } \\
\text { capacidades }\end{array}$ \\
\hline $\begin{array}{l}\text { Social } \\
\text { (Extensión, } \\
\text { transferencia de } \\
\text { conocimiento } \\
\text { y la proyección } \\
\text { social) }\end{array}$ & $\begin{array}{l}\text { La RSU impacta } \\
\text { en el progreso de } \\
\text { la comunidad y } \\
\text { ayudando a resolver } \\
\text { sus problemas } \\
\text { fundamentales }\end{array}$ & $\begin{array}{l}\text { Cursos y programas de actualización, } \\
\text { participación en redes de } \\
\text { desarrollo local, participación en el } \\
\text { cumplimiento de planes y programas } \\
\text { locales, comunidades incluyentes de } \\
\text { aprendizaje. }\end{array}$ & $\begin{array}{l}\text { Stakeholders } \\
\text { Legitimidad }\end{array}$ \\
\hline $\begin{array}{l}\text { Educativo } \\
\text { (Formación } \\
\text { académica) }\end{array}$ & $\begin{array}{l}\text { La RSU impacta en } \\
\text { la formación integral } \\
\text { de los futuros } \\
\text { profesionales y la } \\
\text { ética profesional. }\end{array}$ & $\begin{array}{l}\text { Transversalidad de la ética en } \\
\text { el currículo, integración entre } \\
\text { academia, investigación y desarrollo } \\
\text { regional, Currículos que respondan } \\
\text { a los núcleos problémicos de las } \\
\text { disciplinas. }\end{array}$ & Ética \\
\hline $\begin{array}{l}\text { Cognitivo } \\
\text { (Investigación, } \\
\text { epistemología) }\end{array}$ & $\begin{array}{l}\text { La RSU impacta en } \\
\text { la producción del } \\
\text { conocimiento, su } \\
\text { pertinencia y sus } \\
\text { destinatarios a partir } \\
\text { de la investigación }\end{array}$ & $\begin{array}{l}\text { Interdisciplinariedad y } \\
\text { transdisciplinariedad en la } \\
\text { investigación, integración de actores } \\
\text { sociales externos a los procesos de } \\
\text { investigación, pertinencia social de } \\
\text { la investigación, responsabilidad } \\
\text { social de la ciencia, socialización del } \\
\text { conocimiento. }\end{array}$ & $\begin{array}{l}\text { Legitimidad } \\
\text { Ética }\end{array}$ \\
\hline
\end{tabular}

Fuente: Las autoras a partir de Vallaeys (2015), Larrán y Andrades (2015) y Gaete (2012).

De acuerdo con Collin et al, citado por Larrán y Andrades (2015), la base de la teoría de la agencia está en realizar rendiciones de cuentas de las actuaciones organizacionales, demostrando que sus acciones son responsables y transparentes y alineadas con los intereses de la comunidad. Lo que significa, en el caso de las instituciones universitarias, la necesidad de ejercer control a la autonomía. Para ello se requiere la implantación de un modelo de gestión que tenga en cuenta los intereses de los agentes sociales involucrados como son los estudiantes, administrativos, docentes, proveedores y comunidad; dándoles participación en la toma de decisiones (Collin et al., 2009). Ahora bien, Deegan, citado por Larrán y Andrades (2015), expresa como por medio de la 


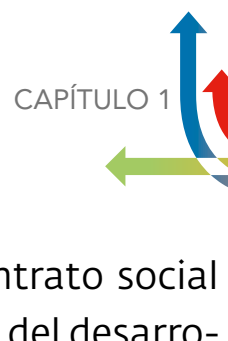

teoría de la legitimidad es posible establecer una especie de contrato social
dando un papel protagónico a las universidades como impulsoras del desarroIlo a la vez que reconoce su compromiso con sus diversos stakeholders

Por otra parte, la aplicación de la teoría de los recursos y capacidades busca desarrollar en las organizaciones universitarias características especiales que las diferencien de las otras existentes a partir de las capacidades nucleares que poseen las personas que la conforman. En tal sentido cuando las personas y la misma organización se comportan en forma responsable generan una ventaja competitiva (Sanje \& Senol, 2012). En el mismo sentido, la aplicación de la teoría de la ética en el desarrollo de los planes curriculares permite el desarrollo de competencias en los estudiantes, basadas en valores, formando egresados enfocados en desarrollar acciones responsables para satisfacer las necesidades del entorno, que les permite generar comportamientos exitosos en su desempeño y en forma indirecta el obtener un reconocimiento social (Núñez, 2012).

\subsection{Análisis bibliométrico de la responsabilidad social universitaria}

Un análisis bibliométrico consiste en la revisión de bases de datos para hacer un seguimiento a las publicaciones científicas de un tema en particular en un periodo determinado. Esta técnica permite medir en un momento histórico y en forma cuantitativa, los avances sobre la temática seleccionada en cuanto a autores que han publicado, su afiliación y país de origen, así como también el tipo de publicaciones que se han realizado.

Con la medición de los tres primeros elementos: autores, afiliación y país de origen es posible determinar factores asociados a fenómenos como la evolución del concepto en un lugar, espacio o situación determinada. Mientras la medición de fechas, tipo de publicación y palabras claves permitirá comparar los resultados construidos a partir de la línea del tiempo. 
Para realizar el análisis bibliométrico en responsabilidad social universitaria, de acuerdo a la primera fase del proyecto, se utilizó la base de datos Scopus por considerarse como una de las más extensa en citas y resúmenes de literatura. Se encuentra en ella más de Go millones de registros de revistas científicas, más de 130.000 libros disponibles como monografías, volúmenes editados, obras de referencia y libros de texto de posgrado. Así también, Scopus cuenta con herramientas inteligentes para rastrear, analizar y visualizar la investigación desarrollada en los campos de ciencia, tecnología, medicina, ciencias sociales y artes y humanidades.

En la búsqueda se utilizó el descriptor "responsabilidad social universitaria" OR "university social responsibility" y se encontraron 112 documentos en un rango comprendido entre el 2006 y el 2018. En la base de datos Scopus, se evidencian publicaciones de responsabilidad social universitaria desde 2006, como se muestra en la figura 2, con una mayor productividad en el año 2012 y 2018. Ahora bien, es posible señalar un auge de publicaciones sobre responsabilidad social en el 2012, que puede obedecer a la creación de observatorios y redes en torno a la RSU, en el mismo año de observación, lo que posiblemente impulsó el desarrollo de investigaciones en ese campo, Sin embargo, el estándar de crecimiento se vuelve a mantener a partir del 2013.

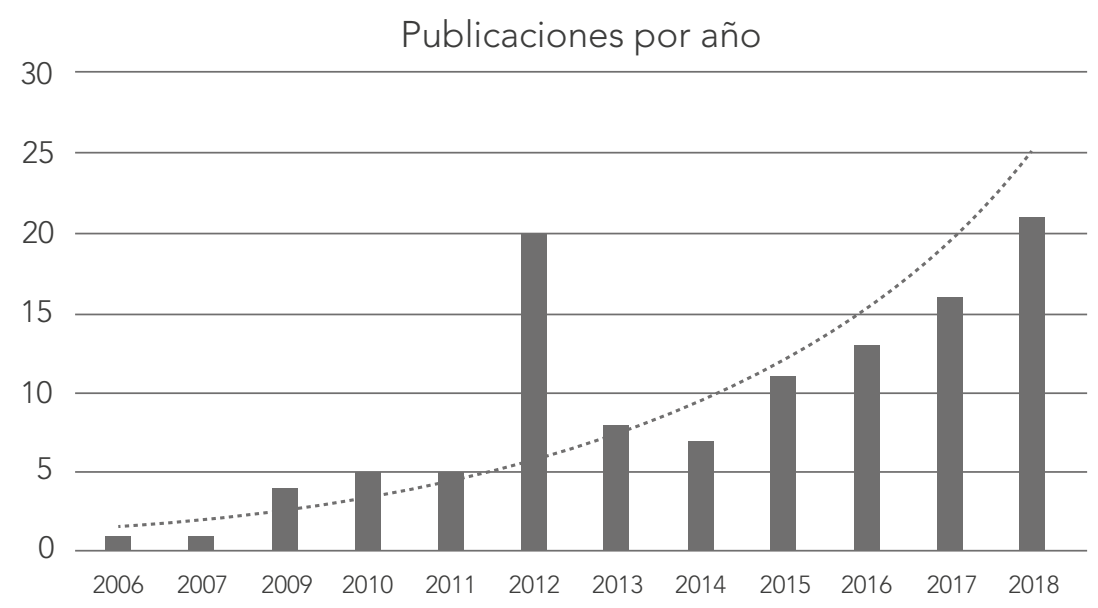

$\mathrm{N}=112$

Figura 2. Producción literaria en responsabilidad social universitaria por año.

Fuente: Adaptado por las autoras a partir de la base de datos Scopus. 
En cuanto a las fuentes, como se evidencia en la Figura 3, la revista de investigación Opción ${ }^{2}$, de la Universidad del Zulia (República de Venezuela), es la que hasta el momento tiene mayor número de publicaciones en RSU, con un $13 \%$, seguida de la revista World Review Of Entrepreneurship Management And Sustainable Development con un $9 \%$. Le sigue la revista Venezolana de Gerencia con un 4\%. Las revistas Espacios e International Review On Public And Nonprofit Marketing comparten cada una un $3 \%$ de las publicaciones existentes.

Aunque las revistas Opción y Venezolana de Gerencia son de la República de Venezuela, los autores que publican en ellas son de países como España, Venezuela, Colombia, México, Argentina, Chile, entre otros. Esto se debe a las exigencias de los servicios de indexación para evitar la endogamia y a los intereses de los mismos autores en publicar en revistas especializadas en el tema

\section{Fuentes de mayor publicación}

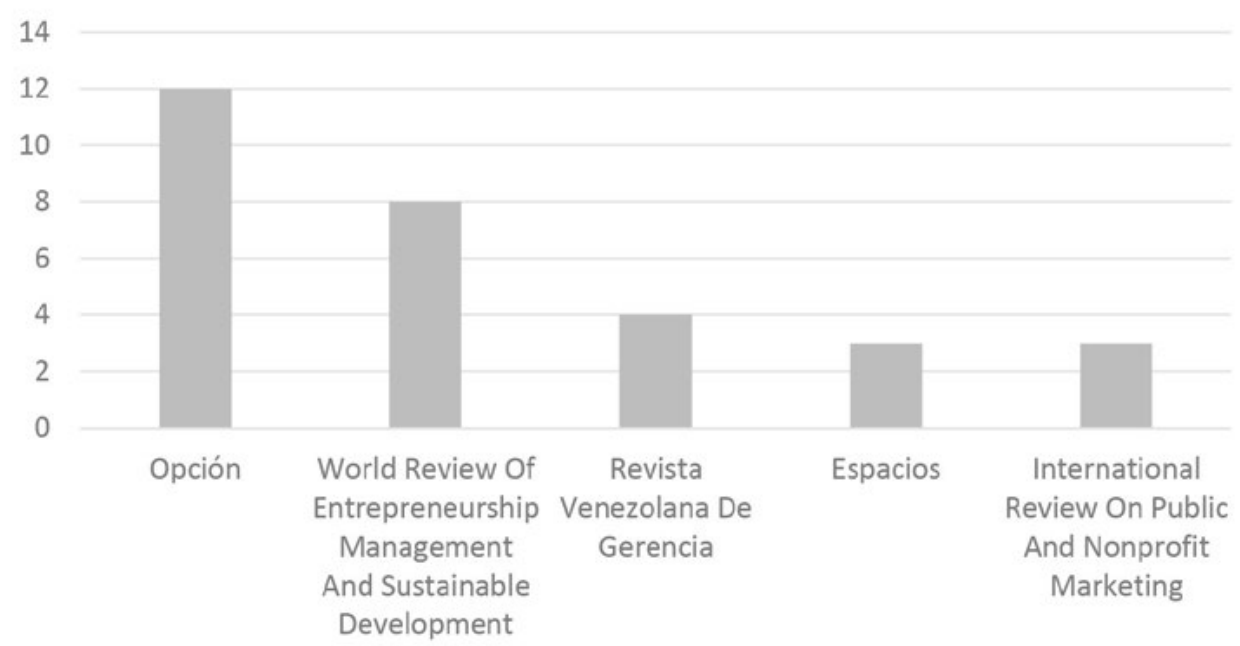

$\mathrm{N}=94$

Figura 3. Fuentes de mayor publicación en responsabilidad Social universitaria.

Fuente: Adaptado por las autoras a partir de la base de datos Scopus.

2 Publicación trimestral en las áreas de ciencias sociales y humanas. 
Ahora bien, en cuanto a los autores, sobresalen con mayor número de escritos Quezada, Ricardo Andrés Gaete, del Departamento de Ciencias Sociales de la Universidad de Antofagasta (Chile), con un 3\% de producción; Chang, Elizabeth J de la School of Business de la University of New South Wales (Australia), con el $2 \%$ y Esfijani, Azam de la Faculty of Education and Psychology de la Univerty of Isfahan, con el $2 \%$ de la producción (Ver figura 4 ).

\section{Documentos por autor}

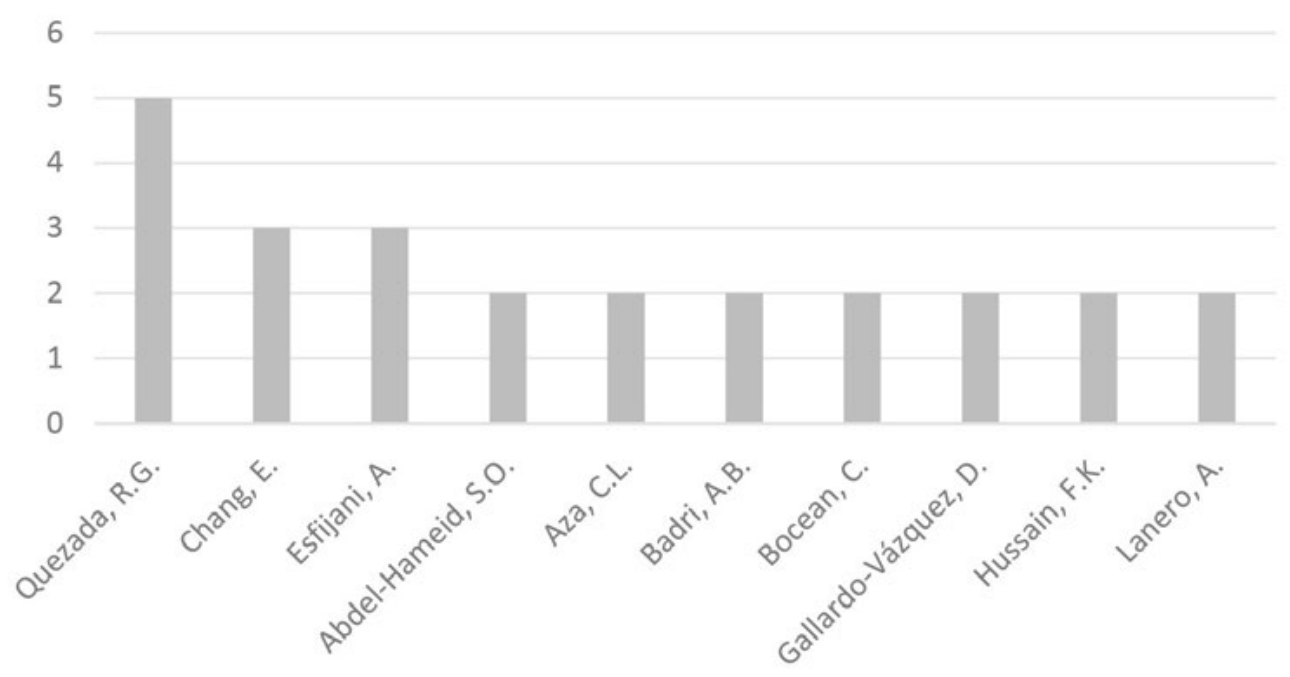

$N=179$

Figura 4: Autores sobresalientes en temas de responsabilidad social universitaria.

Fuente: Adaptado por las autoras a partir de la base de datos Scopus

Para clasificar la productividad de los investigadores, siguiendo a Cole y Cole (1973), se agruparon los autores de acuerdo al número de publicaciones. Así, por ejemplo, aquellos autores que solo tienen una publicación se denominan transeúntes, de dos a cuatro publicaciones se conocen como pequeños productores, entre cuatro y siete productores medios y más de diez como elevada producción. En el tema de RSU la mayoría de los autores (91\%) se clasifican como transeúntes, el 9\% como pequeños productores, el 1\% con media productividad y no existen autores con alta productividad en el tema, como se observa en la figura 5 . 


\section{Clasificación de los autores según productividad}

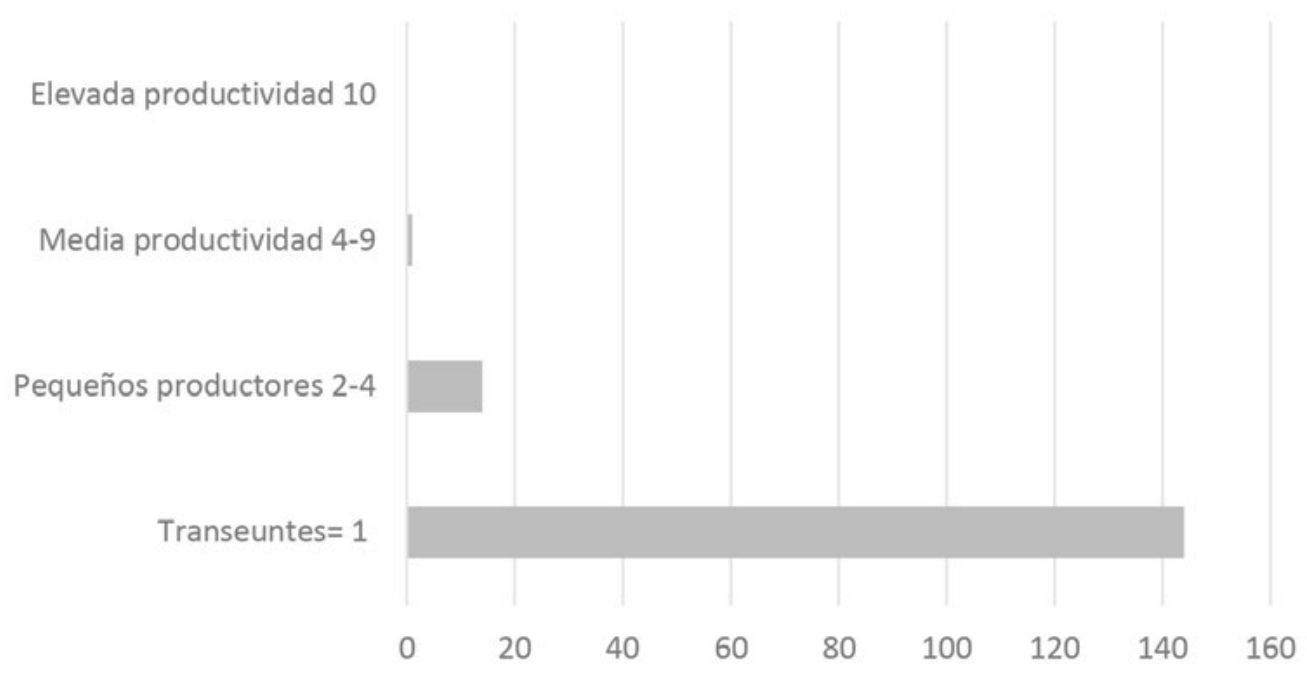

$N=159$

Figura 5. Clasificación de los autores según la productividad.

Fuente: Adaptado por las autoras a partir de la base de datos Scopus

La afiliación de los investigadores, con intereses en responsabilidad social universitaria, es la siguiente: de la Universidad del Zulia en Maracaibo Venezuela $5 \%$, de la universidad de Antofagasta en Chile $3 \%$, de la Universidad de Extremadura en España 3\% y de Universidad Complutense de Madrid en España 2\%, como se aprecia en la Figura 6.

El hecho de encontrar un gran número de autores transeúntes, puede obedecer, en la preocupación de los actores universitarios por encontrar respuestas y desarrollar acciones que les permita crear modelos para planear e implementar la responsabilidad social en las universidades de las que hacen parte. Lo que es evidencia de auge en la temática, pero no la especialización en el tema. De Colombia se destaca la aparición en el ranking de investigadores de la Pontificia Universidad Javeriana. 


\section{Documentos por afiliación}

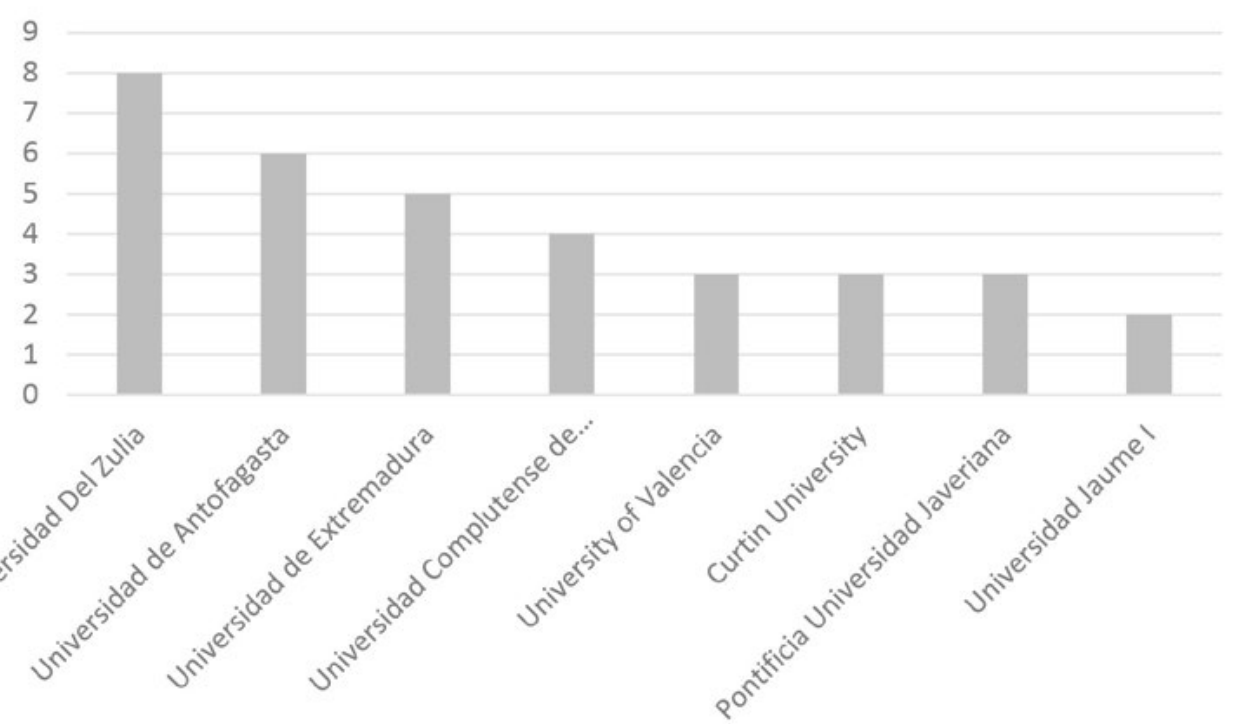

$\mathrm{N}=173$

Figura 6. Afiliación de los autores con interés en el tema de responsabilidad social universitaria.

Fuente: Adaptado por las autoras a partir de la base de datos Scopus

Los países donde se investiga más en el tema son: España $25 \%$, seguido por Venezuela $11 \%$, luego Colombia 9\%, y Chile 7\% como se observa en la Figura 7.

Se destaca la relación que existe entre la nacionalidad de los autores y la afinidad de los mismos en publicar en revistas venezolanas, de igual forma se evidencia como emerge la productividad científica por parte de autores venezolanos. En menor medida emergen publicaciones desde Colombia y Brasil. 


\section{Documentos por país}

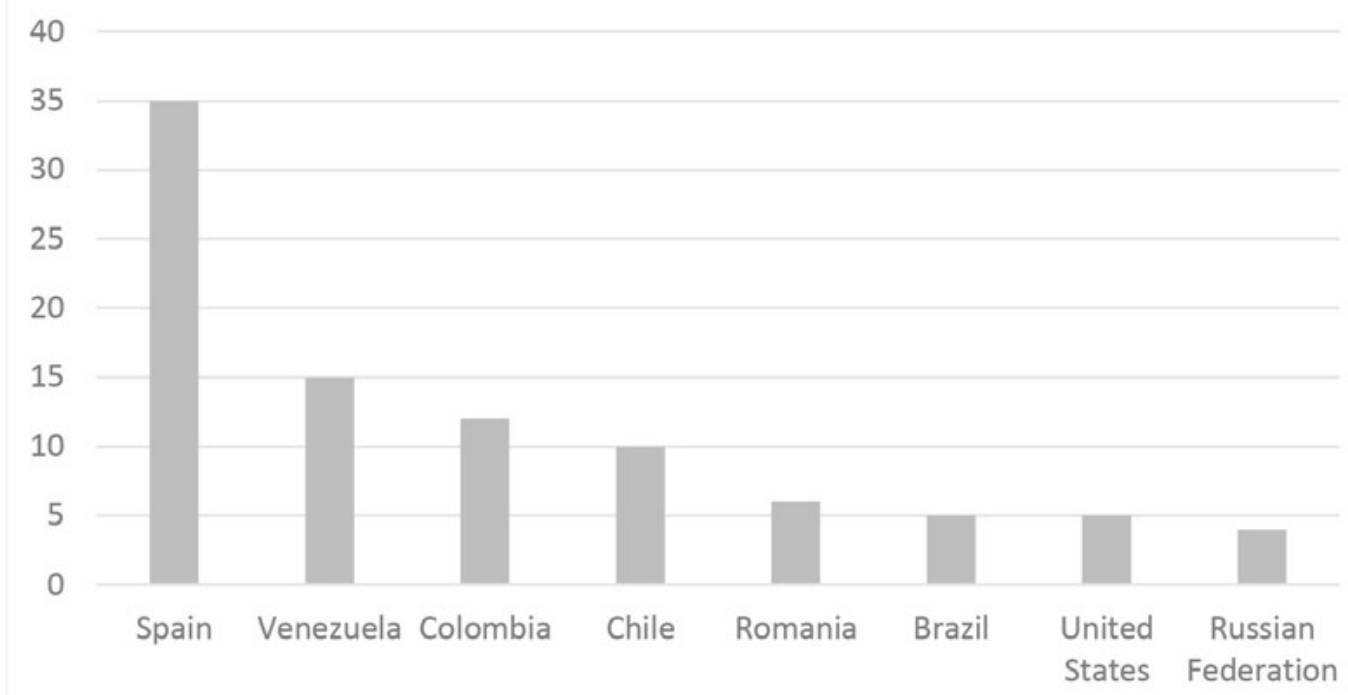

$\mathrm{N}=138$

Figura 7. Países con mayores publicaciones en el tema.

Fuente: Adaptado por las autoras a partir de la base de datos Scopus

Ahora bien, la producción sobre responsabilidad social universitaria se encuentra en su mayoría en artículos $69 \%$, documentos de trabajo $9 \%$, capítulos de libro $15 \%$ y reseñas $6 \%$, como se muestra en la figura 8 . El que los artículos superen cualquier otro tipo de publicación es positivo por cuanto lo que se publica tiene arbitraje y revisión de pares. Se observa un crecimiento en la publicación de capítulos de libro. 


\section{Documentos por tipo}

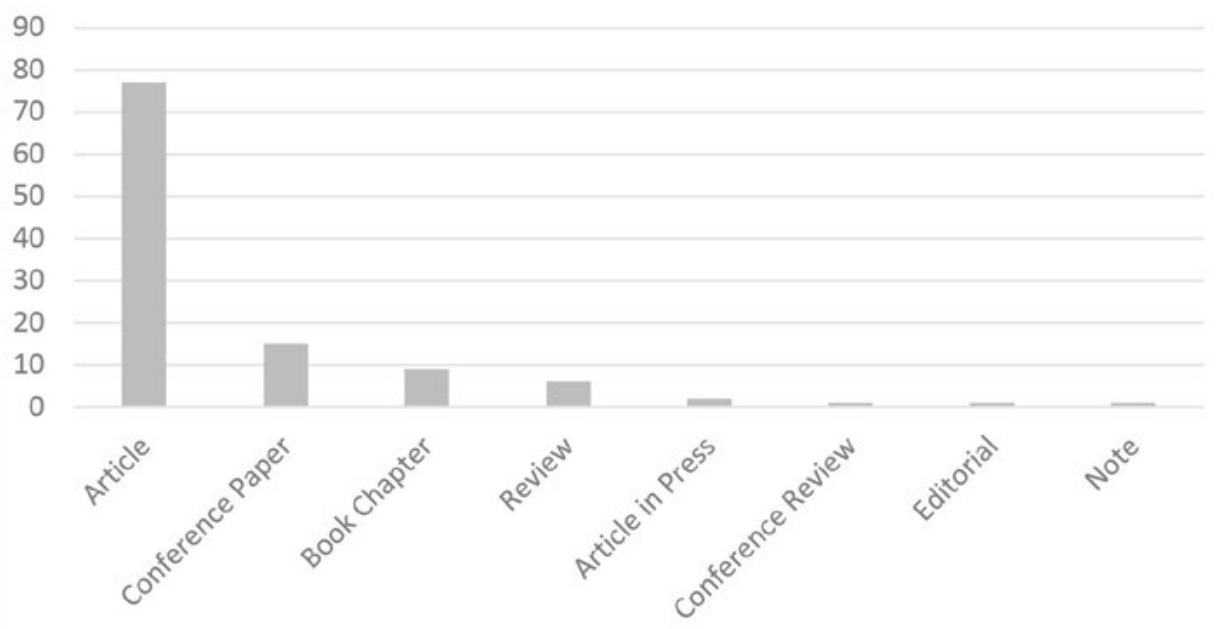

$\mathrm{N}=112$

Figura 8. Publicaciones en documentos sobre RSU.

Fuente: Adaptado por las autoras a partir de la base de datos Scopus

Las publicaciones sobre RSU se centran en las disciplinas de ciencias sociales $37 \%$, Negocios, administración y contabilidad 15\%, economía, econometría y finanzas $24 \%$, artes y humanidades $23 \%$ como se evidencia en la Figura 9. 
Documento por área

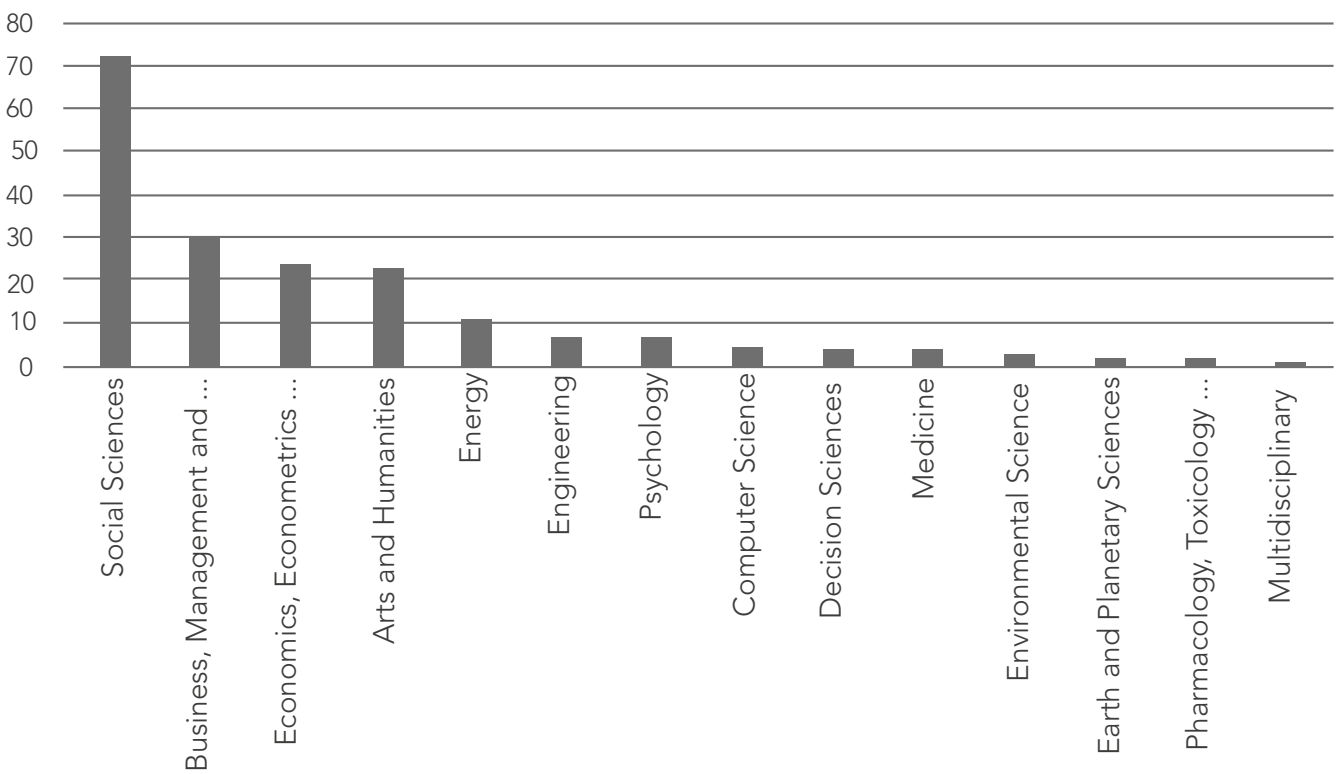

$\mathrm{N}=194$

Figura 9. Área temática de la RSU.

Fuente: Adaptado por las autoras a partir de la base de datos Scopus

La productividad que se encuentra en la base de datos Scopus, relacionada con la RSU, identifica diversas palabras claves, las que mayor nivel de coocurrencia o que se repiten en los documentos son las relacionadas con el factor humano, los stakeholder, la sostenibilidad, el desarrollo sostenible, el comportamiento y la justicia social, al igual que la sociedad y las instituciones. En menor término se repiten conceptos como la participación comunitaria, los planes de estudio, el compromiso institucional, los procesos de transferencia de tecnología y de conocimiento, los aspectos y participación social, la transparencia y los valores, como también la gestión universitaria (Ver figura 10) 


\section{PALABRAS CLAVES}

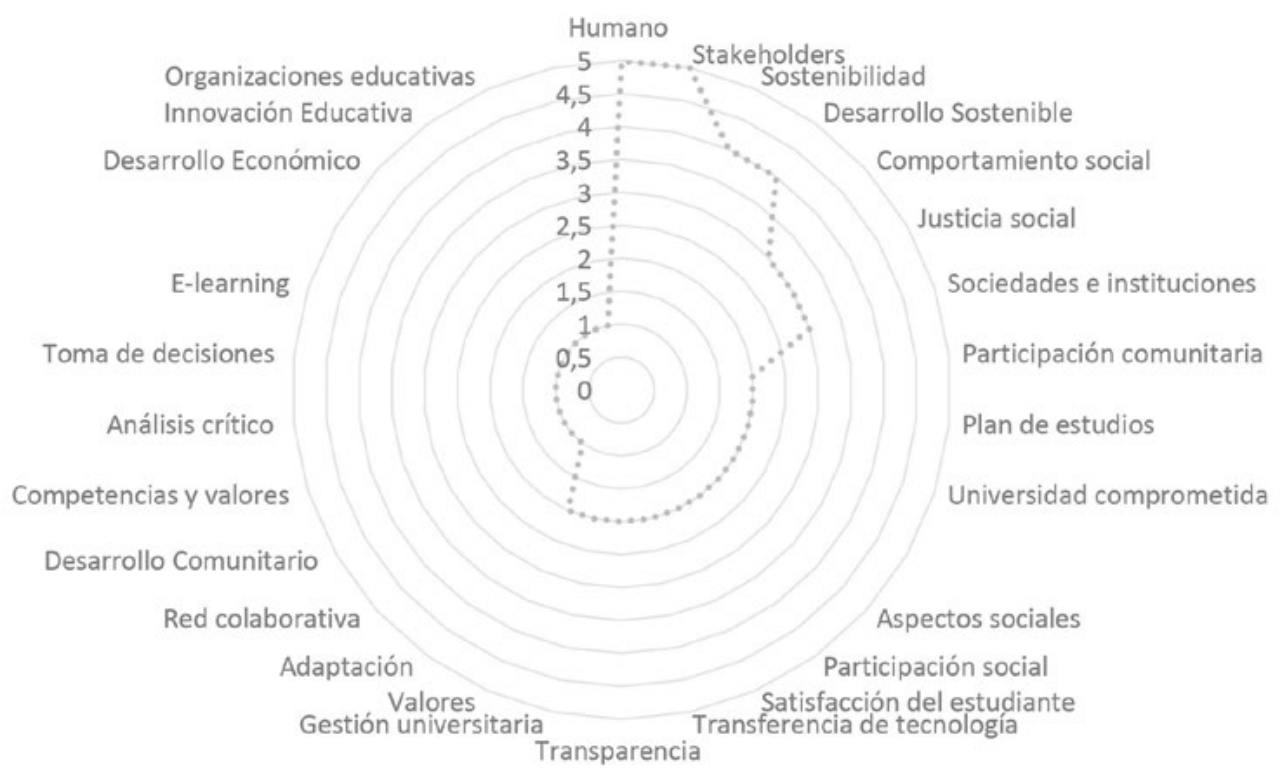

$\mathrm{N}=61$

Figura 10. Palabras claves sobre la temática de la RSU.

Fuente: Adaptado por las autoras a partir de la base de datos Scopus

Para tener una aproximación de las relaciones de los términos se utilizó el programa VOSviewer, donde se incluyó la data de los documentos de Scopus y se encontraron 3 cluster (o agrupaciones), el nodo (o centro) que presenta mayor coocurrencia es el de desarrollo, seguido por el de investigación lo que significa que en términos científicos existe una dependencia entre la RSU y el desarrollo y la investigación (Ver figura 11). 


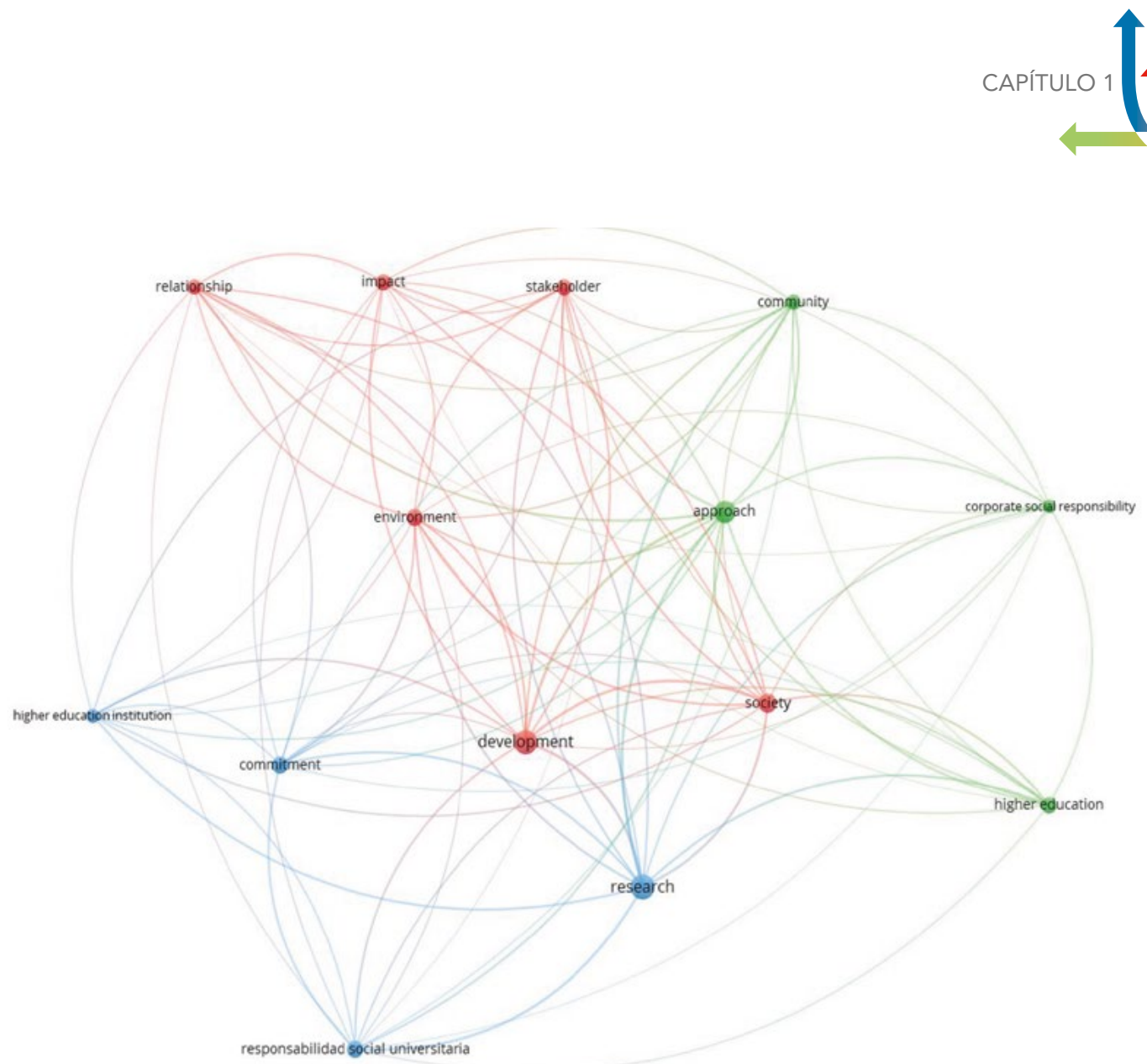

Figura 11. Análisis de relaciones de la data de RSU.

Fuente: Construido por las autoras a partir de la base de datos Scopus y el programa VOSviewer

Al observar el nodo de responsabilidad social universitaria propiamente dicha, se encuentra que ésta depende de factores internos a la institución como es el compromiso y la investigación; de igual forma en él confluyen factores externos como son las relaciones e impactos con la sociedad, el ambiente y con los stakeholders, adicionalmente el desarrollo se relaciona con la responsabilidad social corporativa que integra a la sociedad y el sector universitario (Ver figura 12). 


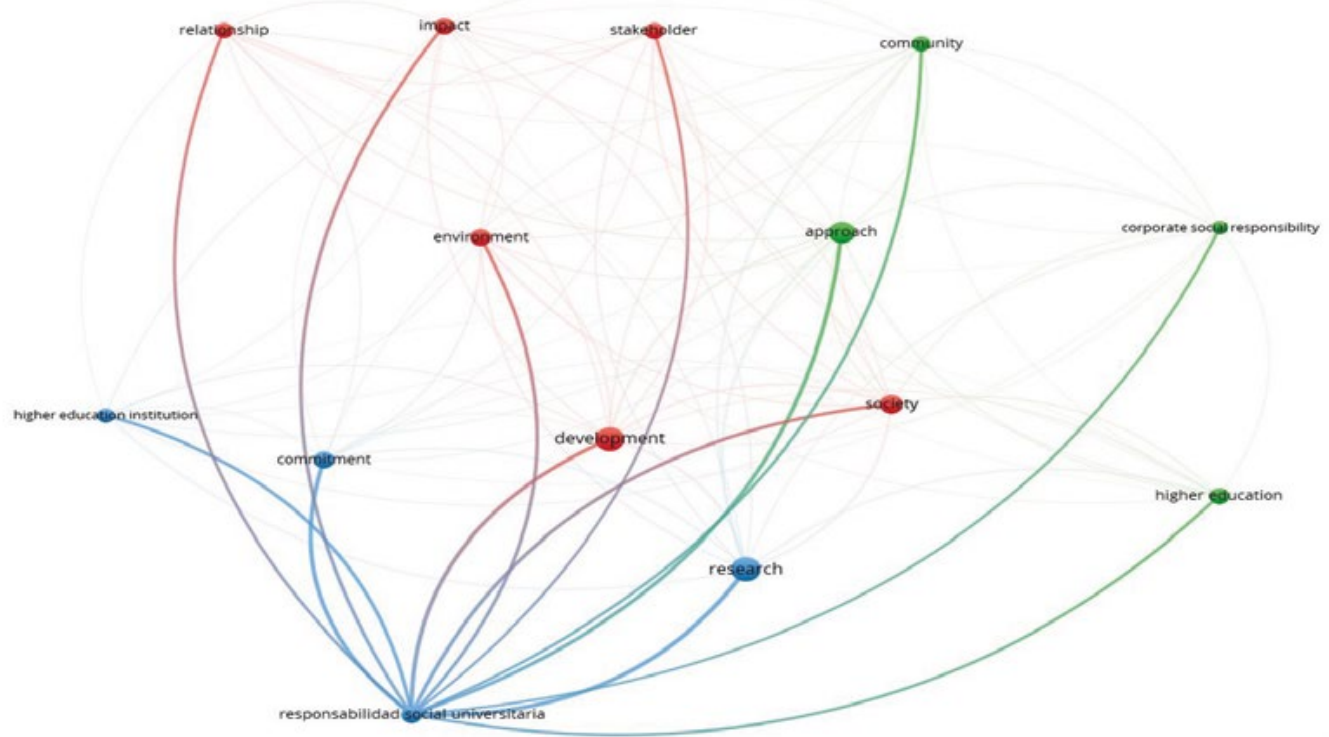

Figura 12. Análisis de relaciones de la RSU.

Fuente: Construido por las autoras a partir de la base de datos Scopus y el programa VOSviewer

Con el uso de la bibliometría fue posible establecer, en términos generales, que la definición de RSU es reciente, empieza a consolidarse a partir del 2006 y a diferenciarse de la responsabilidad social empresarial, gracias a autores como Quesada, Chang y Esfijani, entre otros. El mayor número de publicaciones sobre RSU se alcanzó en el 2018. Aunque las publicaciones sobre RSU han ido en permanente aumento, en el 2012 se fortaleció su productividad por factores de asociatividad y la creación de redes y observatorios.

Los autores más representativos proceden de países como España, Venezuela, Colombia y Chile. Sin embargo, existe un vacío científico en cuanto no hay suficientes investigadores especializados en el tema de RSU, es así como los autores alcanzan niveles entre transeúntes y de productividad media. Dos revistas venezolanas de investigación sobresalen por sus publicaciones en el tema de RSU, Opción y la Revista Venezolana de Gerencia. La revista mundial de emprendimiento, gestión y desarrollo sostenible (World Review of 
Entrepreneurship Management And Sustainable Development), del Reino Unido, ocupa el segundo lugar en productividad con un $9 \%$. Un gran porcentaje de la productividad científica que se encuentra en la base de datos de Scopus está representada por artículos.

La indagación en la base de datos Scopus, permite evidenciar las primeras categorías y sus relaciones. Sin embargo, se hace necesario realizar una revisión en buscadores para encontrar documentos académicos que permiten constatar todas las categorías y subcategorías existentes. En tal sentido se realizó una revisión bibliográfica con la ayuda del software Atlas ti, hasta agotar los conceptos.

\subsection{Evolución conceptual de la RSU}

En investigación cualitativa se conoce como categorización al proceso de clasificar situaciones o aspectos relacionados, en las temáticas que los abarca, para así encontrar significado a un grupo de datos (Romero, 2005). Ahora bien, una de las formas para identificar categorías es por medio de la revisión documental; esta metodología hace posible encontrar relaciones entre fenómenos en un periodo de tiempo.

Así entonces, con el propósito de comprender la evolución conceptual de la responsabilidad social universitaria y de acuerdo con la metodología propuesta, se realizaron dos fases en el proceso de recogida de datos y análisis de datos, luego de realizar el estudio bibliométrico se procedió a empaquetar los documentos en el software Atlas Ti, para realizar un análisis detallado de los mismos y como resultado obtener una línea de tiempo que permitió ver la evolución del concepto a través de los años y un listado de categorías

Los artículos analizados evidencian avances conceptuales desde 1953, lo que permitió evidenciar que el concepto de RSU, no es tan reciente como se pudiera pensar, pero si es evidente de sus cambios a través de los años. De los artículos encontrados y con ayuda del Atlas Ti, se extrajo el concepto de Responsabilidad Social Universitaria (RSU), que se tenía en cada momento del tiempo. Estas 
categorías se constituyen en la trazabilidad y experiencia de más de tres décadas y sus resultados permiten alimentar la forma en que se crean y ejecutan los planes de RSU. En primera medida, el concepto de RSU ha evolucionado en la misma medida que lo ha hecho el pensamiento económico, político, filosófico y social (Freeman, 1984). De acuerdo con Bowen (1953), la misión de la universidad está orientada hacia la de los individuos, en la cual el conocimiento se complementa con la ética y la moral, como bien lo sustenta la teoría ética. Posteriormente la UNESCO (2008) y Morín (2004) orientan el concepto de RS en la universidad, hacia la construcción de conocimiento para la solución de problemáticas sociales, sustentada en la teoría de la legitimidad y de los stakeholders. Adicionalmente Van Ginkel (2002) identificó la necesidad de incluir dentro del marco de la RSU el currículo y el compromiso por un desarrollo sustentable (Ver Figura 13).

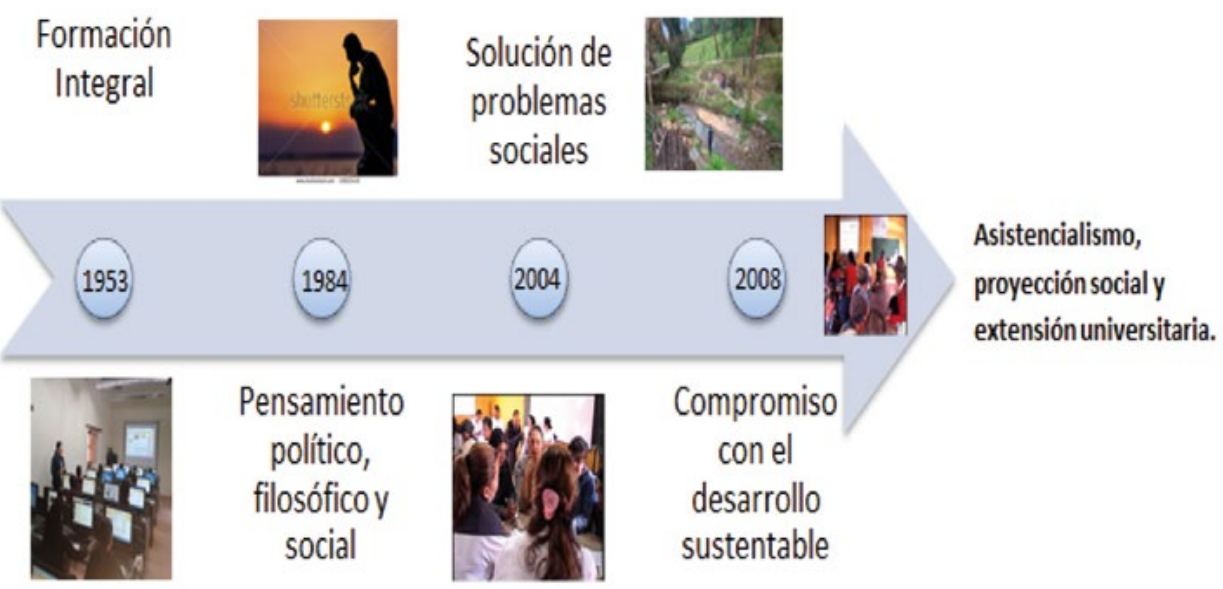

Figura 13. El concepto de la responsabilidad social universitaria como asistencialismo

Fuente: Elaboración propia.

En los primeros años de análisis, la concepción de la RSU se entendía como una orientación a las demandas sociales, o lo que se conoce como asistencialismo, proyección social y extensión universitaria (Ver figura 1); mientras el verdadero concepto apuesta también a la gestión y funciones sustantivas de la universidad (Vallaeys, 2009). Ahora bien, la RSU tiene diferencias notables con la responsabilidad social empresarial (RSE), se trata del "conocimiento en acción" 
Vallaeys (2008). Así entonces, su impacto va más allá de lo organizacional y social incluyendo dos ejes adicionales como son lo educativo y lo cognitivo y por medio de los currículos y de la producción del conocimiento se busca responder de manera asertiva a las necesidades regionales o núcleos problémicos detectados en la construcción del currículo.

La RSU no es un modelo mercantilista, pues se enfoca en potenciar el talento humano a partir de la dignificación de sus condiciones laborales y la instauración de la persona como el centro de la organización (Zárate \& García,2014). Por otra parte, no solo se enfoca en las personas que hacen parte de la institución, sino que se proyecta a las redes o agrupación de personas que actúan con la institución para la obtención de fines comunes y a aquellas de la sociedad a las que la institución empodera a partir de la transferencia de conocimientos (Cohen, 2007). De acuerdo a la teoría de los stakeholders, las redes están constituidas por individuos que en un momento dado pueden llegar a afectar o a verse afectados por los impactos de una organización, cuando las organizaciones tienen en cuenta a estas personas es posible reconstruir la cultura y el saber hacia una sociedad más justa y humana (Sánchez, 2007; Cevallos, 2008; Martínez \& Picco, 2008; Vallaeys, 2008), así como también, la construcción de organizaciones centradas en el ser humano (Ver Figura 14).

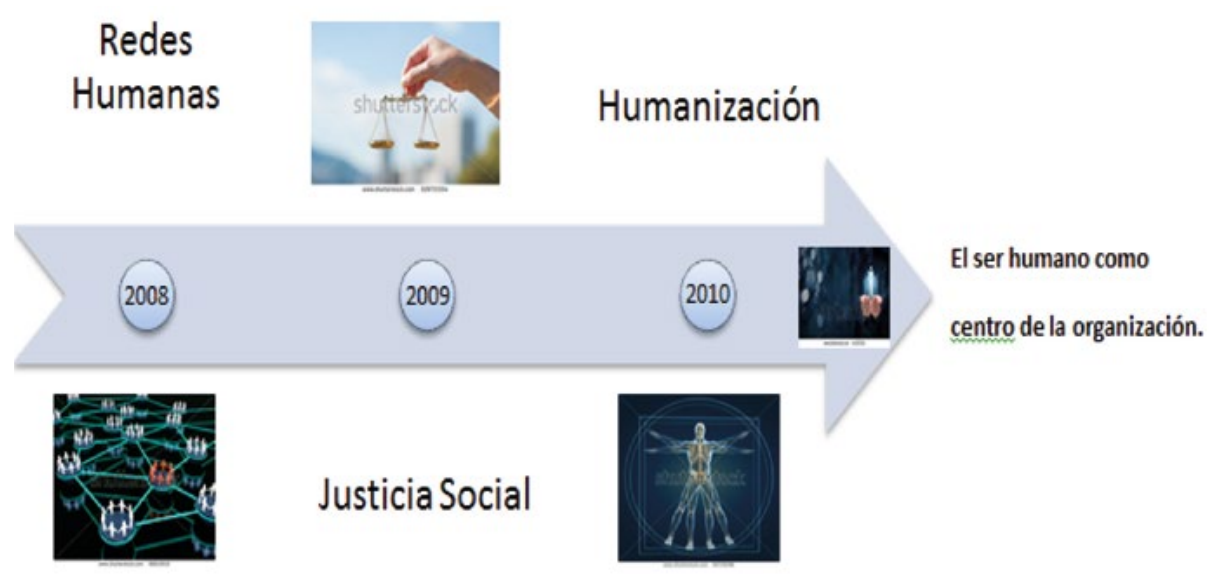

Figura 14. El concepto de la responsabilidad social y su evolución hacia la consideración del ser humano como el centro de la organización

Fuente: Elaboración propia. 
Las investigaciones más recientes apuntan a la implementación de la RSU a partir de innovaciones en la planeación, estas innovaciones integran un afianzamiento o relación directa con el contexto (Martínez, 2011), en tal sentido, se evidencia la teoría de la legitimidad, donde se hace necesario: establecer estructuras de relación con el sector productivo y social a partir de consultorías, políticas y estrategias que respondan al entorno (Ramos, 2012).

Por otra parte, a pesar de las diferencias que existen en la filosofía de una u otra universidad, la RSU impacta directamente desde su misión, como resultado de la fusión de intereses entre los actores que hacen parte de la organización y aquellos que hacen parte del entorno que son quienes en últimas evalúan por sus acciones a las universidades (Hernández \& Saldarriaga, 2009, Rodríguez, 2010) es por ello principalmente que deben existir planes de RSU donde se establezcan en forma clara las acciones que la universidad emprenderá y los actores que involucrará para alcanzar los logros e impactos esperados (Botero, González, Durpan \& Bolivar, 2012). En tal sentido, se requiere de estructuras internas en las que se integre en forma transversal la RSU, en su misión, funciones sustantivas y planeación diferenciadora y las relaciones externas en las que sea posible la transferencia de conocimiento y la integración de saberes. Estos planteamientos presentados están relacionados ampliamente con la teoría de la agencia (Ver figura 15).

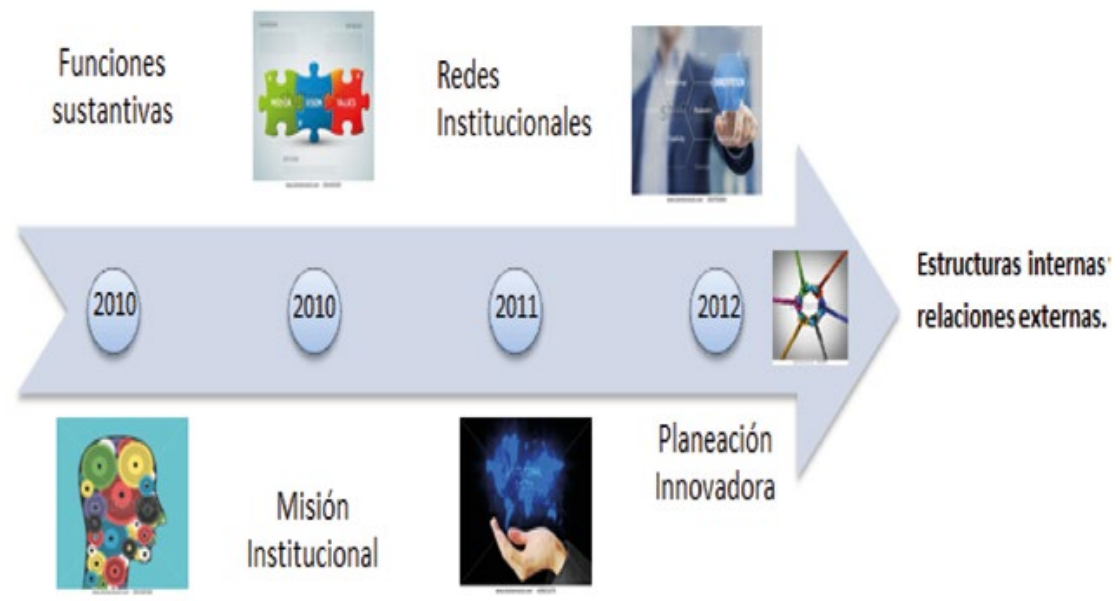

Figura 15. Estructuras internas y relaciones externas de la RSU Fuente: Elaboración propia. 
En el periodo comprendido entre 2014 a 2018 es posible evidenciar como en la conceptualización de la responsabilidad social universitaria confluyen la teoría ética con la teoría administrativa de calidad total, que no se había considerado en años anteriores. Se aprecia claramente la búsqueda de una responsabilidad autorregulada por estándares internacionales y la gestión permanente del conocimiento en el ámbito social (Ver Figura 16). La calidad total, en relación con la RSU se demuestra en los procesos de mejoramiento continuo de sus funciones sustantivas, donde cada actor es consciente de su quehacer y lo aplica de forma social y responsable y donde a la vez recibe beneficios que le permiten alcanzar un mejor nivel de vida (Torres \& Sánchez, 2014). Uno de los aspectos más relevantes que es de interés y cumplimiento de las instituciones universitarias corresponde a la gestión social del conocimiento, donde confluye la investigación y el desarrollo regional unido a la transferencia de conocimiento (Montoya, Arenas \& Lorenzo, 2018). De igual forma, para comprender los avances en RSU es importante señalar que las instituciones universitarias como toda organización debe cumplir con ciertos estándares internacionales para medir su responsabilidad social y estos resultados pueden servir como insumo para implementar una integración con la responsabilidad social universitaria que realizan (Huerta-Riveros \& Gaete-Feres, 2017)

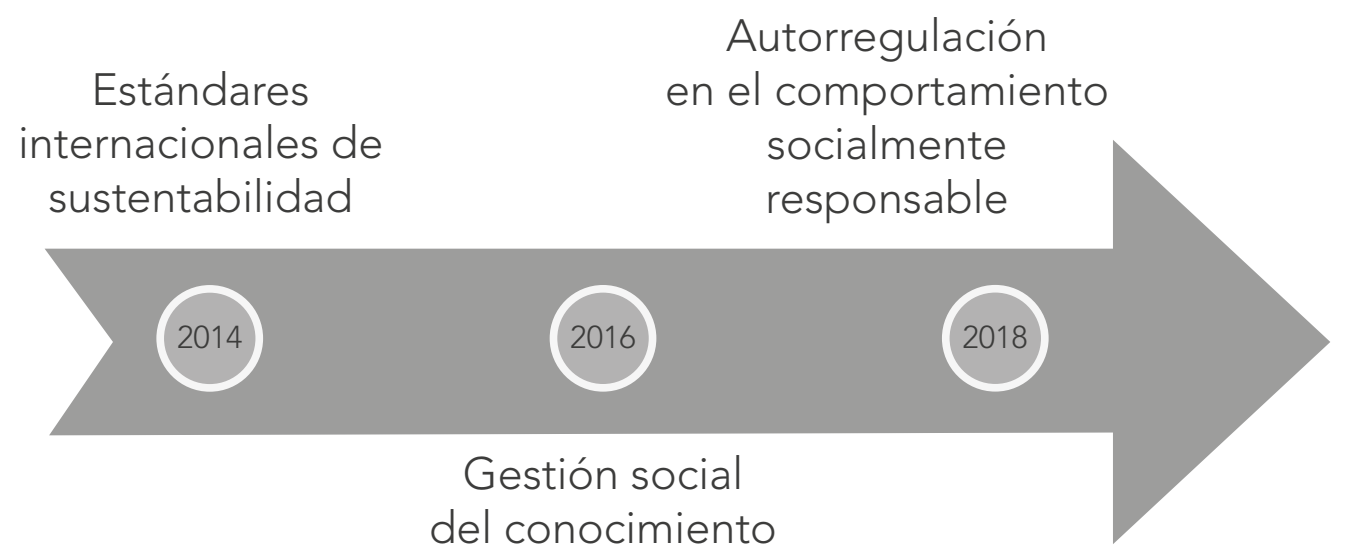

Figura 16. Autorregulación para el cumplimiento de la RSU

Fuente: Elaboración propia. 
Como resultado del análisis y aplicando los criterios de relevancia. exclusividad, complementariedad, especificidad y exhaustividad, se encontraron ocho (8) categorías: a) aprendizaje organizacional, b) necesidades regionales, c) internacionalización, interdisciplinariedad e interculturalidad, d) sustentabilidad y calidad de vida, e) redes, f) planeación y aplicación innovadora, g) filosofía Institucional y h) humanización (Ver figura 17).

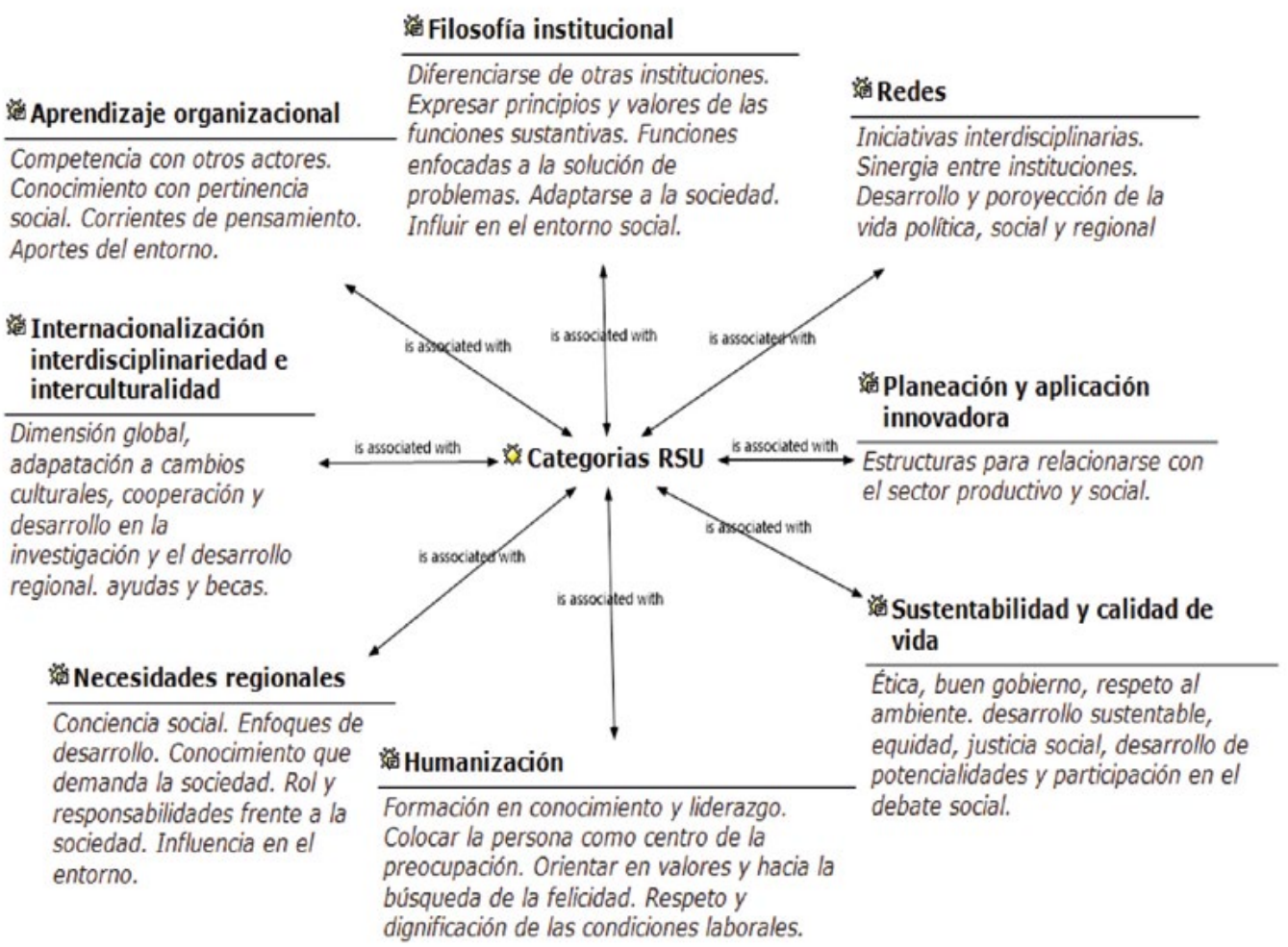

Figura 17. Gráfico Categórico de la Responsabilidad Social Universitaria con la aplicación del Software Atlas Ti.

Fuente: Elaboración propia. 


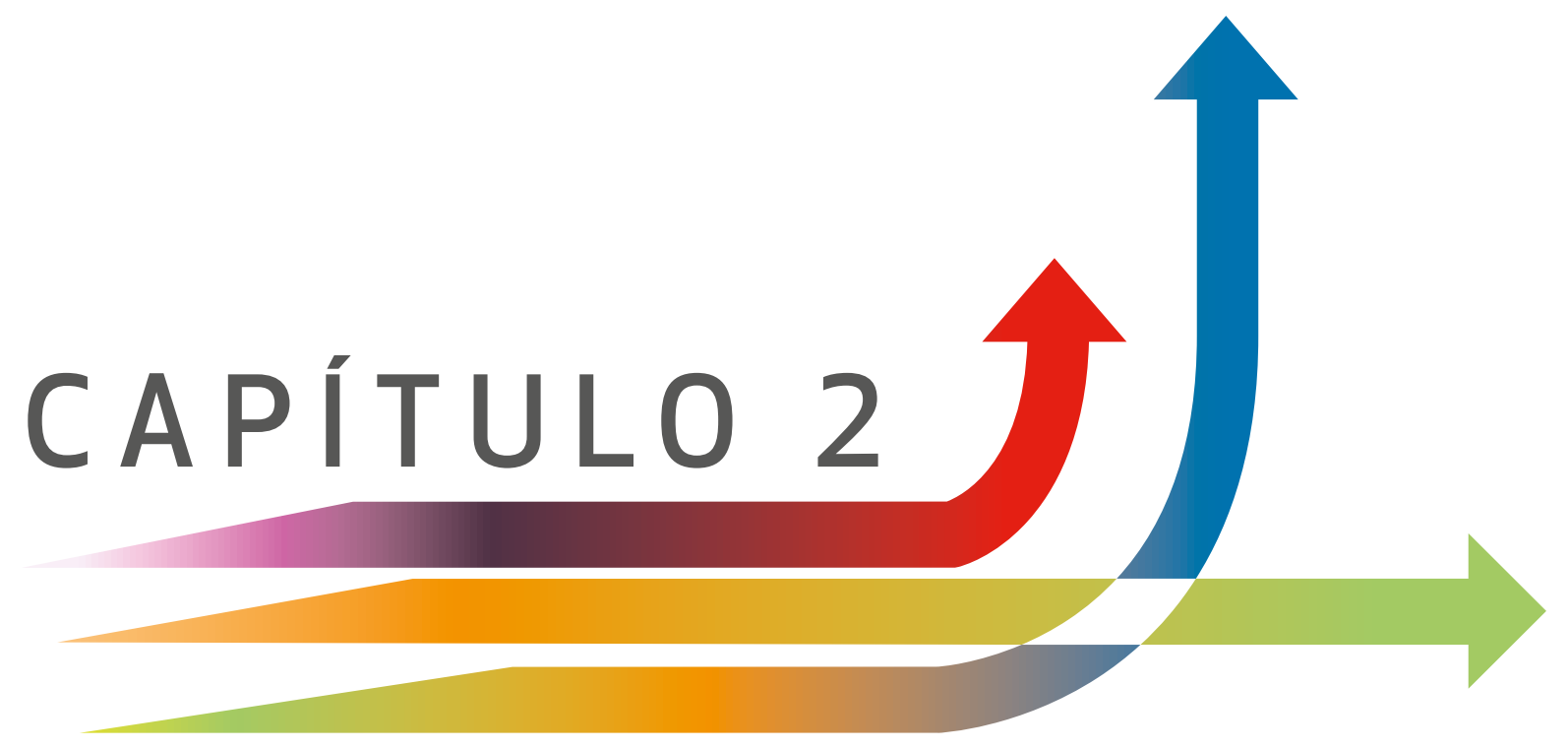





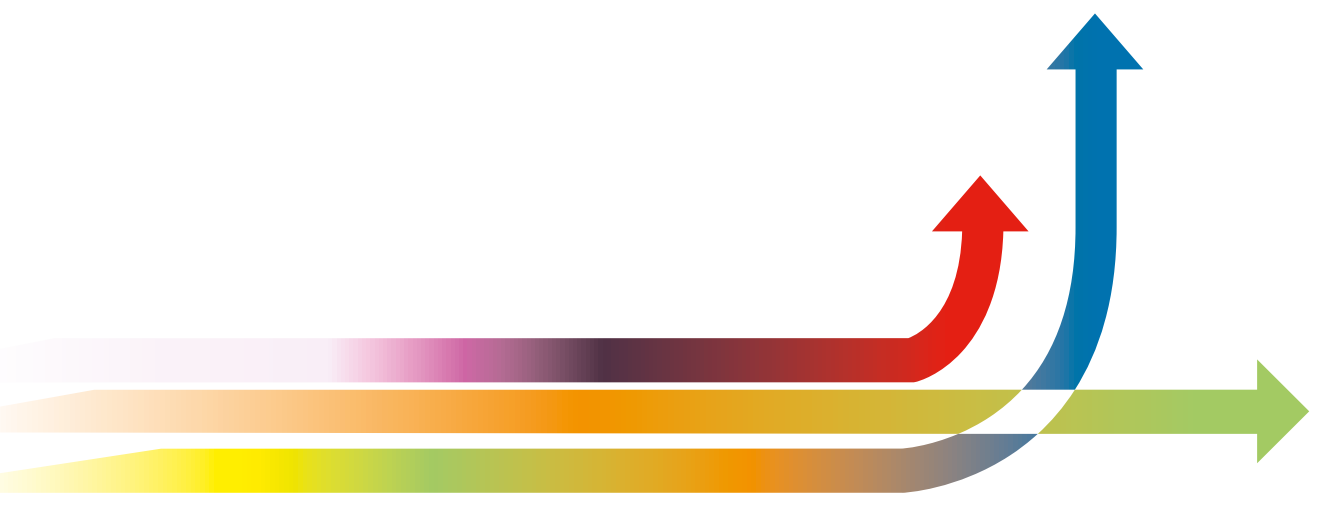

\section{Descripción de las categorías relacionadas con la Responsabilidad Social Universitaria}

A continuación, se presentan los resultados de la fase 4 de la metodología de la investigación, correspondiente a la discusión y se descripción de las categorías encontradas. El propósito de la descripción es comprender el significado, los niveles de profundidad, la exactitud de cada una de las categorías, la consistencia y su relevancia en relación con el tema y compararla con los resultados de otros autores para darle validez a las ocho categorías.

\subsection{Aprendizaje organizacional}

El concepto de responsabilidad social universitaria (RSU), está en permanente construcción. Durante los últimos años las definiciones al respecto presentan elementos tanto iguales como con polos opuestos, sin embargo, muchos de ellos temen apartarse del término responsabilidad social empresarial (Peña, 2011). Cantú-Martínez (2013) afirma que no existe una fecha donde se pueda dar por sentado la aparición del término, no obstante, a través de la historia y de las evoluciones y cambios acontecidos en el entorno ha permitido igualmente pronunciarse para definir el concepto.

Sin embargo, los primeros escritos que se logran encontrar sobre responsabilidad social remontan la antigua Grecia, con pensadores como Platón, Aristóteles y Cicerón y en el régimen romano de derecho y justicia (Camargo, 2007; Rivera \& Malaver, 2011). Podría pensarse por lo tanto que la 
responsabilidad social empresarial ha sido en un principio el modelo a seguir por la responsabilidad social universitaria, pero no se ha quedado ahí, sino que ha evolucionado por los cambios que ocurren en el entorno y que influyen en la construcción de las funciones sustantivas que cumplen los entes universitarios y la misión y visión que estas profesan, para la formación de personas que transformarán lo económico, social y cultural (Bernal \& Rivera, 2011). Como bien lo manifiesta Rodríguez (2010), las universidades deben ser muy cercanas con la sociedad, para de esta forma comprender hacia donde orientar su quehacer para buscar una verdadera transformación hacia las necesidades de las personas, sociedades, grupos, instituciones, el mercado y la sociedad civil y en este quehacer permanente ha encontrado asiento la RSU (Ver figura 18).

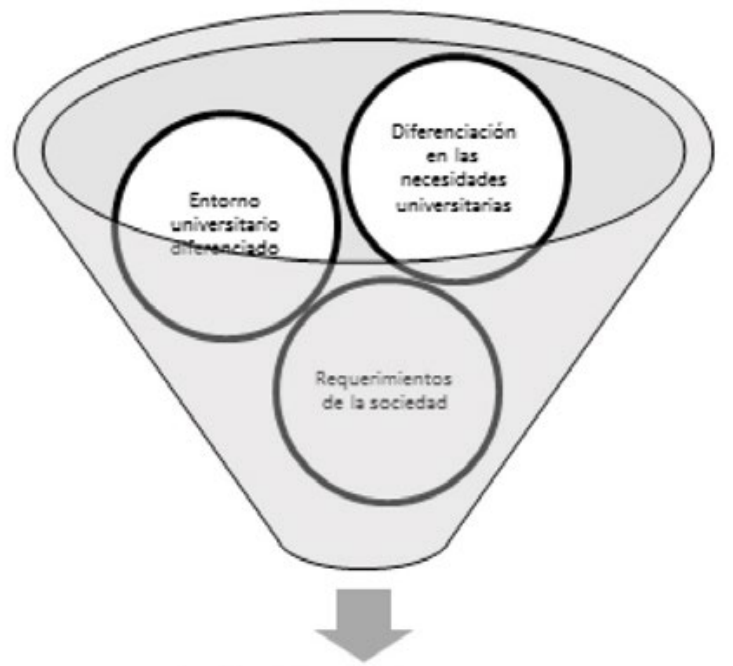

Evolucioción de la RSE a RSU en instituciones universitarias.

Figura 18. Evolución de la RSE a RSU

Fuente: Elaboración propia

Por otra parte, De la Cruz (2011), manifiesta que la RSU se visualiza como bien público desde tres niveles: a) promueve y protege la institución b) genera conocimiento a partir de la investigación de excelencia c) orienta las prácticas de los agentes económicos. El concepto de RSU va más allá de la proyección 
social o extensión universitaria porque le apuesta a lograr un cambio del entorno a partir del conocimiento (Vallaeys, 2008).

Así entonces, la responsabilidad social universitaria no es ajena a los procesos de práctica organizacional. Las universidades cambian y se reinventan, al mismo tiempo que cambia el entorno y se adaptan a las normas de conducta que reclama la sociedad. Estos cambios se evidencian tanto en sus principios como en las prácticas que realizan, en los currículos que diseñan y la formación que imparten a sus estudiantes (Ver Figura 19).

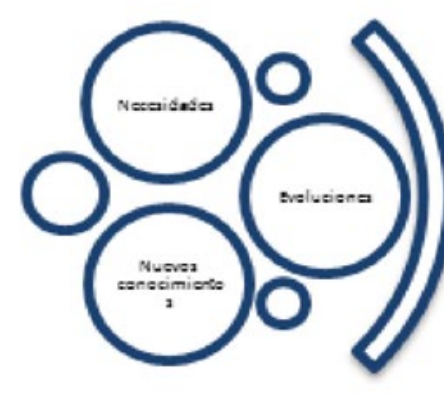

Entorno

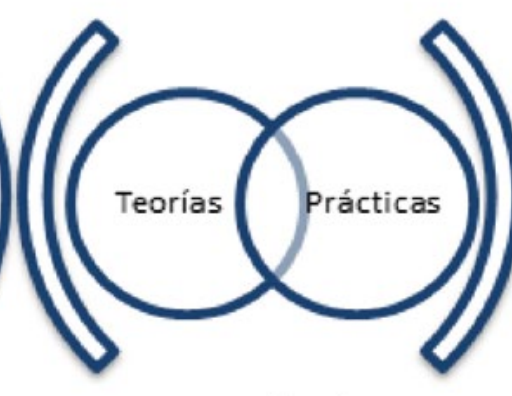

Currículo

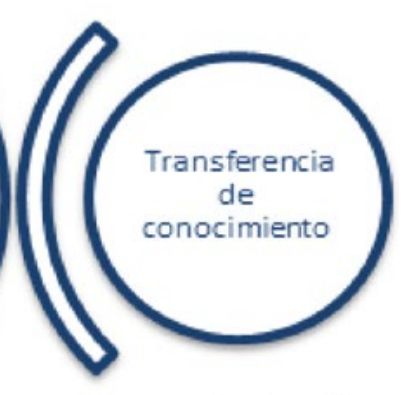

Sociedad

Figura 19. Transferencia de conocimiento del entorno hacia la sociedad Fuente: Elaboración propia.

\subsection{Necesidades regionales}

Se han propuesto varios debates respecto al papel que debe orientar la universidad hacia la sociedad. En este sentido Morín (2004), se pregunta si es la universidad la que debe adaptar sus acciones a la sociedad o, en otro sentido, es la sociedad la que debe ajustarse a las pretensiones de las universidades. Para dar respuesta a esta pregunta, es necesario definir el rol y las responsabilidades de la universidad frente a los requerimientos de la sociedad donde éstas se encuentra inmersas. 
Por una parte, le corresponde a la universidad estudiar, analizar y propender por encontrar nuevos enfoques que permitan el crecimiento y desarrollo, donde orienten los aspectos económicos sociales, teniendo en cuenta la características particulares de las regiones para mejorar el bienestar del individuo en su contexto y constituirse en motor del desarrollo para resolver problemas de violencia, pobreza, injusticia y discriminación (Hernández \& Saldarriaga, 2009; Lerner, 2007) y para ello debe formar ciudadanos íntegros, con competencias para intervenir en un desarrollo sustentable y sostenible para las organizaciones y el país (Viteri, Jácome, Medina \& Piloto, 2012; Sánchez, 2010). Según Arana, et al., (2007) la responsabilidad social aplicada en una universidad debe partir del conocimiento de la situación y unirse a un propósito de cambio que integre los conocimientos que se imparten en las aulas, así como también, la ética y valores que se adquieren para la realización de las funciones sustantivas como son la formación profesional, la investigación; así como también en la innovación y proyección social.

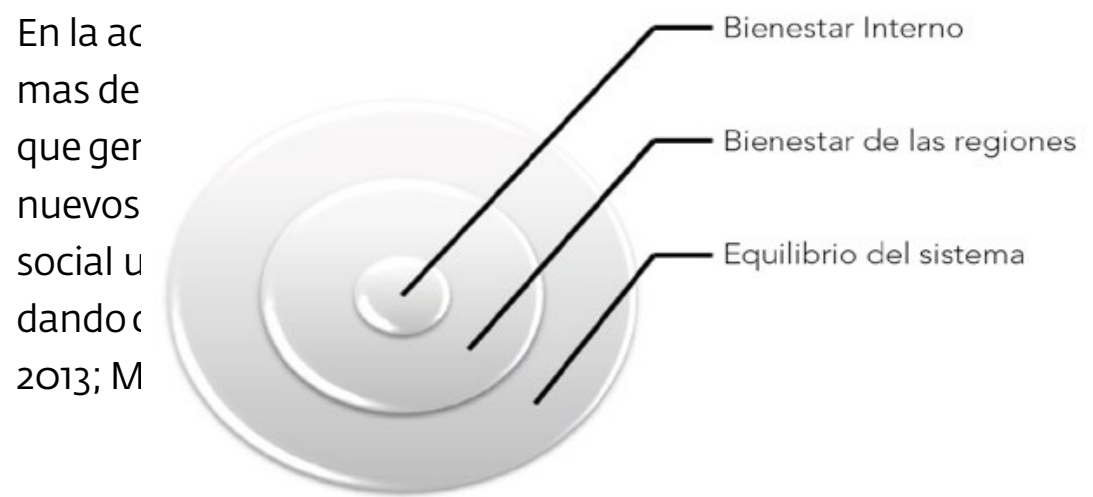

jevas forxctuación nación de Isabilidad Jucación, Jiménez,

Figura 20. Propósitos de la universidad para con las necesidades de la región Fuente: Elaboración propia.

Vera, Gómez, Acosta y Perozo (2012) presentan la docencia como una actividad rigurosa entre el conocimiento y la práctica en el contexto. Vega citado por Sacco (2009) afirma que "el concepto de Responsabilidad Social Universitaria busca comprometer a la institución con su entorno a través de lo que ella produce. Las investigaciones que se llevan a cabo deben considerar estos mismos compromisos" (p.395). Por otra parte, las universidades deben propender por mejorar la calidad de vida de las co- 


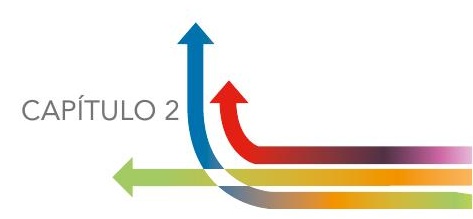

munidades al igual que la calidad de la misma institución (Cohen, 2007; Fernández \& Jiménez, 2013).

Para su abastecimiento y el financiamiento de su quehacer, la universidad debe contar con un enfoque empresarial. En tal sentido, como lo expresan Maldonado, García y Giménez (2007) la responsabilidad social requiere de una revisión desde dos miradas, la interna para su sostenibilidad y la externa en aquella interrelación de solidaridad que se establece con las comunidades locales. Para ello es relevante establecer con claridad que responsabilidad permitirá a la universidad equilibrar las posibilidades de impactar en la comunidad y las necesidades reales de las mismas sociedades (Cohen, 2006)

\subsection{Internacionalización, interdisciplinariedad e interculturalidad}

La educación tiene como misión, según Delors (1996) que emerjan nuevos talentos, con habilidades, para retarse a construir su proyecto de vida hacia la búsqueda del desarrollo de la humanidad. En tal sentido señala el autor, la globalización se sitúa en el mundo actual como el núcleo que permite impulsar el crecimiento tanto de las personas como de sus comunidades.

Quezada y Bratos (2012) señalan como la internacionalización universitaria puede considerarse desde la responsabilidad social, para cuyos efectos es importante establecer becas y ayudas, construir de redes de investigación y desarrollar investigaciones de calidad, abriendo así oportunidades para todos y prefiriendo aquellas personas y regiones de menor acceso a estas estrategias (Ver Figura 21). 


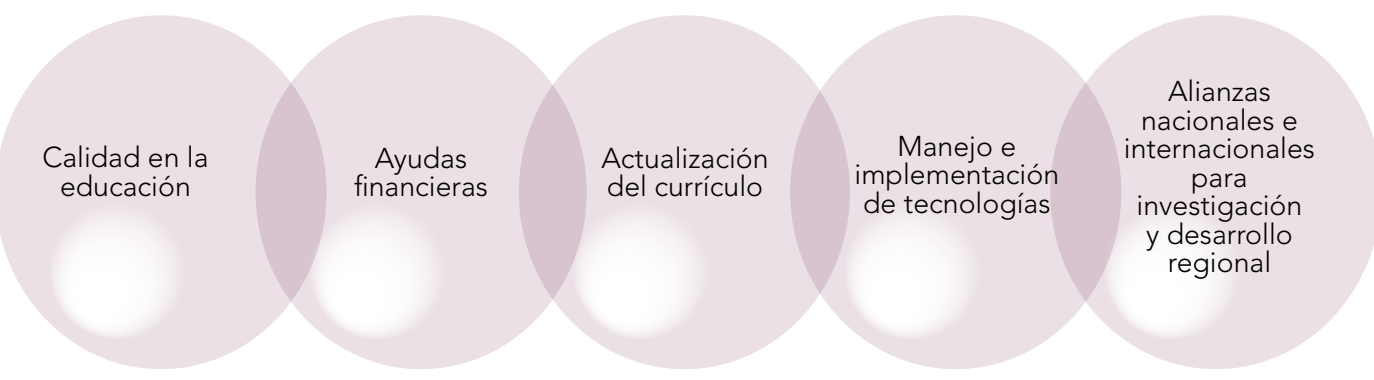

Figura 21. Compromisos con la internacionalización, interdisciplinariedad e interculturalidad.

Fuente: Elaboración propia.

Gaete y Bratos (2012) afirman que las universidades deben estar muy atentas a aquellos cambios que surgen en la sociedad y lo pueden hacer al estar vigilantes a las situaciones que se han presentado en los últimos años donde la educación parece que se imparte de la misma forma para un gran número de personas y se imparte el mismo mensaje, por tanto, las tecnologías de la información han permitido llegar a diferentes culturas y países diversos para masificar de esta forma el conocimiento. En este sentido, los autores plantean que la internacionalización del quehacer universitario puede ser entendida como "el proceso de integración de la dimensión global, intercultural e internacional" (p.3), sin embargo Fernández y Ruzo (citado por Gaete \& Bratos,2012), argumentan que "las motivaciones de las universidades para internacionalizar su quehacer en la actualidad son diferentes y se pueden resumir en cuatro grandes motivos: económico-financiero, culturales, políticos y académicos" (p.3).

De igual manera Sebastián (citado por Gaete \& Bratos, 2012) plantea que en la dimensión internacional de las universidades se deben tener en cuenta tres aspectos como son la cooperación que se puede dar entre diversas universidades para la gestión del conocimiento, los compromisos por el desarrollo y la proyección social y la asociación para investigaciones conjuntas. Ahora bien, para la implementación de la internacionalización en las universidades Quezada y Bratos (2012) sugieren oferta de posgrados en regiones geográficas con ma- 


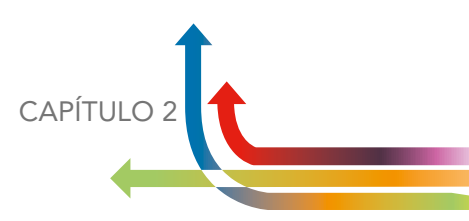

yores dificultades y mayor respaldo a los estudiantes en los diversos trámites administrativos y de convenios.

Desde esta perspectiva, vemos como la internacionalización es un aspecto fundamental y hace parte de las responsabilidades sustantivas de las universidades, sin embargo, para realizarse en forma responsable deben incluir acciones de cooperación entre diversas universidades. En lo que respecta a la cooperación universitaria para el desarrollo, según River \& Unceta (citado por Gaete \& Bratos, 2012), esta ha dejado de ser exclusiva de entes gubernamentales y Organizaciones no gubernamentales (ONG) apreciando a otras instituciones y universidades que han aumentado de manera importante su participación en este campo.

\subsection{Sustentabilidad y calidad de vida}

Según Castro (2007) la educación es el medio que tienen las personas para mejorar su calidad de vida ya que gracias a ella es posible mejorar los ingresos, las condiciones de salud, organización familiar, impulso de valores, convivencia y autonomía. Sin embargo, gestionar el mejoramiento de la calidad de vida es una tarea difícil, pues permite diversas interpretaciones y toma sentido en relación a un sistema de valores. Leva (2005) afirma que entre los indicadores de calidad de vida es necesario en primer lugar cubrir las necesidades básicas como salud, educación, trabajo, vivienda y alimentación, también debe existir una buena interacción del individuo con la comunidad donde hace presencia. En tal sentido, como lo expresa Criado (2006), es necesario despertar una inquietud en las universidades hacia el trabajo comunitario en busca de incidir en la mejora de las condiciones de vida de las personas en el entorno del que hace parte la institución (Ver Figura 22). 


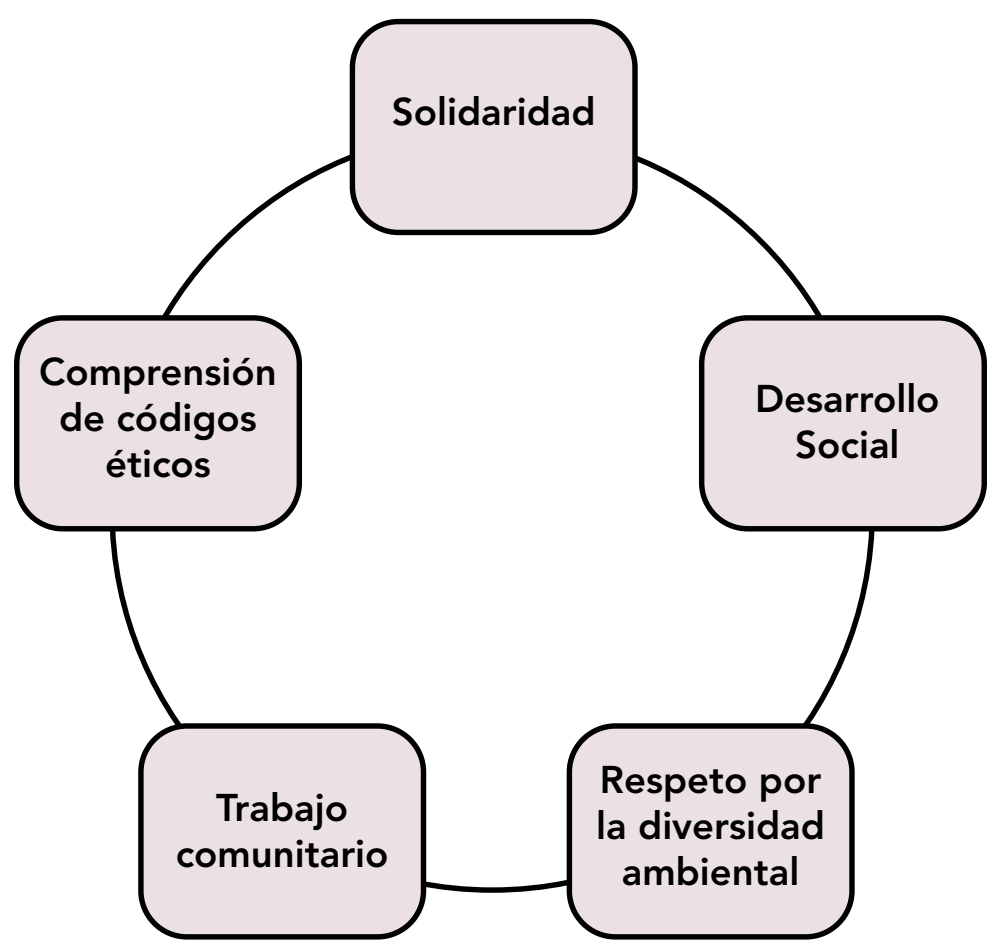

Figura 22. Aportes de la universidad que pueden hacer posible la sustentabilidad y una mejor calidad de vida

Fuente: Elaboración propia.

El enfoque de responsabilidad social presenta un mayor repunte cuando se abre la discusión a temáticas relacionadas con la crisis ambiental y por los proyectos de desarrollo sustentable, los cuales están alineados a parámetros de desarrollo socioeconómico y a los diversos estilos de vida, que deben ser parte de las habilidades y competencias que las instituciones de educación superior en la formación de recursos humanos pueden lograr (Domínguez, 2009). El contacto que los estudiantes tienen con las problemáticas sociales de su entorno les hace comprender las diversas realidades de las personas y despertar en ellos la solidaridad (Caponni, 2012).

En ese orden de ideas, la universidad debe tener espacios que motiven a una permanente reflexión analítica, centrada y con argumentos sobre el papel que desempeña cada uno de sus actores como protagonistas del mejoramiento de 
la calidad de vida del hombre en área de influencia (Brunner, 2008). Craveri y Spengler (2007) argumentan que las funciones docentes han evolucionado, el docente ya no es el centro del aprendizaje sino el orientador para que el estudiante desarrolle conocimiento que le permita transformar la sociedad en busca del bienestar humano y de su entorno. Para ello es importante el conocimiento de códigos de conducta nacionales e internacionales, el manejo de normas para la sostenibilidad, sin violentar los derechos sociales de la comunidad y de sus trabajadores, ni provocar un deterioro del medio ambiente (Salazar, 2004).

\subsection{Redes}

La RSU se puede transformar en un eje transversal del currículo, contribuyendo a la formación integral del estudiante. Para esto es necesario el conocimiento de la realidad, de los problemas del entorno y de la forma de dar solución desde la academia (Peralta, 2012). El impacto que las universidades esperan ejercer en su entorno se puede construir mediante un enfoque holístico de relaciones y redes interdisciplinarias e interinstitucionales (Martínez, 2011).

La RSU debe potencializar la inclusión, la ética y la sustentabilidad. Inclusión referida al trabajo en red con otras organizaciones públicas y privadas; sustentabilidad al potenciar las capacidades de cuidado del ambiente y ética cuando los logros se obtienen con responsabilidad (Casilla \& Camacho, 2012). Por lo tanto, es necesario que los docentes adquieran nuevas competencias sociales y cognoscitivas y las apliquen en su práctica pedagógica, para fortalezcan el trabajo en red, la formación continua y la práctica hacia las realidades de la región (González, Pirela \& Zerpa, 2012).

Como manifiesta Cavero (2006), es fundamental que la universidad realice alianzas estratégicas entre la triada (Estado, sociedad civil y sociedad económica) que permitan cambios relevantes contribuyendo al impacto deseado: el cambio social y la transformación de los hábitos universitarios tradicionales (Ver Figura 23). En tal sentido, la docencia se fortalece con la investigación y 
con mecanismos para que los docentes formen sus pares potenciales y socialicen experiencias (Misas, 2002). Ahora bien, estas alianzas estratégicas pueden darse con sus mismos grupos de interés o stakeholders, al acoplar sus funciones y las potencialidades de los grupos a las necesidades de la sociedad (Esfijani, Hussain y Chang, 2013).

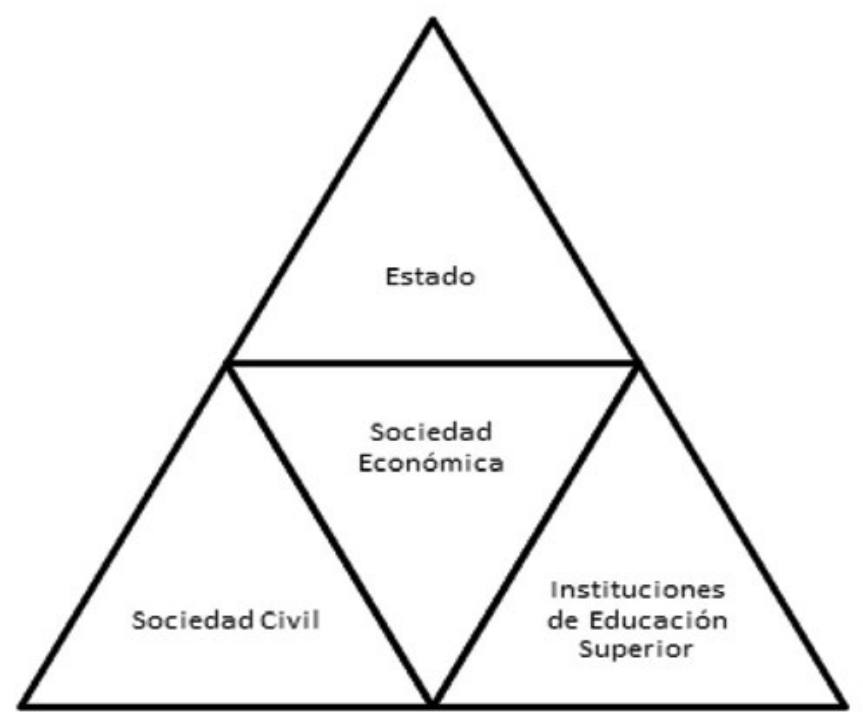

Figura 23. El trabajo universitario en red

Fuente: Elaboración propia.

\subsection{Planeación y aplicación innovadora}

Otro aspecto fundamental relacionado con la RSU, lo constituye su aplicación innovadora que le da un carácter diferencial a cada institución. Esto significa una estructura de relaciones tanto con el sector productivo y social como son las consultorías, políticas y estrategias que respondan al entorno; como también nuevas formas para fortalecer la extensión universitaria, revisar permanentemente la pertinencia de los programas, relacionar investigación con desarrollo regional y mirar el entorno con la óptica de la planeación estratégica (Ramos, 2012), (Ver Figura 24). 


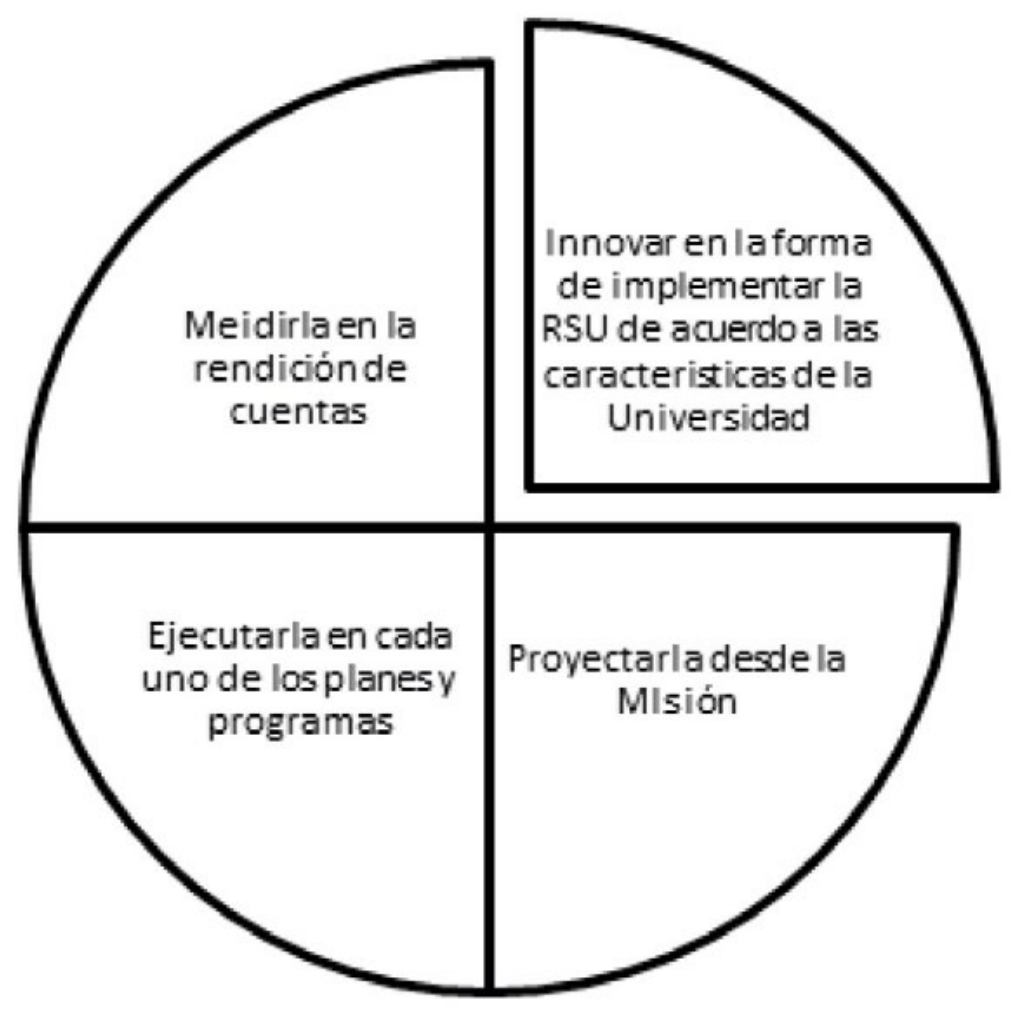

Figura 24. Elementos que permiten dar un carácter diferenciador a la planeación de la responsabilidad social universitaria

Fuente: Elaboración propia.

Los estudios de Botero, González, Durán y Bolívar (2012), demuestran cómo la aplicación de la RSU puede alcanzar impactos positivos ya sea en el currículo, en el bienestar institucional o en lo académico. Ahora bien, en el componente curricular, la responsabilidad social universitaria se evidencia tanto en los valores que se adquieren como en la misma autonomía y responsabilidad. Por otra parte, las prácticas de bienestar permiten la cohesión y genera confianza entre los integrantes de la universidad (Bustos \& Inciarte, 2012). Mientras que los impactos académicos se relacionan más con la construcción de conocimiento y transferencia del mismo. El currículo debe apropiarse de los hallazgos encontrados en este tipo de actividades. La ética, la justicia, 
la libertad y la autonomía deben traducirse en conocimiento transversal y transferible y la aplicación de los resultados y sus avances han de socializarse y darse a conocer para ser evaluados por otros y también para ponerse en práctica (Casilla \& Camacho, 2012).

En el contexto europeo, una de las prácticas más enriquecedoras sobre responsabilidad social en universidades es el realizado por el Instrumento de Medida para la Sostenibilidad de la Alta Educación (AISHE por sus siglas en inglés), un instrumento desarrollado por la organización holandesa DHO (Fundación para la Educación Superior Sostenible). El propósito de esta organización es que todos los profesionales posean las competencias necesarias que le permitan contribuir al desarrollo sostenible. En este sentido, se hace necesario la integración de las universidades, asociaciones estudiantiles, entes gubernamentales, empresa y comunidad. Es tanto el compromiso de la organización que su lema está sustentado en que los egresados deben contar con habilidades de liderazgo para el desarrollo sostenible (Aldeanueva \& Jiménez, 2013).

El principal aporte de Viteri, Jácome, Medina y Piloto (2012) lo constituye la propuesta de evaluar la RSU, aplicando un índice integral con diez indicadores que calculan el efecto establecido por los procesos misionales de la universidad: Gestión, docencia, investigación y proyección a la comunidad con las perspectivas: ambiental y comunicacional. De esta forma, el índice integral permite a la universidad detectar los factores críticos y de esta forma le indica al ente universitario hacia qué procesos dirigir las propuestas de mejora y que estén alineadas con los objetivos estratégicos de la institución.

Por otra parte, los autores Viteri, Jácome y Medina (2012) proponen un modelo conceptual que permite la alineación con los objetivos estratégicos de la RSU, fundado en el seguimiento y determinación de las necesidades del entorno y con postulados centrados en el respeto del medio ambiente, los derechos humanos y las prácticas justas con los trabajadores. Este modelo se sustenta en un compromiso con los grupos de interés, mediante una estrategia sistémica, con enfoque en procesos de mejora continua y apoyada en el liderazgo, 
la honestidad, los valores y la formación permanente para conseguir impactos duraderos y significativos en la sociedad y un desarrollo sostenible.

Ramos (2010) indica que la RSU se demuestra cuando un egresado pone en práctica la moral y la ética que adquirió durante su formación. Por lo tanto, afirma el autor que la RSU se debe centrar en formar profesionales éticos, entendiendo que la ética compromete a los individuos con la práctica de principios y valores que se reflejan en hábitos y costumbres beneficiosos para la sociedad y que se encuentran en defensa de la vida y de la restauración de la reflexión filosófica sobre "el vivir". Señala el autor que las universidades sin ser empresas generan impactos hacia su interior como hacia la sociedad en donde hacen presencia, son organizaciones con compromisos distintos frente a la sociedad por cuanto su misión corresponde a la formación del cuerpo que la sostiene; sus ciudadanos, en tal sentido propone la implementación de la RSU desde los micro currículos con un enfoque bioético.

Algunas universidades han implementado modelos de RSU mediados por las TIC y unidas a algunas asignaturas obligatorias relacionadas con la ética, la gobernanza, el desarrollo comunitario, el medio ambiente, los derechos humanos y las prácticas justas como lo señala la norma ISO 26000 (Domínguez, 2012). En otros casos se encuentran casos de universidades que integran un concepto doblemente social a la RSU, la extensión y sus mismas prácticas responsables que son consecuencia de sus actividades (Gorrochategui, 2012). Así también algunas organizaciones, como el Banco Interamericano de Desarrollo BID, han colaborado en la creación de un manual para la implementación de la RSU buscando coherencia y consistencia en el discurso entre lo que se dice y las acciones que se implementan, al tiempo que integra las funciones con el plan de desarrollo institucional y los procesos de rendición de cuentas (Vallaeys, De la Cruz \& Sasia, 2009).

Algunos trabajos como el de Cortes (2012) aplican las metodologías diferenciales como la de sistemas suaves y algunos elementos de multi metodología, se contrasta el modelo con datos empíricos. En este modelo la RS se entiende como algo inherente a las organizaciones, cuyo alcance debe sobrepasar el 
tema de los stakeholders y concentrarse en los agentes. Considera el autor, que es necesario identificar la motivación de la organización antes de seleccionar el paradigma de RSU que se va a implementar.

\subsection{Filosofía institucional}

La misión social de la universidad es la gestión del conocimiento no la misión mercantil como se está presentando actualmente (Manzano, 2010). Sin embargo, las políticas nacionales e internacionales la han obligado a buscar por sí misma una supervivencia financiera (Zárate \& García, 2014). Esto ha desembocado como apunta Santos (2005) en una crisis de identidad y en una fuerte competitividad que la aleja de su misión y filosofía propia.

El Proyecto universidad construye país ejecutado en Chile, entre los años 2001 y 2008, es una muestra clara de cómo las universidades pueden poner en práctica sus principios y valores por medio de procesos claves de gestión de sus funciones sustantivas, como respuesta a la comunidad y al país. Mediante esta opción conceptual se concibe la RSU como un modo de ser universidad (Hernández \& Saldarriaga, 2009; Fernández \& Jiménez, 2013). Una universidad socialmente responsable se acopla con las comunidades a través de sus funciones sustantivas, la ética y la transparencia (Esfijani, Hussain y Chang, 2013)

Botero, González, Durpan y Bolívar (2012) la responsabilidad social se percibe como un elemento del proyecto educativo por su cohesión con los valores y principios emanados de la filosofía organizacional, que permite crear estrategias para reconocerse o diferenciarse de otras instituciones desde lo social, cognitivo, organizacional y educativo (Ver Figura 25). 


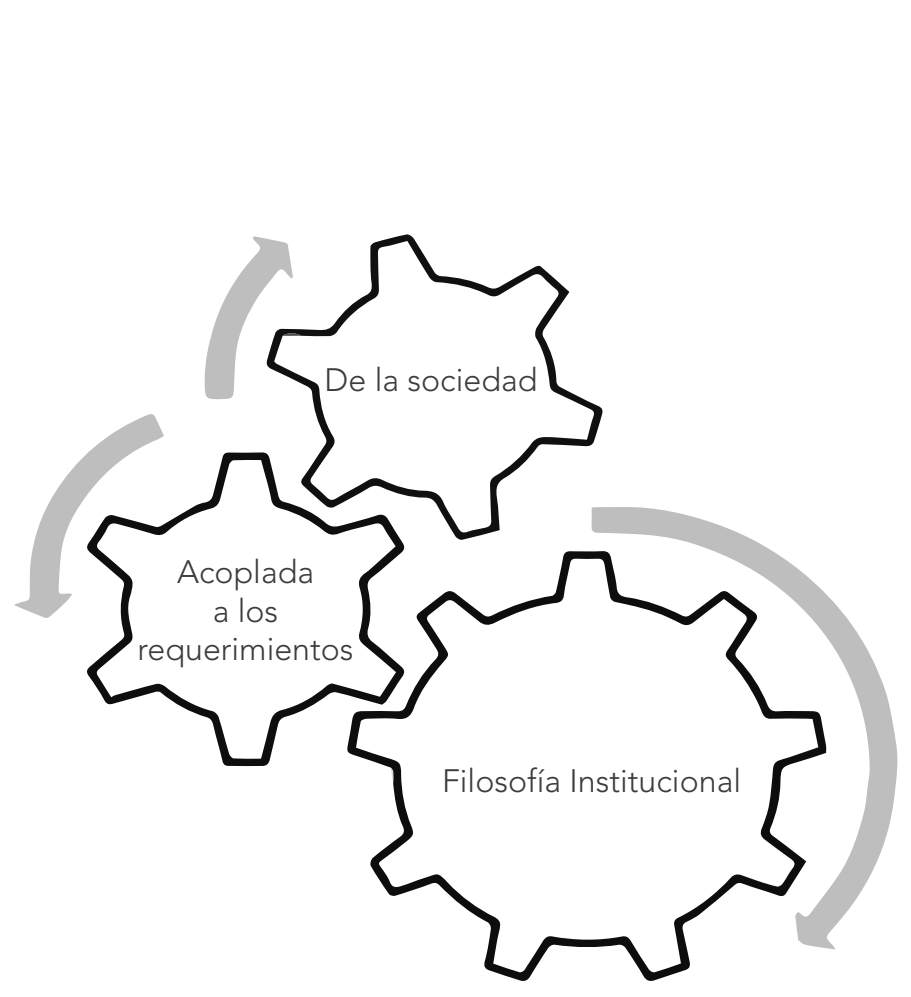

Figura 25. Integración de la filosofía institucional con las necesidades de la sociedad.

Fuente: Elaboración propia.

De acuerdo con la Organización de Naciones Unidas para la Educación, la Ciencia y la Cultura (UNESCO), (citado en Núñez, Salom, Rosales \& Paz, 2012), las universidades deben integrar en su misión la responsabilidad social. De manera tal que los objetivos de la universidad estén alineados con los requerimientos y necesidades sociales (Díaz y García, 2011; Martínez, Mavarez, Rojas, Rodríguez \& Carvallo, 2006).

Como resultado de lo anterior, las universidades podrán articular sus proyectos y prácticas de conocimiento a los saberes propios de las comunidades y especialmente a aquellas que los actores reclaman en forma permanente (Cantú-Martínez, 2013). Como lo plantea Ausjal, 2009, la RSU es una facultad de poder integrarse para lograr un impacto que redunde en transformaciones oportunas y pertinentes con la sociedad y sus actores, para ello puede integrar actividades de formación, así como también de inclusión y desarrollo regional que redunden en un permanente crecimiento y desarrollo que permitan una sociedad más justa y equitativa. 
Así también, Garza (2007) afirma que debe existir un diálogo y consenso de los actores universitarios y comunidades que buscan un objetivo común como es hacer de cada región un crecimiento sostenible, equitativo y solidario.

Siguiendo a Gaete (2011), la RSU es uno de los desafíos que deben afrontar las IES con el ánimo de demostrar su funcionamiento y su razón de ser, en busca de un espacio dentro de la sociedad. Martinez \& Picco (2006), también construyen una definición acertada sobre este concepto señalando que la RSU es: "el conjunto de acciones que realiza la universidad como resultado de la ejecución de su proyecto institucional; la orientación y coherencia de sus valores y actividades con la búsqueda de la felicidad y el bienestar de los seres humanos y la consolidación de una sociedad más justa y equilibrada" (p.1).

En los impactos educativos, se puede considerar que la formación de los futuros profesionales debe estar permeada por la ética y los valores, para que al querer comprender el mundo lo entiendan no como el logro de metas sino de un trabajo conjunto para el beneficio común. En tal sentido, las instituciones universitarias deben planear en forma permanente que tipo de profesional quieren entregar a la sociedad y que acciones y objetivos estratégicos se deben trazar para lograr una formación integral y un pensamiento crítico (Vallaeys, 2008).

Al impartir el conocimiento, la universidad debe seguir una enseñanza donde los elementos cognitivos que se expresan como búsqueda de la verdad estén orientados a aspectos como la justicia social y la equidad. Las instituciones universitarias han de ser consientes tanto del conocimiento que producen como la forma en que este puede ser transferido a las diferentes instancias de la sociedad para que pueda ser aplicado (Vallaeys, 2008).

\subsection{Humanización}

En esta línea de ideas, se relacionan varios términos que diferentes autores han propuesto para la RSU. Así, por ejemplo, Sánchez (2007) lo define como la responsable de reconstruir los saberes para lograr una sociedad humana en la 
que se promueva la justicia social. Cevallos (2008) por su parte, orienta su definición a la persona como la más importante de las preocupaciones que deben orientar los procesos de enseñanza aprendizaje y que sus expectativas pueden trascender más allá del mismo ser. Por otra parte, Van Ginkel (2002) se centra más en los procesos curriculares y los medios y mediaciones que se emplean en la formación de los estudiantes para un mundo global y con orientación a la sostenibilidad y sustentabilidad de las organizaciones.

La cualificación de un profesional en formación tiene que ver con competencias para que se desempeñe en forma responsable y que pueda utilizar las capacidades que adquiere en beneficio de otros. (UNESCO, 2008). Así entonces, Rodríguez (2010) afirma que los buenos resultados, se obtienen cuando las tareas se realizan con excelencia. Sin embargo, Manzano (2010) conceptúa la necesidad que para lograr los ideales de la educación debe estar integrada la actividad a la ética y no solo debe pensarse en alcanzar la excelencia, si no existen normas, códigos ni principios no se pueden garantizar actos éticos (Kisnerman, 2001).

Al hacer referencia al concepto general de la Responsabilidad, Saldarriaga (2013) establece que la RSU debe ser parte de la esencia del sujeto, que se forme, es esta la verdadera integralidad que la educación le puede dar, cuando es posible que el educando esté preparado para integrarse al mundo laborar con una visión y acción responsable que lo potencie como líder a la vez que promueva tanto productividad como competitividad social y solidaria.

Casilla y Camacho (2012) refieren el concepto de RSU al actuar corresponsable entre la organización y los actores, organizaciones públicas, privadas y las comunidades con quienes desarrolla proyectos y experiencias para la solución de sus necesidades y posibilitar la construcción sustentada en sus aportes, capacidades e iniciativas, que impacten favorablemente el desarrollo humano sustentable (Ver Figura 26).

La docencia en el marco de la responsabilidad social universitaria posibilita pensar la educación como la oportunidad de llegar a cada estudiante y brindarle las herramientas e instrumentos que le permitan el desarrollo pleno 
de sus potencialidades como persona y futuro profesional, superando así el simple entrenamiento de personas y evidenciando la necesidad de revisar la naturaleza y esencia de la docencia universitaria (Vera et al., 2012).
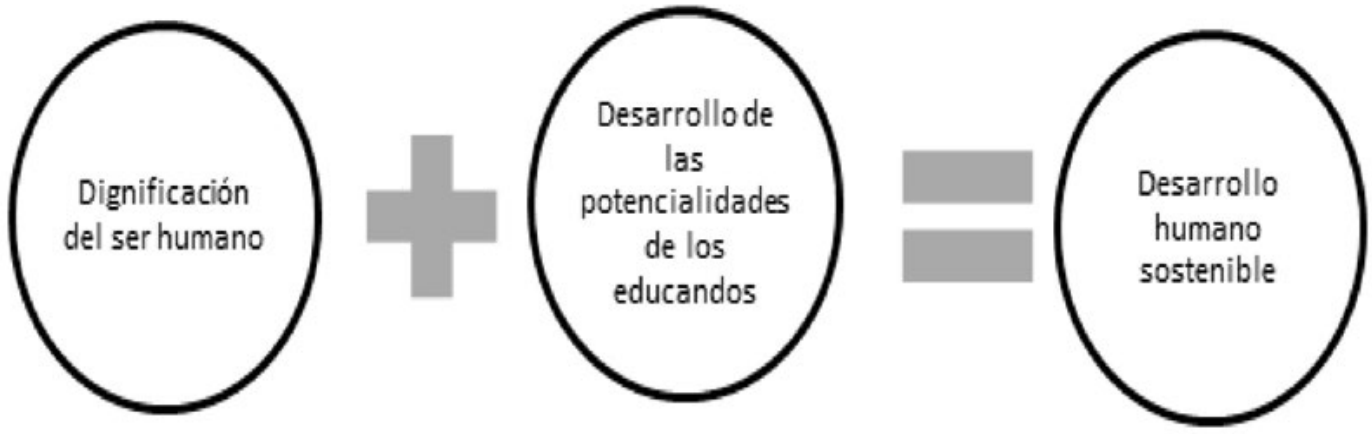

Figura 26. La humanización desde la dignificación y el desarrollo de las potencialidades.

Fuente: Elaboración propia.

Bacigalupo (citado por Sacco, 2009) asume la responsabilidad social universitaria desde esa relación ética que vincula a la universidad con la sociedad. Es el compromiso moral e irrenunciable que permite la aplicación directa del saber científico y tecnológico, posibilita la generación de nuevo conocimiento, en respuesta a las problemáticas sociales de su entorno, mediante una formación humanitaria de profesionales. También, Romero (2007) afirma que la responsabilidad social de la universidad debe estar dirigida a la persona y asumirla como pilar fundamental, con quien desarrolla las funciones de educar, aprender, investigar e innovar.

Uno de los objetivos de desarrollo del Milenio según las Naciones Unidas (2005), es garantizar el derecho de las personas a la educación. En este sentido, es necesario para la universidad entender la educación como un derecho, para darle el estatus que le permita ampliar el grado de obligatoriedad y exigibilidad para todos los ciudadanos del mundo, integrada al derecho del trabajo docente para garantizar calidad y potenciar la ampliación de cobertura. 


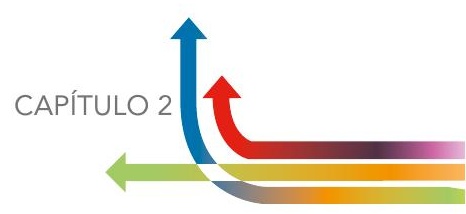

\section{En términos generales para la construcción de los planes de RSU es necesario considerar cada una de las categorías descritas (Ver Tabla 2). Como resulta- do de la revisión de las categorías se pudieron establecer subcategorías que permiten tanto la construcción como la evaluación de los planes de responsa- bilidad social universitaria, como se aprecia en la tabla 3.}

\section{Tabla 2. Conceptualización de las categorías de la RSU}

\begin{tabular}{ll}
\hline Categorías & Conceptualización \\
\hline & Relaciones con los cambios del entorno para consolidar su \\
& quehacer. Las Universidades cambian, se reinventan al mismo \\
tiempo que cambia el entorno y se adaptan a las normas \\
oprendizaje & de conducta que reclama la sociedad. Estos cambios se \\
& evidencian tanto en sus principios como en las prácticas que \\
& realizan, en los currículos que diseñan y la formación que \\
& imparten a sus estudiantes.
\end{tabular}




\begin{tabular}{ll}
\hline Categorías & Conceptualización \\
\hline & Las universidades pueden poner en práctica sus principios \\
& y valores por medio de procesos claves de gestión de sus \\
& funciones sustantivas, como respuesta a la comunidad y al \\
& país. Por su cohesión con los valores y principios emanados \\
& de la filosofía organizacional, que permite crear estrategias \\
para reconocerse o diferenciarse de otras instituciones & desde lo social, cognitivo, organizacional y educativo. Las \\
& funciones sustantivas de las universidades deben tener \\
& expreso la búsqueda de justicia, solidaridad y equidad social, \\
& adelantando procesos que den respuesta a los retos que \\
& implica el desarrollo humano sustentable. \\
\hline & La RSU debe centrar su accionar en el sujeto, a la persona \\
& que forma parte de la universidad, en calidad de trabajador, \\
& se le debe propiciar un ambiente enmarcado en el respeto y \\
& dignificación de sus condiciones laborales, en su valoración \\
& como persona; las instituciones deben propender por formar \\
& y fortalecer su talento humano y sustentar sus acciones en el \\
& desarrollo de las potencialidades de cada persona.
\end{tabular}

Fuente: Las autoras a partir de los resultados de la revisión documental.

\section{Tabla 3. Subcategorías de la RSU}

\begin{tabular}{|c|c|}
\hline Categorías & Subcategorías \\
\hline \multirow{2}{*}{$\begin{array}{l}\text { Aprendizaje } \\
\text { organizacional }\end{array}$} & $\begin{array}{l}\text { Currículos pertinentes a las necesidades regionales, } \\
\text { Cultura organizacional con visión compartida, Transferencia } \\
\text { de conocimiento del entorno a las prácticas universitarias. }\end{array}$ \\
\hline & $\begin{array}{l}\text { Integración de los resultados de la investigación y de las } \\
\text { prácticas regionales al currículo }\end{array}$ \\
\hline Necesidades regionales & $\begin{array}{l}\text { Participación de la universidad hacia nuevos enfoques } \\
\text { de desarrollo en la región, Transferencia de conocimiento } \\
\text { disciplinar a las necesidades regionales, Personal con } \\
\text { preparación social comunitaria, Prácticas sociales en la } \\
\text { región de alto impacto. }\end{array}$ \\
\hline \multirow{3}{*}{$\begin{array}{l}\text { Internacionalización, } \\
\text { interdisciplinariedad e } \\
\text { Interculturalidad }\end{array}$} & El currículo responde a la flexibilidad y movilidad académica, \\
\hline & El currículo integra la diversidad cultural en el marco global. \\
\hline & Grupos de investigación y prácticas interdisciplinares \\
\hline \multirow{4}{*}{$\begin{array}{l}\text { Sustentabilidad } \\
\text { y calidad de vida }\end{array}$} & $\begin{array}{l}\text { Currículos con componentes prácticos con enfoque } \\
\text { socio ambiental. }\end{array}$ \\
\hline & Formación integral con enfoque social solidario y sustentable \\
\hline & Inclusión \\
\hline & Cobertura y equidad. \\
\hline
\end{tabular}




\begin{tabular}{ll}
\hline Categorías & Subcategorías \\
\hline \multirow{3}{*}{ Redes } & Participación en las agendas regionales de investigación, \\
& ciencia, tecnología e innovación \\
& Alianzas estratégicas \\
& Convenios interinstitucionales \\
& Diálogos con los grupos de interés. \\
\hline Planeación y aplicación & Estrategias de diferenciación en sus planes \\
innovadora & y programas de RSU \\
& Coherencia e integración entre el plan de RSU con el plan \\
& de desarrollo de la universidad \\
\hline Ética y valores. \\
Funciones sustantivas que respondan a las necesidades \\
locales y globales. \\
Currículos que integren la formación ciudadana. \\
Transparencia y rendición de cuentas. \\
\hline Dignificación de las condiciones laborales, en la valoración \\
de las personas. \\
Cualificación del talento humano. \\
Sinergia. \\
Democracia y participación en estamentos. \\
Mecanismos de resolución de conflictos. \\
Motivación \\
\hline Humanización
\end{tabular}

Fuente: Las autoras a partir de los resultados de la revisión documental 



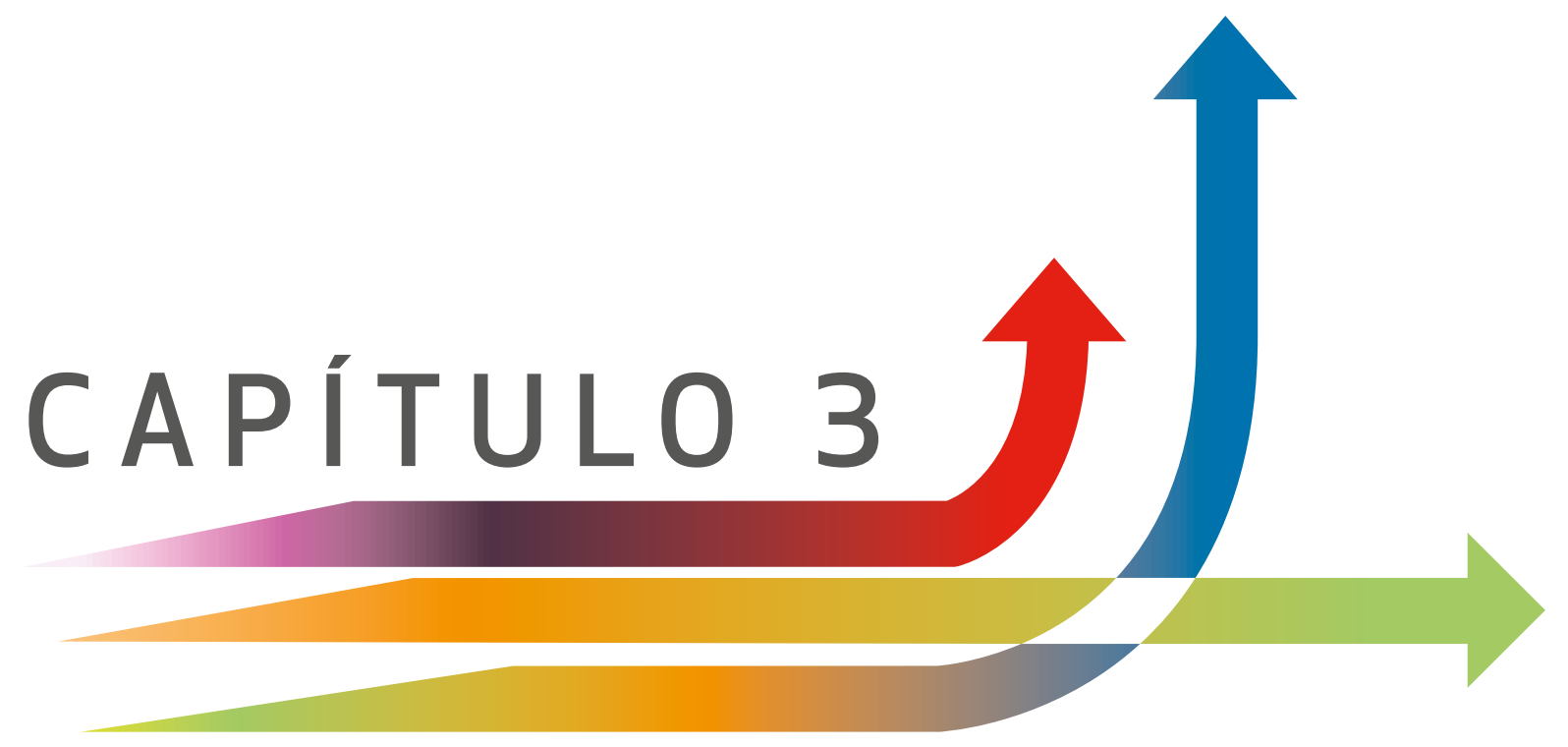





\section{Integración sistémica de las categorías dentro de un Plan de Responsabilidad Social Universitaria}

Continuando con la cuarta fase de la metodología planteada se presenta a continuación la teoría sustantiva como resultado de la discusión y utilizando los mapas causales para determinar la integración de categorías para la construcción de un plan innovador de RSU

\subsection{Plan Innovador de RSU}

Un plan de responsabilidad social universitaria parte de la filosofía institucional (misión, visión, objetivos) y requiere de una planeación innovadora tanto en su gestión como en su aplicación. La innovación en la RSU le da un carácter especial a la universidad y la diferencia de otras organizaciones existentes. Ahora bien, la innovación consiste en encontrar formas diferentes de impactar en el entorno dejando huella ecológica y conciencia social. Es posible construir este impacto mediante estrategias propias y específicas, tales como la creación de un voluntariado, la transversalización del currículo con el liderazgo social, la creación de redes y alianzas estratégicas, entre otras.

En relación a lo anterior, la aplicación innovadora de la RSU puede ejecutarse en tres momentos. El primero de ellos es la transferencia de conocimiento a los sectores productivos, sociales y comunitarios. El segundo, es entregar egresa- 
dos integrales, a partir de la apropiación de los conocimientos, de los saberes producto la investigación; así como también la acción solidaria y ética para el desarrollo de competencias sociales. El tercer momento es el compromiso con los stakeholders involucrados con la institución ya sean estudiantes, administrativos, docentes, egresados y los sectores tanto productivos como gubernamentales donde reine la democracia, transparencia, equidad y solidaridad.

Es necesario que las relaciones éticas sean plasmadas en la misión, visión, valores y códigos éticos. Adicionalmente, es importante contar con una cultura empresarial que la fortalezca y donde los valores se puedan convertir en hábitos (Pelekais., De Pelekais \& Frassati, 2009). La ética en las relaciones laborales debe incluir el respeto hacia la institución y los grupos de interés, el desarrollo integral y la divulgación de los valores (Hartman, 2011).

Por otra parte, para que exista una planeación eficaz es necesario integrar en sus procesos a la gerencia y a todas las unidades que hacen parte de la organización. Esta integración incluye las funciones sustantivas que se desarrollan en el ámbito externo e interno, tales como cooperación y desarrollo, docencia y currículo, investigación y transferencia del conocimiento, al igual que los procesos de gestión universitaria (Ver Figura 27).

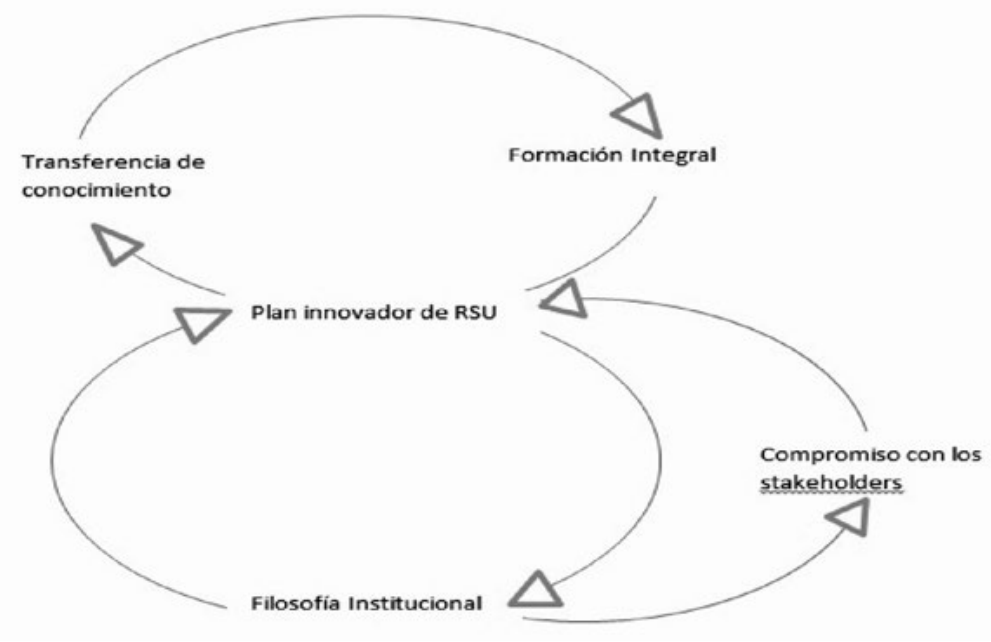

Figura 27. Plan innovador de RSU

Fuente: Elaboración propia. 
Así también, los currículos de las universidades deben estar pensados no para saciar ambiciones individuales sino para formar profesionales capaces de solucionar problemas, de pensar la complejidad y de sentir a los demás (Manzano, 2010). Para lograrlo es necesario enseñar comportamientos éticos y solidarios, en pro del desarrollo; permitir la creación de redes basadas en la confianza y la tolerancia; buscar el entendimiento mutuo y los valores compartidos (Castañeda, Ruiz, Viloria, Castañeda \& Quevedo, 2007).

Los currículos deben reflejar las necesidades de las regiones, los avances disciplinares y los saberes comunitarios (Gorrochategui, 2012). Pérez, (2009) define la responsabilidad social universitaria como una forma diferente de hacer las cosas, de funcionamiento de la universidad, es un cambio que asumen la universidad en la forma de hacer y comportarse frente a su entorno social, fundado en relaciones más fluidas y directas, visualizando siempre los efectos, repercusiones y expectativas que la acción de la universidad pueda generar tanto en sus propios miembros como en la sociedad. En tal sentido, los elementos de la RSU son la sociedad, las personas y la misma universidad. Las personas son el elemento con mayor incidencia. Se espera entonces que la aplicación de la RSU influya en sus potencialidades y estas impacten en su entorno.

Como en toda planeación, la RSU debe, en forma periódica, presentar resultados congruentes (hacer lo que se dice) de su ejecución a nivel interno y externo por medio de rendición de cuentas (decir lo que se hace), claras y transparentes (mostrar lo que se hace) que permita evaluar los avances e identificar falencias donde se deben enfocar esfuerzos de cambio (Londoño, 2013). Ahora bien, en el caso de la RSU los planes deberán estar integrados con los planes de desarrollo de la organización universitaria e incluso se pueden incluir como un componente transversal (Valarezo \& Túnez, 2014).

Por otra parte, cada institución posee unas características propias de RSU puesto que las acciones que las personas realizan dependen de la filosofía institucional y de allí se desprende la gestión Vallaeys (2008) visibiliza la responsabilidad social universitaria como la expresión de voluntades para la creación e implementación de planes de RSU. 
Las instituciones universitarias deben velar por la aplicación efectiva de sus principios, guías y valores inherentes a su filosofía, cultura y gobernanza organizacional (González, Pirela \& Zerpa, 2012). Para lograrlo es indispensable que su filosofía sea entendida por todos y tenga el mismo sentido. En el concepto de responsabilidad social universitaria se aplica una serie de principios y valores, que se declaran en su filosofía de gestión y en la praxis de sus funciones básicas, cumpliendo lo declarado en su misión, visión, principios, valores y criterios de actuación; si la filosofía institucional se desconoce o no se entiende claramente esto va en detrimento de su real cumplimiento (Castañeda et al, 2007)

\subsection{Elementos que promueven la humanización en el plan de RSU}

En un plan de RSU, el ser humano debe ser el centro de atención. En tal sentido, es importante tener en cuenta que todas las decisiones que se tomen en una organización universitaria afectan en forma directa, ya sea positiva o negativamente a los integrantes de la misma, a sus familias y repercuten en su calidad de vida. Por lo tanto, la organización debe observar principios éticos que dignifiquen las condiciones laborales, propender por el respeto y darle a cada persona el valor que se merece (Vallaeys, De la Cruz \& Sasia, 2009)

Por otra parte, la cualificación del talento humano en principios como la ética, solidaridad, sustentabilidad y el compromiso para dar solución a las necesidades más apremiantes de las regiones, se convierte en la piedra angular que permite una transformación coyuntural (Sidorovas, 2015).

Otro aspecto que humaniza la organización universitaria es su proceder frente a la resolución de conflictos. (Ver Figura 28). Bajo esta perspectiva, una buena solución y un buen acuerdo pueden llegar a ser parte de la regulación de los impactos negativos entre sus actores, lo que promueve el ejercicio de relaciones sanas basadas en la confianza y el respeto (Zárate y García, 2014). Del mismo 


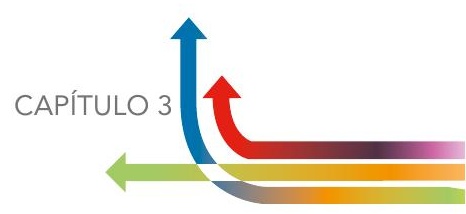

modo, la democracia participativa, libre y con transparencia de los estamentos que hacen parte de la organización implica el compromiso en la búsqueda de soluciones solidarias y responsables y la construcción de un orden basado en derechos y deberes (De La Jara, 2008).

Cuando los miembros de la organización y de los estamentos sienten que se les reconoce y se les respeta toman conciencia y asumen la universidad como parte de su vida, esta actitud hace posible un mayor esfuerzo para conseguir las metas por medio de acciones voluntarias y la autoconfiguración de la vida personal en actos de motivación propios (Jaramillo, 2009). Adicionalmente, los actores universitarios están Ilamados a participar en forma holística con otras facultades y con otras organizaciones universitarias, para de esta forma, lograr una sinergia en beneficio de la comunidad (Martínez, Mavárez, Rojas \& Carvallo, 2008).

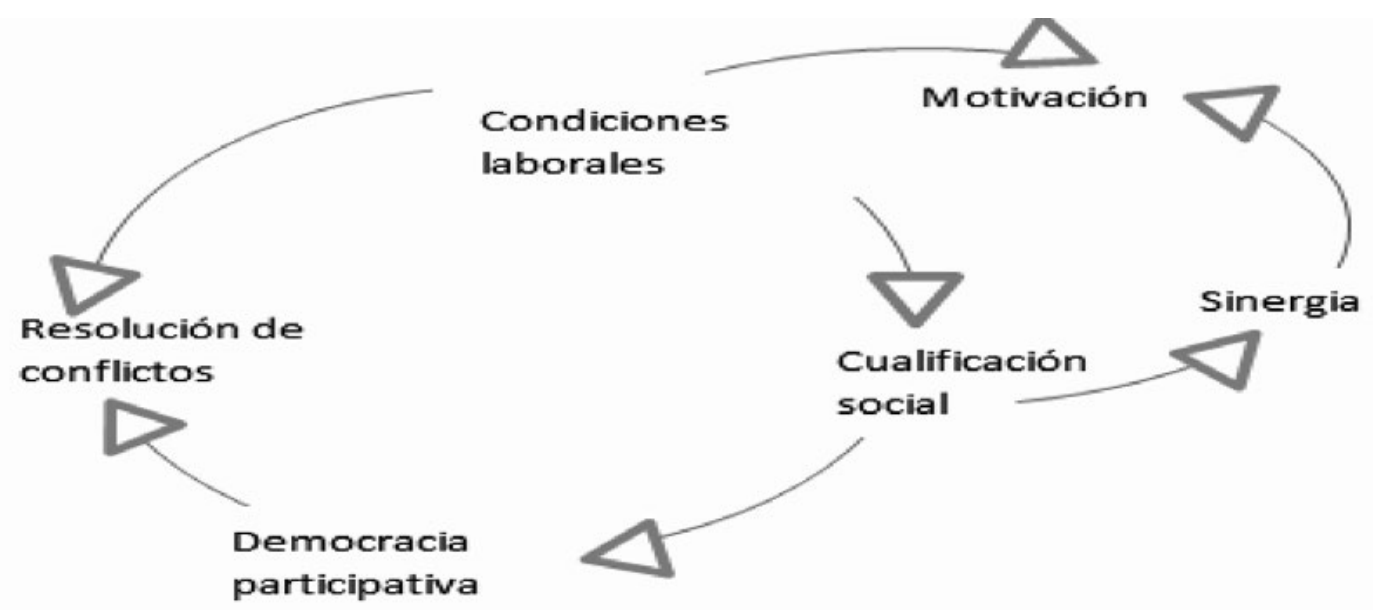

Figura 28. Elementos que promueven la humanización.

Fuente: Elaboración propia.

La responsabilidad social define acciones, más allá de lo que dice la ley. En tal sentido, la gestión interna de la universidad demanda planes y políticas en consideración con el recurso humano diferenciado que posee, dotados de personalidad propia, historias, conocimientos, habilidades, destrezas y capacidades que impulsan la organización al cumplimiento de sus objetivos como 
si fueran socios de la misma. El paso de estas personas en las organizaciones, su desarrollo y capacitación al igual que el momento de despido debe ser considerado en forma socialmente responsable, teniendo en consideración todos los elementos que le permitieron a la organización crecer y beneficiarse y esto no solo se paga con dinero sino también con consideración de parte de los empleadores o gerentes (Camejo \& Cejas, 2009).

Según la declaración de los objetivos del milenio, la educación superior tiene entre otras funciones, erradicar la intolerancia. Con tolerancia, es posible alcanzar la evolución de una cultura de paz. La intolerancia, como síntoma de enfermedad social, puede acarrear una enfermedad aún más peligrosa que es la violencia (UNESCO, 1994).

\subsection{La transferencia de conocimiento desde el aprendizaje organizacional}

La responsabilidad social universitaria ha evolucionado a medida que evoluciona el pensamiento y se dan cambios en el entorno. Las universidades inteligentes, realizan procesos de aprendizaje organizacional para integrar los saberes y experiencias significativas de otros a las prácticas que realizan. Ser socialmente responsable, es comprender el impacto o huella que las prácticas pueden dejar en la organización y en el entorno comunitario y ambiental. En tal sentido, la RSU tiene un carácter sistémico y colectivo (Vallaeys, 2008). Las acciones que realiza una organización universitaria llevan una doble vía, por una parte, afianzan las rutinas a partir de la gestión del conocimiento y, por otra parte, transfiere esos conocimientos para impactar en el entorno. Ante esta situación Herrera citada por Londoño (2013), sugiere articular saberes, necesidades y conocimientos a los programas de estudio, a la investigación que se realiza y a los procesos de desarrollo regional que se ejecutan. 


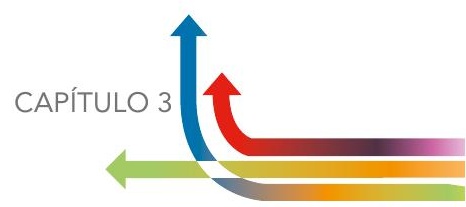

Para alcanzar cambios significativos en materia de educación, es necesario que los procesos curriculares estén en permanente actualización y sean pertinentes a las demandas de la sociedad (Escorcia, Gutiérrez \& Henríquez, 2007). La Universidad comprometida con sus impactos en la sociedad, requiere mantener la cultura organizacional del permanente aprendizaje y su adaptación a los cambios. Es por ello, que en cada uno de sus integrantes debe sentirse el efecto que trae una cultura fuerte, flexible y compartida por todos, que posibilite la sinergia, dinamice el sentido de su misión, enfatice los valores y dé sentido de pertenencia organizacional, que refleje los esfuerzos realizados (Pirela y Sánchez, 2009). En ese proceso de aprendizaje organizacional (Ver Figura 29), también, las universidades como cualquier organización que aprende deben generar mecanismos que le permitan evaluar su apropiación, al establecer formas de medir los avances y construir planes de mejoramiento que aporten credibilidad y sostenibilidad a la RSU (Hernández \& Saldarriaga, 2009).

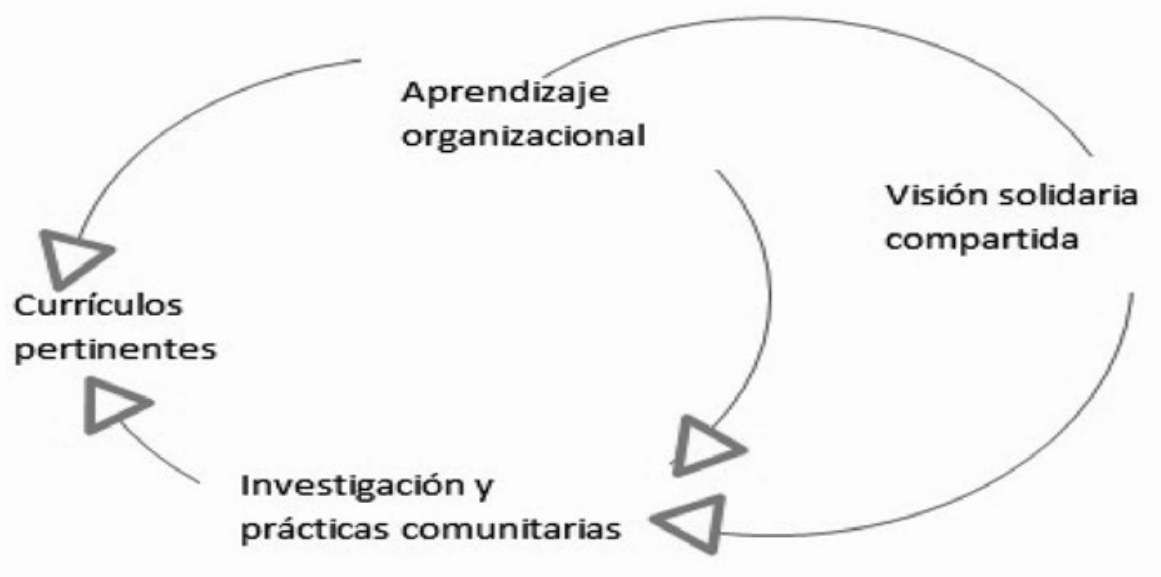

Figura 29. Transferencia de conocimiento desde al aprendizaje organizacional

Fuente: Elaboración propia. 


\subsection{Cumplimiento de las normas sustentables y de calidad de vida}

Las organizaciones universitarias han adoptado normas de conductas hacia el respeto por las diferencias, el cuidado del ambiente, la inclusión social, la rendición de cuentas, como también del cumplimiento de reglas internacionales y condiciones dignas relacionadas con la sustentabilidad y calidad de vida (Bacigalupo, 2008),

Ahora bien, Schalock y Verdugo citados por Gaete (2011) asocian la calidad de vida tanto a lo individual como a lo colectivo; a lo social y lo natural. A partir de este enfoque, la calidad de vida supera las necesidades básicas y se conecta con las necesidades para relacionarse con otros, y con las posibilidades de beneficiarse de las políticas públicas y de las redes para ampliar las alternativas existentes, obtener logros y satisfacción en el trabajo.

Adicionalmente, la calidad de vida posee una responsabilidad con la sostenibilidad que consiste en aprovechar el ecosistema sin destruirlo, permitiendo que las generaciones futuras también lo puedan aprovechar. En tal sentido, una universidad responsable formará sujetos con altas capacidades para lograr aportar a la satisfacción de las demandas del medio ambiente.

La educación universitaria debe propender por el desarrollo de la personalidad de los jóvenes, con fuertes compromisos por el respeto de los derechos humanos. En ese orden de ideas, en educación la sostenibilidad hace referencia a los principios éticos en una sociedad compleja. La sostenibilidad solidaria incluye currículos con componentes prácticos, enfoque socio ambiental, formación integral, solidaria y sustentable, inclusión social, cobertura y equidad (Santos, 2009).

Una organización universitaria responsable, demuestra sus niveles de inclusión social cuando en los cargos de mayor responsabilidad existe igualdad de género; cuando la infraestructura y los materiales académicos de la organización se 
adecua para las personas con discapacidad, y en la existencia de apoyo para los estudiantes que no poseen una situación económica suficiente para acceder a la matrícula o a sufragar los gastos educativos.

Para alcanzar estos propósitos es importante que dentro de las investigaciones que se desarrollan en la universidad, se dé cuenta de los niveles de inclusión local o regional que existen y se vinculen estos resultados a los programas de extensión y a la formación y cualificación de los estudiantes y docentes para la atención y el trabajo con población en situación de vulnerabilidad (De la Red, 2009).

La privatización de las universidades con el pretexto de la sostenibilidad ha implicado un olvido de la verdadera esencia de la misma, dando más importancia a la generación de recursos (GUNI, 2008). No obstante, los recursos de las universidades deben tener un retorno de disponibilidad abierta al conocimiento para que este se difunda en todas las esferas sociales y especialmente a la población menos favorecida. (De la Cuesta \& Sánchez, 2012). En ese orden de ideas, deben primar la creación de convenios, descuentos diferenciados por estratos y becas para estudiantes por medio de alianzas, apoyos gubernamentales e inversión de las mismas universidades en las personas en situación de vulnerabilidad.

Las universidades vienen asumiendo el reto de transformar sus planes de estudio desarrollando estrategias de educación para la sostenibilidad y promoviendo políticas universitarias de cuidado del medio ambiente y de consumo sostenible. De esta manera, se plantean cambios profundos desde lo pedagógico, buscando que se estimule en los estudiantes el consumo responsable y permear incluso a la sociedad y el diseño de distintos enfoques académicos para formar ciudadanos integrales, con altas capacidades de aportar al desarrollo sostenible (Olarte \& Ríos, 2015). Estas estrategias permiten asociar la universidad al desarrollo, en cuanto se considera que a través suyo se puede lograr el despliegue completo del hombre en sus diferentes dimensiones (Ver Figura 30). 
Sin embargo, como afirma Gómez (citado por Peña, 2012) la ampliación de la cobertura educativa que se ha logrado en las últimas décadas no va de la mano con la movilidad social, con la búsqueda de la equidad e igualdad y se afianza en la idea de que se invierte más en los que tienen más, lo que refleja inequidad en el sistema educativo. Ahora bien, no toda la población de una región tiene las mismas capacidades para aprovechar las oportunidades de capacitación universitaria. En tal sentido es un reto para las universidades contribuir en la búsqueda de la equidad (Castañeda et al., 2007). Hoy en día la infraestructura no solo responde a espacios físicos, sino que también incluye el campus virtual, cuyo caso, estrategias como la Internet y la web 2.o permiten una relación más fluida con el entorno y una participación en dos direcciones permitiendo la co-creación y transferencia de conocimiento (De la Cuesta \& Sánchez, 2012).

El objetivo central de la educación inclusiva es identificar las barreras de aprendizaje que existen y emprender acciones desde el sistema para mejorar. En educación superior, deben ser las instituciones las que propicien las condiciones para que los estudiantes puedan acceder, permanecer y graduarse: es el sistema de educación debe transformarse para atender las exigencias de la educación inclusiva. (Mineducación, 2013)

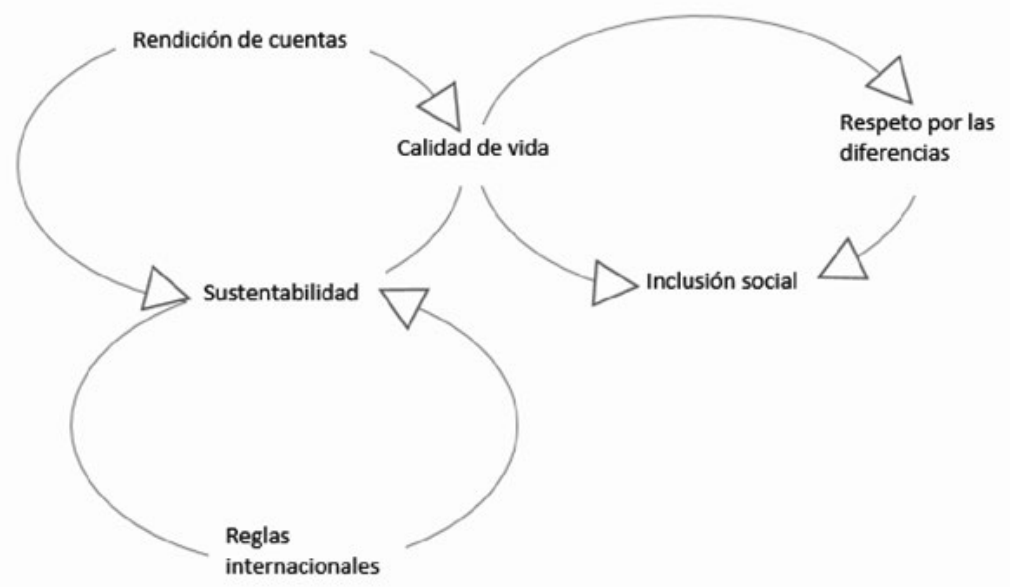

Figura 30. Cumplimiento de normas sustentables y de calidad de vida Fuente: Elaboración propia. 
Las sociedades desarrolladas se diferencian de las que no lo son por sus altos niveles de inclusión educativa, siendo este la base que requiere la sociedad para su desarrollo (Leal, 2012). Los problemas que se han generado en torno a la globalización han dejado de enseñanza que no solo se requiere ser más competitivos, sino que es más importante aprender a compartir siendo solidarios ante situaciones como el desempleo, la soledad, la incomunicación, la crisis del medio ambiente, entre otros (De la Red, 2009). Empero, también se debe repensar la solidaridad desde lo interno y sustentada en los valores. Una sociedad sin justicia, sin igualdad, sin fraternidad, no tiene futuro, en pocas palabras: sin solidaridad; pero la solidaridad no se puede quedar en palabras sino demostrarse en acciones, de ahí la necesidad de definirla y pensarla desde su interiorización y vivencia (Universidad construye país, 2004).

\subsection{Acceso e intervención por medio de las redes}

La universidad como agente de desarrollo tiene amplias posibilidades en la creación de redes de interacción social internas y externas con fines comunes, que contribuyan al establecimiento de la responsabilidad social. De esta forma, se eliminan las barreras del conocimiento fragmentado y se impulsa el trabajo colaborativo y pluridisciplinario. En este orden de ideas, a partir de las redes se beneficia la participación en agendas regionales de investigación, ciencia, tecnología e innovación, se establecen alianzas estratégicas y convenios interinstitucionales y una comunicación asertiva entre los grupos de interés.

Así entonces, con el propósito de que la responsabilidad social sea transversal al proceso de producción y gestión del conocimiento, es relevante que desde el momento de iniciar el plan de RSU, se identifique tanto los problemas que se busca solucionar como las actividades de investigación y desarrollo que desean trabajar. De igual forma, se hace necesario saber con qué actores internos y externos se pueden establecer alianzas para su ejecución y qué políticas pueden favores esta operatividad (Organización de Estados Iberoamericanos, 2014). 
Ahora bien, en todos los procesos de investigación e innovación es necesario la movilización de las diferentes instituciones universitarias para construir acuerdos que permitan enfrentar las problemáticas sociales que sus regiones poseen (Misas, 2002). Así entonces, por medio de la creación de grupos de interés, equipos de mejora y círculos de creatividad dentro de las universidades o la creación de plataformas tecnológicas conjuntas se posibilita que investigadores, docentes, expertos en las áreas que se requieran y estudiantes pongan sus conocimientos al servicio de las comunidades (Castañeda \& Pérez, 2005). A partir de la autonomía es posible que las universidades y los grupos de interés se comprometan con la búsqueda de la verdad para contribuir a la justicia social (Peña, Medrano y Rodríguez, 2012).

En el campo de la investigación es necesario orientar los desarrollos hacia la solución de los problemas regionales, de tal forma que se logre insertar a la sociedad en un futuro digno (Manzano, 2010). Para lograrlo la universidad tiene un compromiso en la participación y transformación de las comunidades de aprendizaje y una orientación hacia el desarrollo regional (GUNI, 2008). La investigación científica y social debe estar encaminada directamente a fomentar y promover el aprendizaje comunitario y realizar intervenciones relevantes en la sociedad (Castañeda, et al, 2007). Para ello se requiere de universidades con mente abierta, que creen redes transdisciplinares con el entorno y alianzas con empresas y comunidad tanto nacionales como internacionales que les permitan pasar de los saberes del capital humano a las capacidades (Domínguez, 2012).

Así entonces, es responsabilidad de las universidades establecer procesos dialógicos para escuchar a los stakeholders. (Lozano, 2009). Por medio de ello y a partir del debate se pueden tomar decisiones acertadas en beneficio de los actores, las redes, y de la misma sociedad (De la Cuesta \& Sánchez, 2012). La comunicación estratégica en la universidad incluye a su personal interno y externo para que todos se encuentren informados de la realidad y puedan hacerse participes activos de las decisiones que se toman. La responsabilidad social ayuda a luchar contra el riesgo del egoísmo y la apatía (Vallaeys, 2008). 
Así también es necesario que los currículos de las universidades se piensen para formar profesionales que den solución a problemas en un mundo complejo (Manzano, 2010). Los currículos deben incluir competencias para desarrollar comportamientos éticos y solidarios, que generen desarrollo, enseñar la creación de redes fundadas en la confianza, tolerancia, que busquen el entendimiento mutuo y la promoción de valores compartidos (Castañeda, et. al, 2007). Deben integrar el conocimiento con en las necesidades de las regiones, los avances disciplinares y los saberes comunitarios (Gorrochategui, 2012).

Ahora bien, las alianzas estratégicas que se establecen entre organizaciones universitarias y otras instituciones para realizar trabajos conjuntos de intervención deberán crearse de tal forma se complementen sus saberes y prácticas; es necesario identificar aliados que sumen en potencialidades, bajo un enfoque holístico, caracterizado por el deber ser, enmarcados en principios y valores, donde la ética, la cooperación, el sentido de pertenencia y la solidaridad sean prácticas habituales (Pulgar \& Pelekais, 2014). Las redes internas y externas deberán permitir que se realicen acciones en favor de la comunidad y que estas influyan en la gestión del conocimiento (Ver figura 31).

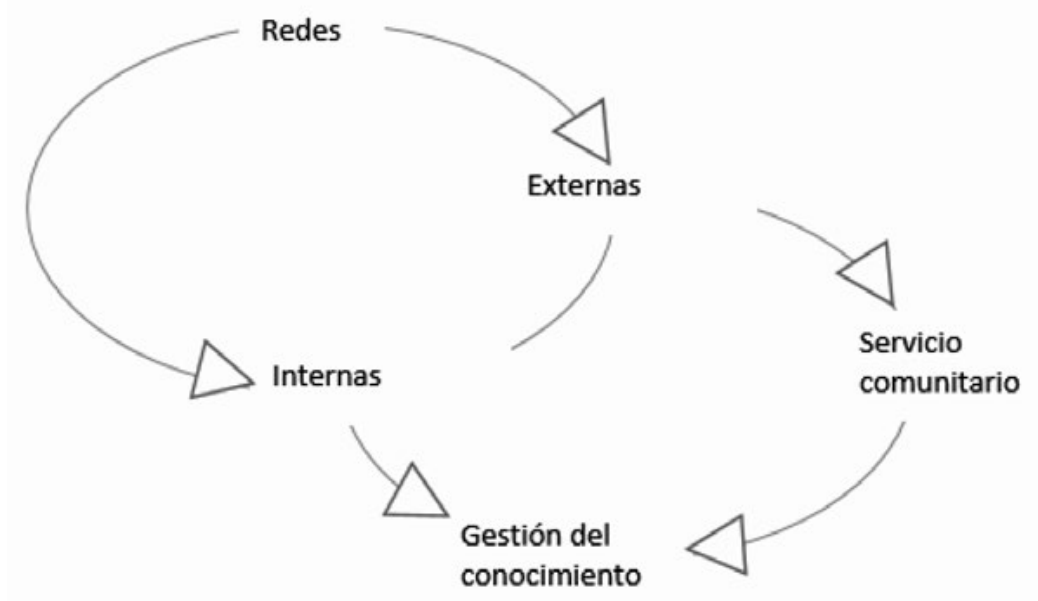

Figura 31. Acceso e intervención por medio de las redes

Fuente: Elaboración propia. 


\subsection{Relaciones entre cultura, disciplinas y naciones}

Hoy en día no se puede pensar en procesos responsables sin involucrar elementos como la internacionalización, interdisciplinariedad e interculturalidad. En primera instancia, la internacionalización permite una flexibilidad en el currículo, un aprendizaje global y la movilidad de los actores académicos: cada disciplina requiere considerar estudios nacionales e internacionales (Escalona, 2008). En segunda medida la interculturalidad debe ser un diálogo entre iguales, generado en un contexto multilingüe, multiétnico y pluricultural y una relación de fraterna entre actores diferenciados (Giménez, 2000). Por último, la interdisciplinariedad permite desarrollar una visión integradora del conocimiento y al mismo tiempo una acción holística de transformación de las realidades. Donde intervienen diferentes disciplinas es posible llegar a una toma de decisiones más acertada y precisa y un medio para conseguir una sociedad más justa y humana (Carvajal, 2010).

Ahora bien, el término globalización está relacionado con la interculturalidad, entonces, un desarrollo sostenible asegura un hábitat común de paz, bienestar y desarrollo en un mundo global (Saéz, 2001). La relación que existe entre lo intercultural y la RSU aparece, cuando los proyectos de educación se diseñan desde la sostenibilidad, tolerancia, solidaridad, cooperación y respeto por las diferencias. Para Ospina (2000) el desarrollo sostenible significa abrir caminos a partir de los valores para impactar en: la paz, movilizar a la sociedad contra todas las formas de violencia y de injusticia y desarrollar el potencial de todos los seres humanos, esto supone una pedagogía basada en la participación la creatividad y la reflexión (Colom, 2000). Al igual que una pedagogía para la tolerancia y la convivencia fortalecidos por los principios de libertad y libre expresión. Pasando de un sistema nacional a un sistema global. Esta educación mundial permitirá pensar y repensar a partir de los orígenes, un futuro mejor para todos. Educar para una sociedad intercultural es algo ineludible en el momento presente. 


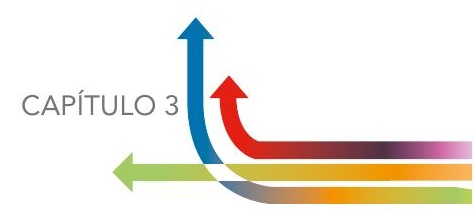

La globalización acompañada de las tecnologías de la información y las comunicaciones han ampliado las posibilidades de movilidad de estudiantes hacia diversos países. A partir de esta concepción se hace obligatorio tener en cuenta en el desarrollo del currículo la diversidad de estudiantes y ofrecer adaptaciones curriculares individualizadas a las particularidades del sujeto (Loret de Mora, Rivero \& Pino, 2012). Así entonces, para transformar las realidades en un mundo global se necesita conocimiento de otras culturas y de sus formas de proceder, en este proceso se propician diálogos entre iguales y se genera una visión integradora del conocimiento (Ver figura 32).

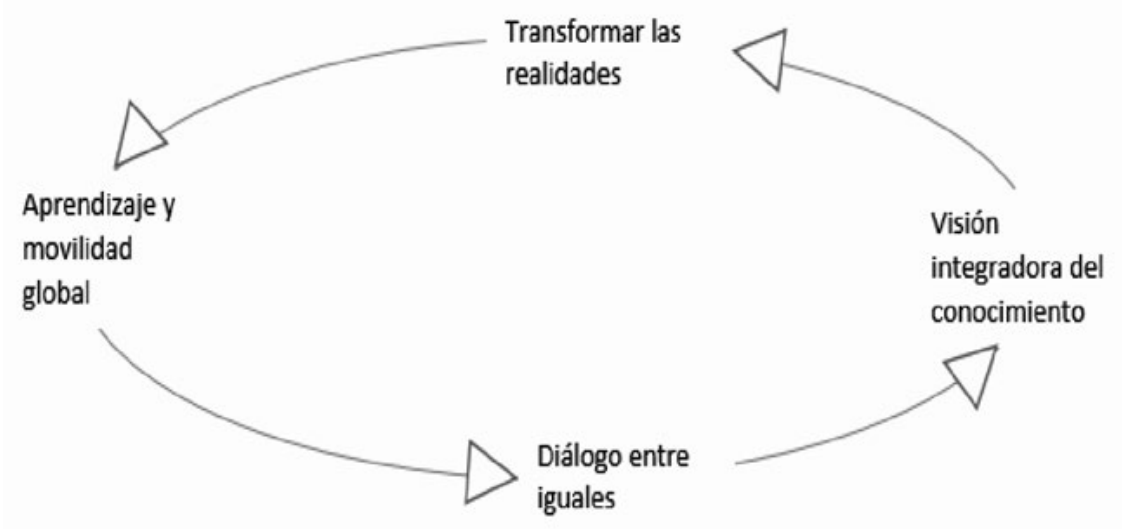

Figura 32. Transformación de las realidades en un mundo global.

Fuente: Elaboración propia.

\subsection{La universidad de cara a las necesidades regionales.}

La sociedad demanda de las universidades, una activa participación en actividades y procesos para el desarrollo y la solución de sus necesidades regionales. A futuro, la educación superior estará enfocada a dar respuestas y crear políticas encaminadas en pro del desarrollo humano y sostenible (GUNI, 2008). 
En tal sentido, un plan de RSU, debe contener elementos necesarios para que la universidad sea partícipe del desarrollo social sostenible en los lugares donde hace presencia. Un primer paso es realizar un diagnóstico para caracterizar la región e identificar los actores con los que se pueden realizar alianzas estratégicas en busca de soluciones pertinentes.

Las ventajas competitivas que posee la universidad para hacer frente a estas situaciones es básicamente el conocimiento, los estudiantes y los docentes que, con sus habilidades y competencias, contribuyen de forma responsable con este compromiso social (Martinez et al, 2008). Asumiendo una visión integral, las acciones desarrolladas desde la universidad resultan pertinentes si realmente logran impactar de manera vinculante e integral la sociedad de la cual forman parte y buscando con su accionar a mejorar las condiciones de vida de las mayorías, no solo en el momento, sino pensando en futuro, tomando en cuenta criterios de sustentabilidad (Naidorf, Giordana \& Horn, 2007).

Es necesario reconocer la presencia de los diversos actores sociales que intervienen en el proceso de la RSU, son los docentes y estudiantes, pero también la sociedad civil, el sector privado y el público, resultando grupo amplio y generalizado de actores sociales, con quienes se estructuran ejes de reforma, quienes deben asumir la responsabilidad social como medio implícito en la formación de ciudadanos responsables, que promueven comunidades de aprendizaje mutuo, justicia, democracia y sostenibilidad (Vallaeys, 2008)

De acuerdo con Domínguez (2009), en la educación superior se vienen desarrollando nuevas modalidades de extensión universitaria, enmarcadas dentro de nuevas formas de llegar a la sociedad; que impliquen el desarrollo y consolidación de acciones estudiantiles innovadoras y pertinentes. Se venían considerando las pasantías estudiantiles y las prácticas pre-profesionales desde de una visión cultural, orientándose ahora hacia la asistencia técnica y la capacitación comunitaria y empresarial. Se plantea así, la ausencia de un desarrollo conceptual y normativo, que ponga en evidencia y propicie el desarrollo articulado de trabajo, conocimiento y aprendizaje (Ver Figura 33). 

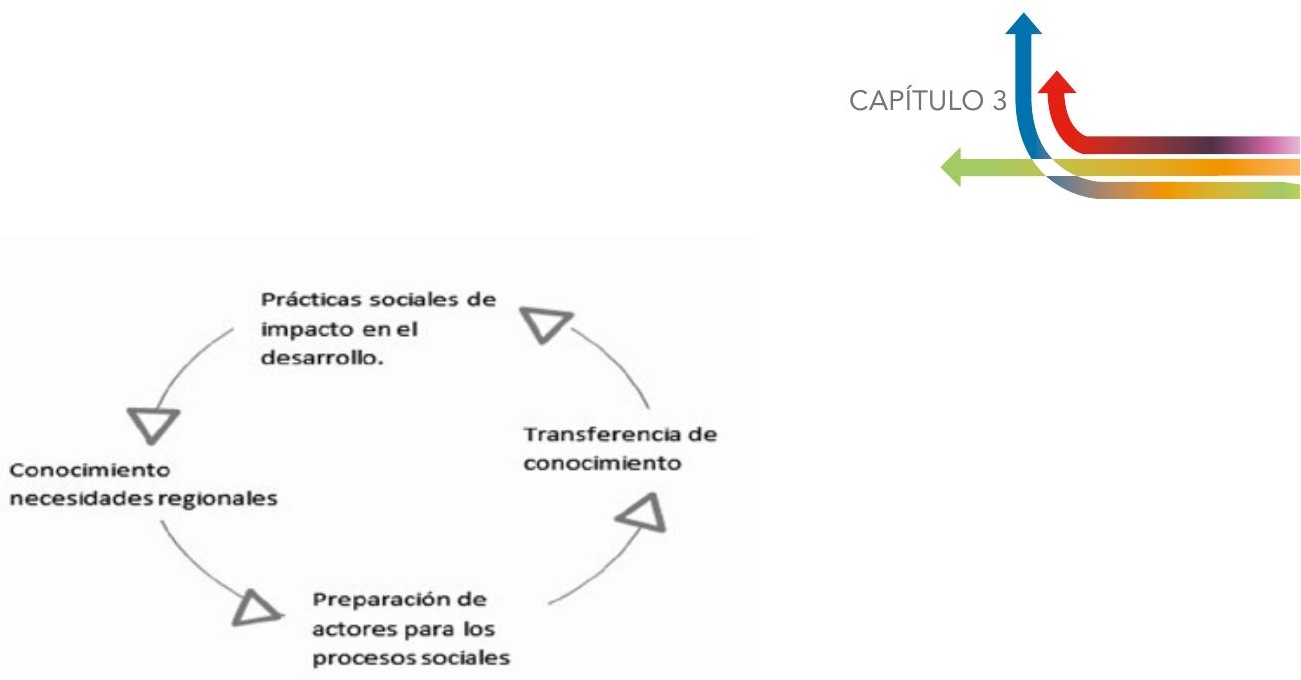

Figura 33. La universidad de cara a las necesidades regionales

Fuente: Elaboración propia.

En la Figura 34 se aprecia el diagrama causal integrado con las categorías y subcategorías relacionadas.

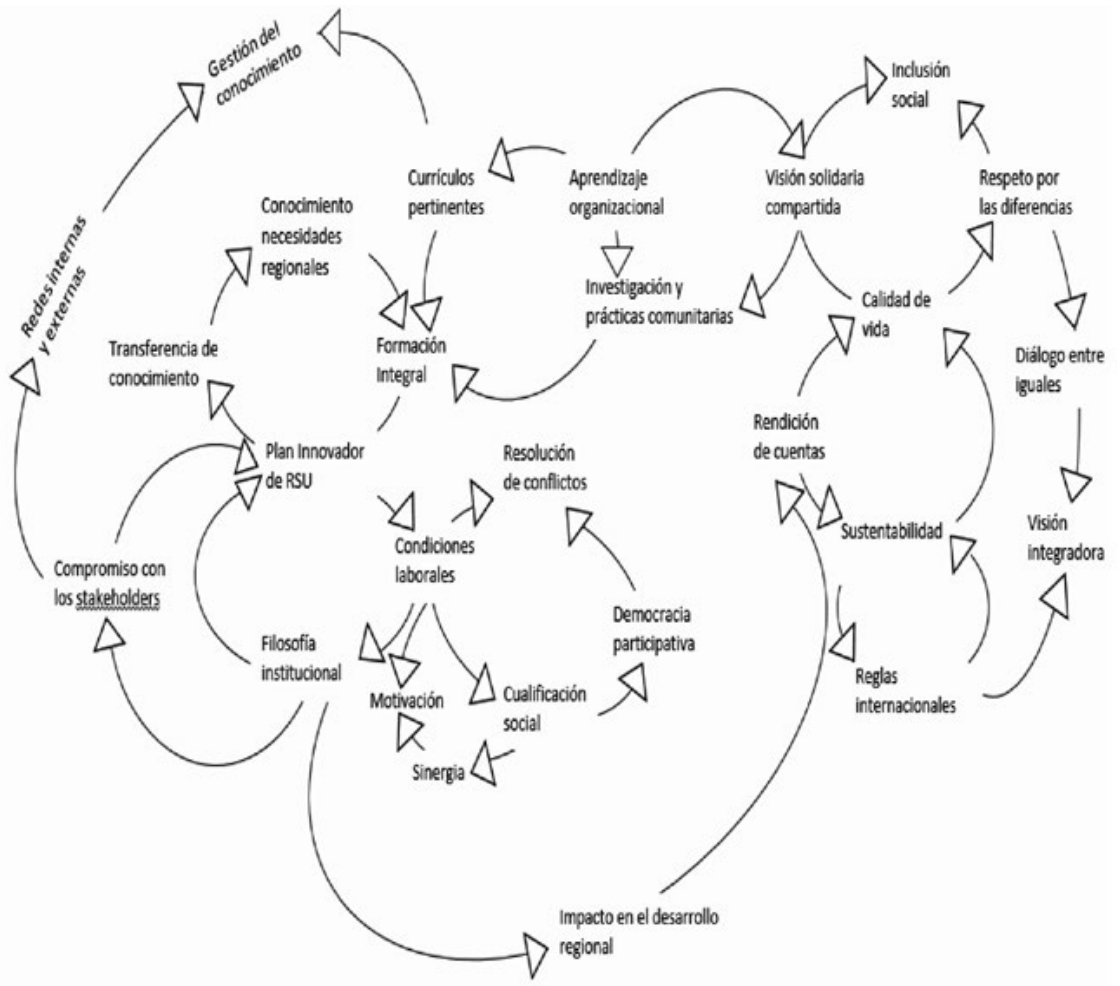

Figura 34: Integración de las categorías para la implementación de un Plan de Responsabilidad Social Universitaria.

Fuente: Elaboración propia. 



\section{Conclusiones}

La investigación documental en el área de responsabilidad social universitaria, al aplicar los criterios de relevancia, exclusividad, complementariedad, especificidad y exhaustividad. Permitió identificar ocho categorías que deben estar presentes en un plan de responsabilidad social universitaria: aprendizaje organizacional, necesidades regionales, internacionalización, interdisciplinariedad e interculturalidad, sustentabilidad y calidad de vida, redes, planeación y aplicación innovadora, filosofía institucional y humanización.

Las categorías encontradas pueden aplicarse en el diseño de un plan de responsabilidad social universitaria pues son el resultado de una revisión exhaustiva de documentos científicos y experiencias de autores por más de tres décadas y fue posible integrar las subcategorías dentro de las categorías.

El aprendizaje organizacional permite a las universidades aprender del entorno y asimilar ese conocimiento para dar respuesta a las necesidades regionales a partir de una visión compartida con currículos pertinentes que involucran transferencia de conocimiento del entorno a los procesos de investigación y de desarrollo. La construcción curricular debe ser participativa, partir de las necesidades comunitarias para fortalecer la formación integral acorde con el entorno social.

La universidad debe ser consciente de la necesidad de impactar en forma positiva en el entorno, para ello debe contar con personal cualificado en el conocimiento de las necesidades regionales, en los procesos de intervención y de transferencia de conocimiento. La extensión de la universidad debe apuntar 
hacia las comunidades, a la superación de la pobreza, a buscar estrategias para el post conflicto y otros problemas sociales. De igual forma, para que la RSU logre su propósito es necesario la cualificación de docentes y estudiantes en nuevas competencias sociales, en el debate y el pensamiento crítico, la creatividad y la innovación.

Los planes de responsabilidad social que se diseñen en una organización universitaria se diferencian unos de otros en el carácter innovador que cada institución le puede imprimir a partir de la filosofía institucional y el compromiso que se tenga con los stakeholders.

Dentro de un plan de responsabilidad social universitaria es imposible desatender las condiciones laborales de la organización y esto se consigue con cualificación, una sana resolución de conflictos y una democracia participativa. De esta forma se puede fortalecer la motivación y la sinergia. La universidad no deja de ser una organización y por lo tanto la aplicación de la RSU debe ser reflejada en su gestión humana y solidaria con el recurso humano.

Un plan de responsabilidad social universitaria no debe desconocer las reglas internacionales para la sustentabilidad y la inclusión social. De esta forma se favorece la calidad de vida de las personas que hacen parte tanto de la organización como del entorno en que la universidad se encuentra inmersa y donde demuestra el respeto y aceptación del otro.

El trabajo a partir de redes internas y externas, para alcanzar los objetivos propuestos en un plan de responsabilidad social universitaria permitirá ampliar los alcances en la gestión del conocimiento y su aplicación al servicio comunitario. La RSU tiene un enfoque holístico de tal forma que interrelaciona la formación integral, las redes para el desarrollo social, la investigación, la internacionalización, la gestión y transferencia de conocimiento. Su aplicación por lo tanto debe impactar en todos estos frentes. Por otra parte, el aprendizaje y movilidad global parte de la necesidad de transformar las realidades e inicia con un diálogo entre iguales para obtener así una visión integradora del conocimiento. 
La responsabilidad social universitaria sigue siendo de mucha relevancia y continúa en permanente investigación pues la mayor parte de la socialización del conocimiento se realiza en artículos documentos de trabajo y reseñas, siendo necesarios más libros sobre esta temática e investigadores especializados en esta disciplina que publiquen conocimiento científico de sus resultados. 



\section{Agradecimientos}

A la UNAD por la financiación del proyecto y el apoyo para

la publicación de este libro. 



\section{Referencias}

Aldeanueva, I. \& Jiménez J. (2013). Experiencias internacionales en materia de responsabilidad social universitaria. Visión de futuro, 17(1), 1-16.

Arana, M., Duque, P., Quiroga, M. \& Vargas, F. (2007). Una aproximación a la responsabilidad social en la formación del trabajo social desde los estudios de ciencia, tecnología y sociedad. Tabula rasa, (8), 211-234.

Asociación de universidades confiadas a la compañía de Jesús (AUSJAL) (2009). Informe final del proceso de autoevaluación de la Responsabilidad Social Universitaria en AUSJAL. Recuperado de: http://www.ausjal.org/tl_files/ausjal/images/contenido/ Documentos/Publicaciones/Investigaciones\%20Publicadas/InformeFinalRSU2011.pdf

Bacigalupo, L. (2008). La responsabilidad social universitaria: impactos institucionales e impactos sociales. Educación superior y sociedad, 13(2), 53-62.

Bernal, H. \& Rivera, B. (2011). Responsabilidad social universitaria, aportes para el análisis de un concepto. Recuperado de: http://www.cna.gov.co/1741/ articles-311056_ResponsabilidadSocial.pdf

Botero, A., González, C., Durpan, D. \& Bolívar, N. (2012). Impactos de responsabilidad social: Fundación Universitaria Monserrate. Revista Venezolana de Gerencia, 17(59), 498-511.

Bowen, H. (1953). Social Responsabilities of the businessman. New York: Harper 
Brunner (2008). Educación superior en Chile: Instituciones, mercados y políticas Gubernamentales 1967-2007. Santiago de Chile: Ediciones UDP.

Bustos, C. \& Inciarte, A. (2012). Dimensión comunitaria de la responsabilidad social universitaria. Opción, 28 (68), 367-379

Carvalho, C., Luzia, J., Soares, S. \& Andrade, M. (2009). Teoría fundamentada en los datos aspectos conceptuales y operacionales: Metodología posible de ser aplicada en la investigación en enfermería. Rev Latino-am Enfermagem, 17(4), 573-579

Camargo, R. (2007). Lo social desde el concepto de ilusión en Platón, Aristóteles, Machiavelo Bacon. Cinta de Moebio, 28, 29-38. Recuperado de http://www.facso. uchile.cl/publicaciones/moebio/28/camargo.pdf

Camejo, A. \& Cejas, M. (2009). Responsabilidad social: Factor clave de la gestión de los recursos humanos en las organizaciones del siglo XXI. Recuperado de: http:// pendientedemigracion.ucm.es/info/nomadas/21/camejo_cejas.pdf

Cantú-Martínez, P. (2013). Las instituciones de educación superior y la responsabilidad social en el marco de la sustentabilidad. Revista Electrónica Educare, 17(3), 41-55. Recuperado de http://www.redalyc.org/articulo.oa?id=194128798004

Caponni, A. (2012). Ejemplos prácticos de responsabilidad social universitaria. En Domínguez, J. \& Rama, C. (Ed.), la responsabilidad Social Universitaria en la Educación a Distancia, (pp.225-253) Chimbote: ULADECH católica.

Carvajal, Y. (2010). Interdisciplinariedad desafío para la educación superior y la investigación. Revista Luna Azul. (31), 156-169

Castañeda, M. \& Pérez, Y. (2005). Aspectos teórico-conceptuales sobre las redes y las comunidades virtuales de conocimiento. Acimed ;13(6), 15-49 
Castañeda, G., Ruiz, M., Viloria, O., Castañeda, R. \& Quevedo, Y. (2007). El rol de las universidades en el contexto de la responsabilidad social empresarial. Revista Negotium, 3 (8), 100-132. Recuperado de: http://www.revistanegotium.org.ve/ pdf/8/Art4.pdf

Castro, Y. (2007). La educación para el desarrollo humano en un mundo globalizado.

Revista Tendencia \& Retos, 12, 157-175. Recuperado de: http://revistas.lasalle.edu. co/index.php/te/article/view/1866/1734

Casilla, D. \& Camacho, H. (2012). Evaluación de la Responsabilidad Social Universitaria. Revista Opción, 28(69), 452-465. Recuperado de http://www.redalyc.org/articulo. oa?id=31025702004

Cavero, L. (2006). La Responsabilidad Social Universitaria: Transformaciones para Perú y América Latina [Mensaje en un blog]. Recuperado de: http://blog.pucp.edu.pe/ item/439

Cevallos, R. (2008). Sobre la Responsabilidad Social en la PUCP [Mensaje en un blog]. Recuperado de: http://blog.pucp.edu.pe/item/44

Cohen, D. (2007). Desafíos de la Responsabilidad Social Universitaria. Revista Razón y Palabra, 12 (55). Recuperado de http://www.redalyc.org/articulo. oa?id=199520735023

Cohen, D. (2006). Responsabilidad Social: Desafíos de la Universidad. Revista DirCom, 65(5), 40-51.

Cole, J. R. y Cole, S. (1973). Social stratification in Science. Chicago y Londres: University Chicago Press.

Colom (2000). La deconstrucción del conocimiento pedagógico. Nuevas perspectivas en teoría de la educación. Barcelona: Padios. 
Cortés, H. (2012). Responsabilidad Social Universitaria. Una mirada a la Universidad Nacional de Colombia. (Tesis Maestría). Bogotá, Universidad Nacional de Colombia. Recuperado de: http://www.bdigital.unal.edu.co/9022/1/822073.2012.pdf

Craveri, A. \& Spengler, M. (2007). El conocimiento de los estilos de aprendizaje como estrategia para un aprendizaje autónomo. Acta Latinoamericana de Matemática, 20, 61-66.

Criado, R. (2006). Responsabilidad Social Universitaria en la Pontificia Universidad Católica del Perú. [Mensaje en un blog]. Recuperado de: http://blog.pucp.edu.pe/item/443.

De la Cruz, C. (2011). Reflexiones sobre promoción de la responsabilidad en instituciones de educación superior: retos, limitaciones y oportunidades. Pensamiento Universitario, (21), 61-74.

De la Cuesta, M. \& Sánchez, D. (2012). Responsabilidad social universitaria. 2.0. Recuperado de: http://www.netbiblo.com/books/?Subject=Coleccion+ Sostenibilidad+y+Responsabilidad+Social+Corporativa

De la Red, N. (2009). Necesidades emergentes y responsabilidad social universitaria Revista Alternativas, cuadernos de trabajo social. (16), 65-76.

Delors, J. (1996). La educación o la utopía necesaria. En: Informe a la UNESCO de la Comisión Internacional sobre la Educación para el Siglo XXI (pp. 13-36). Madrid: Santillana-UNESCO.

De La Jara, M. (2008). ¿Cómo medir la percepción de la responsabilidad social en los diversos estamentos de la universidad?: Una experiencia concreta. Educación superior y sociedad, (2), 139-161.

Díaz, I. \& García, M. (2011). Más Allá del Paradigma de la Alfabetización: La Adquisición de Cultura Científica como Reto Educativo. Formación Universitaria, 4(2), 3-14. 
Domínguez, J. (2012). Conceptualización sobre la responsabilidad social específica de una universidad católica. En Domínguez, J. \& Rama, C. (Ed.), La Responsabilidad Social Universitaria en la Educación a Distancia (pp. 53- 73). Chimbote: ULADECH Católica.

Domínguez, M. (2009). Responsabilidad social universitaria. Humanismo y trabajo social. $8(1), 37-67$.

Escalona, L. (2008). Flexibilidad curricular: elemento clave para mejorar la educación bibliotecológica. Investigación bibliotecológica, 22(44), 143-160.

Escorcia, R., Gutiérrez, A. \& Henríquez, H. (2007). La educación superior frente a las tendencias sociales del contexto. Educación y educadores, 10(1), 63-77.

Esfijani, A., Hussain, F. \& Chang, E. (2013). University Social Responsibility Ontology. Engineering Intelligent Systems. 4, 271-281.

Fernández, A. \& Jiménez, J. (2013). Responsabilidad social universitaria: un estudio de casos. Revista Venezolana de Gerencia, 18(64), 649-662.

Freeman, R. E. (1984), Strategic Management: A Stakeholder Approach, Boston: Pitman Ballinger.

Garza, E. (2007). Responsabilidad Social Universitaria. Tecnológico, Monterrey: México.

Gaete, R. (2011). Responsabilidad social universitaria, necesidades sociales emergentes y calidad de vida de los ciudadanos. Argos 28 (54), 191-216.

Gaete, R. (2011). La responsabilidad social universitaria como desafío para la gestión

Estratégica de la Educación Superior: el caso de España, Revista de Educación, (355), 109-133. Recuperado de: http://www.revistaeducacion.educacion.es/re355/ re355_05.pdf 
Gaete, R. \& Bratos, M. (2012). Los centros comerciales abiertos en España: una mirada desde el concepto de responsabilidad social corporativa. Distribución y consumo, 22(124), 4-44-52.

Gaete, R. (2012). Responsabilidad social universitaria: una nueva mirada a la relación de la universidad con la sociedad desde la perspectiva de las partes interesadas. Un estudio de caso (Tesis Doctoral). Universidad de Valladolid, Valladolid. Recuperado de: https://uvadoc.uva.es/bitstream/10324/923/1/TESIS148-120417.pdf

Gibbons, M.; Limoges, C.; Nowotny, H; Schwartzman; S.; Scott, P. \& Trow, Martin (1997). La nueva producción del conocimiento. La dinámica de la ciencia y la investigación en las sociedades contemporáneas, Barcelona: Pomares-Corredor.

Giménez, C. (2000) Guía sobre la interculturalidad, Guatemala: Editorial Serviprensa CA.

González, N; Pirela, A \& Zerpa, M. (2012). La formación docente como investigador. Una Responsabilidad Social Universitaria. Opción, 28 (69), 466-479.

Gorrochategui, N. (2012). La extensión universitaria como expresión de la Responsabilidad social universitaria (RSU). Chimbote: ULADECH católica.

GUNI, 2008. La educación superior en el Mundo 3: Nuevos Retos y Roles emergentes para el desarrollo social. México: Ediciones Mundi prensa.

Hernández, R. \& Saldarriaga, A. (2009). Gestión de la responsabilidad social universitaria. Caso: Escuela de Ingeniería de Antioquia -eia. Dyna, Año 76, Nro. 159, pp. 237248. Medellín. Recuperado de:_http://www.scielo.org.co/pdf/dyna/v76n159/ a24v76n159.pdf

Hartman, D. (2011). Theory: Corporate Social Responsibility: Chapter 5 from Business Ethics: Decision- Making for Personal Integrity and Social Responsibility, Second Edition byHartman, DesJardin. 
Hartman, D. (2011). Theory: The Corporate Culture — Impact and Implications:

Chapter 4 from Business Ethics: Decision-Making for Personal Integrity and Social Responsibility, Second Edition by Hartman, DesJardins.

Hartman, D. (2011). Theory: Ethical Decision Making: Employer Responsibilities and Employee Rights: Chapter 6 from Business Ethics: Decision-Making for Personal Integrity and Social Responsibility, Second Edition.

Huerta-Riveros, P \& Gaete-Feres, H. (2017). Responsabilidad social universitaria a través de los reportes de sostenibilidad del Global Reporting Initiative: experiencia de una universidad pública. Revista iberoamericana de educación superior, 8(23), 120-137.

Jaramillo, M. (2009). El Ethos de la imaginación como ética de la motivación: una mirada desde la idea de Responsabilidad Social Universitaria. Revista Coherencia, 6 (11), 209-232.

Kisnerman, N. (2001). Ética ¿para qué? En N. Kisnerman (Comp.), Ética, ¿Un discurso o una práctica social? Buenos Aires: Paidós.

Larrán-Jorge, M y Francisco-Javier Andrades-Peña (2015). Análisis de la responsabilidad social universitaria desde diferentes enfoques teóricos. Revista Iberoamericana de Educación Superior, 6 (15), 91-107. Recuperado de: http://www.scielo.org.mx/scielo. php?script=sci_arttext\&pid=S2007-28722015000100005

Leal, J. (2012). La inclusión social educativa en el marco de la modalidad de educación abierta y a distancia. El caso de la UNAD de Colombia. En Domínguez, J. \& Rama, C. (Ed.), la responsabilidad Social Universitaria en la Educación a Distancia, (pp.103122) Chimbote: ULADECH católica.

Leva, G. (2005). Indicadores de Calidad de Vida Urbana. Teoría y Metodología. Buenos Aires: Politike

Lerner, S. (2007). Responsabilidad social de la universidad. Recuperado de: http://blog. pucp.edu.pe/item/439 
Londoño, I. (2013). Responsabilidad social universitaria una estrategia de gestión para la educación superior. Revista de Investigaciones de la Escuela de Administración y Mercadotecnia del Quindío. 5 (5), 137 - 151.

Loret de Mola, E. Rivero, Melva, \& Pino, D. (2012). La configuración curricular desde la atención a la diversidad en el proceso formativo universitario. Humanidades Médicas, 12(3), 464-486. Recuperado de: http://scielo.sld.cu/scielo.php?script=sci_ arttext\&pid=S1727-81202012000300007\&lng=es\&tlng=es.

Lozano, Josep (2009). La empresa ciudadana como empresa responsable y sostenible, Madrid: Trotta.

Maldonado, C; García, J. \& Giménez, A. (2007). La Formación de la Responsabilidad Social en la Universidad. Revista Complutense de Educación Madrid, 18(2), 47-20 Disponible en: http://proquest.umi.com/ pqdweb?did=1978981731\&sid=23\&Fmt=3\&clientld=51739\&RQT=309\&VName.

Morin, E. (2004). El Método, Tomo 6. La Ética, Paris, Seuil, col. Points

Martínez, C. Mavárez, R., Rojas, L. \& Carvallo, B. (2008). La responsabilidad social Universitaria como estrategia de vinculación con su entorno social. Revista de Filosofía Jurídica, Social y Política, 15(3), 81-103

Martínez, C. (2011). Responsabilidad Social Universitaria y su Articulación con las Funciones Docencia-Investigación-Extensión para su Vinculación con el Entorno Social. Boletín IESALC de educación superior N²14. Recuperado de http:// www.iesalc.unesco.org.ve/index.php?option=com_content\&view=article\& $\mathrm{id}=2595 \% 3$ Aresponsabilidad-social-universitaria-y-su-articulacion-con-lasfunciones-docencia-investigacion-extension-para-su-vinculacion-con-el-entornosocial\&catid=126\%3Anoticias-pagina-nueva\&ltemid=712 $\langle=e s$ 
Martínez, C., Mavarez, R., Rojas, L., Rodríguez, J. y Carvallo, B. (2006). La

Responsabilidad social como instrumento para fortalecer la vinculación universidadentorno social. Trabajo presentado en el I Congreso Iberoamericano de Ciencia, Tecnología Sociedad e Innovación CTS+I. México. OEI, AECI, UNAM, IPN, UAM, Academia Mexicana de Ciencias y la Academia de Ingenieros

Martínez, O. \& Pico, Juan. (2006). Responsabilidad social de las universidades. Universidad de Buenos Aires. Argentina.

Manzano, V. (2010). La función comprometida de la Universidad. [Tesis Doctoral sin publicar]. Universidad de Valladolid.

Misas, G. (2002). La ruptura de los noventa. Facultad de Ciencias Económicas, Universidad Nacional de Colombia, Bogotá.

Mineducación. (2013). Lineamientos Política de Educación Superior Inclusiva. Bogotá, Recuperado de: http://www.dialogoeducacionsuperior.edu.co/1750/articles-327647_ documento_tres.pdf.

Montoya, L., Arenas, Diana \& Lorenzo, S. (2018). Gestión social del conocimiento y análisis prospectivo de su incidencia en la universidad contemporánea. MEDISAN, 22(4), 449-459.

Naciones Unidas. (2005). Documento final de la cumbre mundial de 2005. Recuperado de: http://www.un.org/spanish/summit2005/fact_sheet.html.

Naidorf, J, Giordana, P. \& Horn, M. (2007). La pertinencia social de la Universidad como categoría equívoca. Nómadas, (27), 22-33.

Núñez, M; Salom, J; Rosales, V \& Paz, A. (2012). Responsabilidad social universitaria: enfoque de gestión ética compartida. Revista Opción, 28(69), 579-594. 
Olarte, D. \& Ríos, A. (2015). Enfoques y estrategias de responsabilidad social implementadas en Instituciones de Educación Superior. Revista de la Educación Superior, 3(175), 19-40.

Organización de Estados Iberoamericanos OEI (2014). Ciencia, tecnología e innovación para el desarrollo y la cohesión social. (1 ed) Madrid, España: Editorial Asenmac.

Pelekais, E., De Pelekais, C. \& Frassati, E. (2009). Toma de decisiones fundamentada en la gestión ética universitaria. Revista de Artes y Humanidades UNICA, 10(1) 61-91. Recuperado de: http://www.redalyc.org/articulo.oa?id=170118870004

Peña, F. (2012). La masificación de la educación y la búsqueda de igualdad, justicia y equidad sociales en Colombia. Folios Universidad Pedagógica Nacional, 2(36), 189-200.

Peña, Medrano \& Rodríguez, (2012). Análisis de la responsabilidad social Universitaria. Tesis de maestría no publicada. Universidad de La Sabana. Chía, Colombia.

Peña, V. (2011). RSU: Paradigma responsable de ser y hacer universidad. San José: IV Congreso Universitario, UNED, diciembre, (paper)

Pérez, D. (2009). La responsabilidad Social Universitaria. Huelva: Artes Gráficas Bonanza, S.L.

Peralta, R. (2012). Formación académica estudiantil requerida para la praxis de la Responsabilidad Social Universitaria. Opción, 28(69), 498-516

Pirela, L. \& Sánchez, M (2009). Cultura y aprendizaje organizacional en instituciones de Educación. Revista de ciencias sociales. 15(1), 175-188.

Pulgar, C. \& Pelekais, C. (2014). Responsabilidad social basada en alianzas estratégicas en universidades de gestión privada. Formación Gerencial, 13 (2), 198-220

Quezada, R \& Bratos, M. (2012). Una mirada a la internacionalización universitaria desde la perspectiva de la responsabilidad social: discursos de los jóvenes investigadores. Estudios pedagógicos, 38(1), 255-272. 
Quilaqueo, D. \& San Martín, D. (2008). Categorización de saberes educativos Mapuche mediante la Teoría Fundamentada. Estudios Pedagógicos, 33(2), 151-168.

Ramos, N. R. (2010) Desarrollo del enfoque en bioética global para la responsabilidad social universitaria en la Fundación Universidad Autónoma de Colombia. (Tesis de maestría no publicada). Universidad Nacional de Colombia, Bogotá. D.C

Ramos, C. (2012). Cultura innovativa para la universidad de servicio en el marco de la responsabilidad social universitaria. Opción, 28(68), 287-302

Rivera, H. A. y Malaver, M. N. (2011). La organización: Los stakeholders y la

Responsabilidad social. Bogotá: Universidad Colegio Mayor de Nuestra Señora Del Rosario.

Rodríguez, J. M. (2010). Responsabilidad social universitaria. Del discurso simbólico a los Desafíos reales. En De la Cuesta, M., De la Cruz, C. y Rodríguez Fernández, J. M. (Coords.) Responsabilidad Social universitaria (3-24). La Coruña: Netbiblo

Romero, C (2005). La categorización un aspecto crucial en la investigación cualitativa. Cesmag, 11 (11), 13-118

Romero, C. (2007). Sobre la Responsabilidad Social en la PUCP. Recuperado de: http:// dars.pucp.edu.pe/2011/publicaciones_documentos/Sobre-la-ResponsabilidadSocial-en-la-PUCP.pdf

Salazar, S. (2004). La responsabilidad social corporativa en México como una herramienta estratégica para la competitividad: un enfoque econométrico y prospectivo (tesis de maestría no publicada) Instituto Tecnológico y de Estudios Superiores de Monterrey, México.

Sáez, R. La educación intercultural en el ámbito de la educación para el desarrollo humano sostenible. Revista Complutense de Educación, 12(2), 713-737. 
Santos, B. (2005), La universidad en el siglo XXI. Para una reforma democrática y emancipadora de la universidad, Ed. Miño y Dávila.

Santos, M. (2009). Migraciones, sostenibilidad y educación. Recuperado de: http://www. revistaeducacion.mec.es/re2009/re2009_06.pdf

Spengler, M., Egidi, L \& Craveri, A. (2007). El nuevo papel del docente universitario: el profesor colectivo. Departamento de Matemática, Escuela de Estadística. Universidad Nacional de Rosario

Saldarriaga, R. (2013). Responsabilidad social y gestión del conocimiento como estrategias de gestión humana. Estudios gerenciales, 29 (2013), 110-117

Sánchez, M. (2010). La responsabilidad social universitaria y sus actores principales en la formación y capacitación. Universidad de Carabobo. Recuperado de: http://es.wikieducator.org/images/9/91/LA_RESPONSABILIDAD_SOCIAL_ UNIVERSITARIA_Y_SUS_ACTORES_PRINCIPALES_EN_LA_FORMACION_Y_ CAPACITACION.pdf

Sánchez (2007). La Responsabilidad Social Universitaria (RSU) en el contexto del Cambio de educación superior, México, Editorial Universidad Autónoma de México

Sanje, G \& Senol, I. (2012), Corporate social responsibility in higher education institutions: Istanbul Bilgi University case. American International Journal of Contemporary Research, 2 (3), 95-103

Sacco, F. (2009). Responsabilidad, responsabilidad social y responsabilidad social universitaria, perspectivas de tres conceptos. Visión gerencial, 8 (1), 383-397

Sidorovas, L. (2015). Responsabilidad social y gestión organizacional en la universidad de Carabobo: Sincronismo ineludible en cambios coyunturales. Revista Upel. 12 (1), 208-234. 
Torres, A., Sánchez, L. (2014). La responsabilidad social universitaria desde su fundamentación teórica. Libre Empresa 21 (1), 69-105.

UNESCO (1994). La tolerancia, umbral para la paz. Recuperado de: http://www.ocse.org. mx/pdf/130_Tolerancia.pdf

UNESCO (2008). Educación de calidad, equidad y desarrollo sostenible: una Concepción holística. Recuperado de: http://unesdoc.unesco.org/images/0018/001818/181864s. pdf

Universidad construye país. (2004). Observando la responsabilidad social universitaria. Recuperado de: http://www.rsu.uninter.edu.mx/doc/herramientas_RSU/ ObservandolaRSU.pdf

Valarezo, K \& Túnez, J. (2014). Responsabilidad social universitaria. Apuntes para un modelo de RSU. Revista de Comunicación. 13 (1), 84-117.

Vera, L., Gómez, M., Acosta, Y \& Perozo, L. (2012). La docencia en el marco de la responsabilidad social universitaria. Opción, 28(68), 257-272

Vallaeys, F. (2008). Responsabilidad social universitaria: una nueva filosofía de gestión Ética y manejo inteligente para las universidades. Revista Educación Superior y Sociedad. Nueva Época, 13(2), 191-219

Vallaeys, F.; de la Cruz, C. Sasia, P. (2009). Responsabilidad social universitaria. Manual de Primeros pasos. México: BID-McGraw-Hill Interamericana

Viteri Moya, J; Jacome, M; Medina, A \& Piloto-Fleitas, N. (2012). Índice integral para evaluar la responsabilidad social universitaria en Ecuador. Ingeniería Industrial, 23(3), 295-306

Viteri Moya, J; Jacome, M. \& Medina, N. (2012). Modelo conceptual para la Planificación estratégica con la incorporación de la responsabilidad social universitaria. Ingeniería industrial, 34(1), 77-86 
Van Ginkel, H. (2002). Academic freedom and social responsibility the role of university Organisations. Higher Education Policy, 15, 347-351.

Vivar, C., Arantzamendi, M., López-Dicastillo, O. \& Gordo L. (2010). La Teoría Fundamentada como Metodología de Investigación Cualitativa en Enfermería. Index de Enfermería, 19(4), 283-288. Recuperado de http://scielo.isciii.es/scielo. php?script=sci_arttext\&pid=S1132-12962010000300011

Zegarra, F. (2007). Responsabilidad Social Universitaria [Mensaje en un blog]. Recuperado de: http://blog.pucp.edu.pe/item/439.

Zárate, R. \& García, S. (2014). La cultura socialmente responsable de la UIS: una perspectiva desde el ámbito educativo y social. Revista Encuentros, 12 (2), 105-120. 



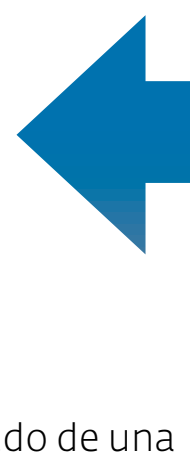

Este documento es el resultado de una investigación realizada con el objetivo de identificar las categorías de análisis útiles en el diseño de planes de responsabilidad social universitaria, a partir de una revisión bibliométrica de bases de datos y la construcción de una línea del tiempo comprendida desde los años cincuenta hasta la actualidad, para ello fue necesario conceptualizar las categorías seleccionadas, mediante un análisis documental, deduciendo subcategorías que explican con mayor claridad los ordenadores epistemológicos que se deben integrar en un plan de responsabilidad social universitaria; al igual que Integrar categorías y subcategorías que sirvan de referente para el diseño de un plan de responsabilidad social universitaria.

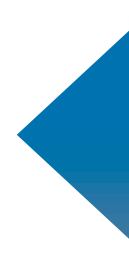

